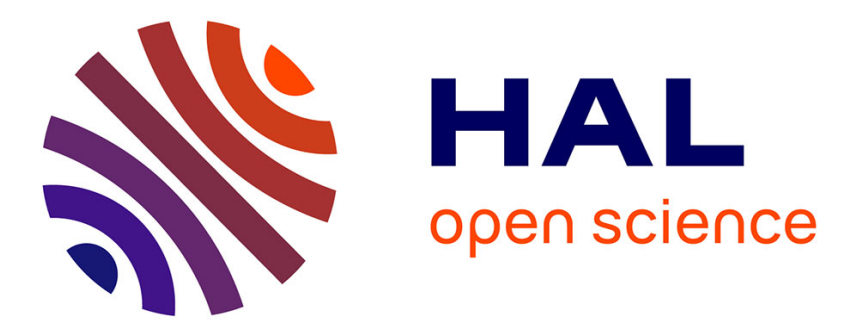

\title{
Un espace funéraire du deuxième quart du Ier s. avant J.-C. (Nîmes, Gard)
}

Michel Feugère, Armelle Gardeisen, Yves Manniez, Martial Monteil, Laurent

Vidal, Françoise Brien-Poitevin, Thi-Mai-Anh Bui, Michel Lejeune, Myriam

Sternberg

\section{To cite this version:}

Michel Feugère, Armelle Gardeisen, Yves Manniez, Martial Monteil, Laurent Vidal, et al.. Un espace funéraire du deuxième quart du Ier s. avant J.-C. (Nîmes, Gard). Gallia - Archéologie de la France antique, 1995, 52, pp.165-204. 10.3406/galia.1995.3138 . hal-01415506

\section{HAL Id: hal-01415506 \\ https://hal.science/hal-01415506}

Submitted on 13 Dec 2016

HAL is a multi-disciplinary open access archive for the deposit and dissemination of scientific research documents, whether they are published or not. The documents may come from teaching and research institutions in France or abroad, or from public or private research centers.
L'archive ouverte pluridisciplinaire HAL, est destinée au dépôt et à la diffusion de documents scientifiques de niveau recherche, publiés ou non, émanant des établissements d'enseignement et de recherche français ou étrangers, des laboratoires publics ou privés.

\section{(ㅇ)(1) $\$$}

Distributed under a Creative Commons Attribution - NonCommercial - NoDerivatives 44.0 
Michel Feugère

Françoise Brien-Poitevin Bui Thi Mai

Monsieur Michel Lejeune Myriam Sternberg

Laurent Vidal

Monsieur Martial Monteil

Yves Manniez

Armelle Gardeisen 


\section{Un espace funéraire du deuxième quart du ler s. avant J.-C. Nîmes, Gard.}

In: Gallia. Tome 52, 1995. pp. 165-204.

\section{Résumé}

Le site du Mail romain à Nîmes (Gard), localisé sur le tracé sud de l'enceinte augustéenne, immédiatement à l'ouest de la porte de France, a fait l'objet d'une fouille de sauvetage en décembre 1988 et janvier 1989.

Outre la reconnaissance d'un tronçon de courtine totalement épierré et d'une voie périphérique, l'opération a surtout permis la fouille fine

d'un espace funéraire comprenant des murs, deux tombes à incinération en coffre de dalles ainsi que de nombreuses offrandes (mobilier céramique et métallique, faune).

Cet ensemble, daté du deuxième quart du ler s. avant J.-C., renouvelle en partie la question des tombes nîmoises d'époque républicaine, pour lesquelles les informations résultaient jusqu'alors de fouilles anciennes ou de découvertes fortuites.

\section{Abstract}

The site of the Mail romain at Nîmes (Gard), located on the south tracing of the augustan walls, just to the west of the "porte de France" was the subject of a rescue excavation in December 1988 and January 1989.

Apart from the section of a partly recognized curtain, completely spoiled, and of a peripheral highway, the operation has allowed the

detailed excavation of a funeral area including walls, two cremation tombs in cases made of slabs as well as numerous offerings (pottery and metallic items and bones).

This group, which dates from the second quater of the 1st century B.C., renews the question of the republican tombs of Nîmes, for which all the information previously collected resulted from earlier excavations, or from chancefinds.

Citer ce document / Cite this document :

Feugère Michel, Brien-Poitevin Françoise, Thi Mai Bui, Lejeune Michel, Sternberg Myriam, Vidal Laurent, Monteil Martial, Manniez Yves, Gardeisen Armelle. Un espace funéraire du deuxième quart du ler s. avant J.-C. Nîmes, Gard. In: Gallia. Tome 52, 1995. pp. 165-204.

doi : 10.3406/galia.1995.3138

http://www.persee.fr/web/revues/home/prescript/article/galia_0016-4119_1995_num_52_1_3138 


\title{
UN ESPACE FUNÉRAIRE DU DEUXIÈME QUART DU I ${ }^{\text {er }}$ S. AVANT J.-C.
}

\author{
Nîmes, Gard
}

Michel Feugère, Armelle Gardeisen, Yves Manniez, Martial MonTEIL

et Laurent VIDAL, avec la collaboration de Françoise Brien-Poitevin, Bui Thi Mai, Michel Lejeune et Myriam Sternberg*

\begin{abstract}
Mots clés. Tombes à incinération, $I^{r}$ s. avani J.-C., rites funéraires, céramiques, mobilier métallique, offrandes alimenlaires, crâne de cheval, Nimes, Gard.

Key words. Cremalion tombs, 1st century B.C., funeral rites, ceramics, metallic items, food offerings, horse skull, Nîmes, Gard.

Résumé. Le site du Mail romain à Nîmes (Gard), localisé sur le tracé sud de l'enceinte augustéenne, immédiatement à l'ouest de la porle de France, a fait l'objet d'une fouille de sauvetage en décembre 1988 el janvier 1989.

Outre la reconnaissance d'un tronşon de courtine totalement épierré et d'une voie périphérique, l'opération a surtout permis la fouille fine d'un espace funéraire comprenant des murs, deux tombes à incinération en coffre de dalles ainsi que de nombreuses offrandes (mobilier céramique et métallique, faune).

Cet ensemble, daté du deuxième quart du $I^{e r}$ s. avant J.-C., renouvelle en partie la question des tombes nîmoises d'époque républicaine, pour lesquelles les informations résultaient jusqu'alors de fouilles anciennes ou de découvertes fortuites.
\end{abstract}

\begin{abstract}
The site of the Mail romain at Nimes (Gard), located on the south tracing of the augustan walls, just to the west of the "porte de France" was the subject of a rescue excavation in December 1988 and January 1989.

Apart from the section of a parlly recognized curlain, completely spoiled, and of a peripheral highway, the operation has allowed the detailed excavation of a funeral area including walls, two cremation tombs in cases made of slabs as well as numerous offerings (pollery and metallic items and bones).

This group, which dates from the second quater of the 1st century B.C., renews the question of the republican tombs of Nimes, for which all the information previously collecled resulled from earlier excavations, or from chancefinds.
\end{abstract}

\footnotetext{
* Michel Feugère, chargé de recherche CNRS, Armelle Gardeisen, doctorante, Myriam Sternberg, doctorante - Centre de documentation archéologique régional, avenue de Pérols, 34970 Lattes.

Yves Manniez, doctorant, archéologue AFAN, Martial Monteil, doctorant, archéologue AFAN, chercheur associé du cDR 954 et du Centre CamilleJullian, Laurent Vidal, doctorant, cherchcur associé du GDR 954 et du GDR 926 - Centre de documentation archéologique du Gard, 396, avenue JoliotCurie, 30900 Nîmes.

Françoise Brien-Poitevin, Le Cyprès, 82, avenue de la Mascotte, 83140 Six-Fours-les-Plages.

Bui Thi Mai, ingénieur CNRs, laboratoire de palynologie, Centre de recherches archéologiques, Sophia Antipolis, 06565 Valbonne.

Michel I.ejeune, membre de l'Institut, 25, rue Gazan, 75014 Paris.
} 
En 1988, la Société méditerranéenne de construction immobilière (SMCI) décidait de construire un petit immeuble avec parking souterrain, sur une parcelle située à l'angle des rues Dagobert et du Cirque-Romain dans le quartier du Mail ${ }^{1}$ (fig. 1 et 2). La situation de ce projet, dans un secteur riche en découvertes archéologiques, motivait une série de tranchées de repérage qui mettaient en évidence un tronçon de courtine de l'enceinte augustéenne, considérablement épierré, ainsi qu'une voie périphérique extra-muros (Célié, 1988). La nécessité d'une opération extensive conduisait alors à la réalisation, entre décembre 1988 et janvier 1989, d'une fouille de sauvetage programmé ${ }^{2}$.

C'est dans ce cadre qu'est intervenue la découverte d'un ensemble funéraire, matérialisé par un " tertre ", des murs et deux tombes accolées en coffre de dalles. La publication de ces documents, exploités de façon minutieuse, offre un ensemble d'informations inédites pour la connaissance des pratiques funéraires à l'époque républicaine ${ }^{3}$. Il suffit, pour en souligner l'intérêt majeur, de comparer cet ensemble aux autres tombes préaugustéennes nîmoises qui résultent toutes de découvertes anciennes n'ayant jamais bénéficié de conditions d'intervention satisfaisantes (Py, 1981a) ${ }^{4}$.

1. Il s'agit de la parcelle EX-594 qui couvre environ $1120 \mathrm{~m}^{2}$ et dont les coordonnées Lambert III centrales sont : $\mathrm{X}=762,440 ; \mathrm{Y}=3172,230 ; \mathrm{Z}$ moy. $=45,34 \mathrm{~m}$ NGF. Le fort taux de destruction de la parcelle n'a permis d'explorer, au total, que $250 \mathrm{~m}^{2}$. L'immeuble construit a été baptisé par la SMCI le « Mail romain ».

2. L'opération, dirigée par Martial Monteil, a été conduite en étroite collaboration avec Yves Manniez et Laurent Vidal. Il nous faut remercier ici les bénévoles qui nous ont apporté leur soutien : $O$. Boudry, M. Chauvet, L. Cornil, S. Barberan, J.-Y. Le Goff, M. Le Goff, F. Gonzales, M.-L. Guibert, A. Haddaoui, M.-L. Reverault, N. Roncaglia, S. Thomas, N. Talhouas, F. Verdier et A. Veyrac. Enfin, nous devons également exprimer notre gratitude à la SMCI, en la personne de M. Levert, au Service régional de l'archéologie et plus particulièrement à M.G. Colin et, enfin, à M. Célié, archéologue rattaché à la ville de Nìmes et à J.-M. Pène, responsable du Centre de documentation archéologique du Gard.

3. I.es éléments d'informations liés à cette intervention ont fait l'objet d'un rapport remis au Service régional de l'archéologie (Monteil, 1989) puis d'une exploitation dans le cadre de mémoires de maîtrise (Monteil, 1990a et Vidal, 1990) et, enfin, d'une brève notice publiée dans un catalogue (Monteil, 1990b). De plus, un des vases des tombes portait un graffite dont M. Lejeune a bien voulu assurer l'étude (Lejeune, 1990). Enfin, deux monnaies de bronze (des imitations tardives de statères de Vercingétorix), découvertes lors de la foulle des niveaux de voie, ont donné lieu à un article (Fischer, 1990).

4. Citons V. Lassalle qui écrit, à propos des sépultures préaugustéennes de Nîmes, que « les découvertes effectuées au cours de la période 19501990 ont ajouté six tombes à la quinzaine que l'on connaissait auparavant. "Les deux plus récentes étant celles du Mail romain, il faut remonter, pour les découvertes précédentes, aux années 1963 (tombe du mar-
Après une brève description du cadre géographique et historique, une présentation des documents de fouille et une proposition de datation, nous traiterons des apports de cette découverte à la connaissance des rites funéraires et de son insertion dans le groupe des sépultures préaugustéennes de Nîmes ${ }^{5}$.

\section{LE SITE ET SON ENVIRONNEMENT (L. V.)}

\section{CADRE GÉOGRAPHIQUE}

La ville de Nîmes est implantée au pied et en partie sur les pentes de collines de faible altitude (180 à $200 \mathrm{~m}$ ) constituées par les calcaires crétacés des garrigues. Dès le début du second âge du Fer, la ville s'étend vers la plaine humide du Vistre qui s'étale au sud des collines et plateaux de la garrigue nîmoise. Le piémont des reliefs, qui s'organise en une ligne sud-ouest-nord-est marquant l'emplacement de l'importante faille de Nîmes, est un long coteau à très faible pente. Il est constitué par une accumulation de débris de calcaires crétacés, nommé « sistre ", que surmontent des sols bruns calcaires (Bonnet, Ménillet et Paloc, 1973). Les tombes ont été découvertes sur cette formation, à $500 \mathrm{~m}$ à l'est de la base des collines de Montaury (108 m) et du Puech du Teil (95 m), mais séparées d'elles par le cours d'eau temporaire dit "Cadereau » qui déroule son lit à leur pied.

\section{CADRE HISTORIQUE}

Les tombes exhumées se trouvent dans un quartier de la ville - anciennement dénommé du Jeu de mail ${ }^{6}$ - surtout connu pour les découvertes archéologiques liées à la présence du rempart augustéen entre la porte de France, encore visible, et la porte du Cadereau récemment mise au jour (Monteil, 1990c) (fig. 2). L'ouvrage de P. Varène. fait aujourd'hui le point sur presque toutes ces trouvailles (Varène, 1992, p. 5470).

ché aux bestiaux) et 1966 (tombe de la Cigale). La dispersion des tombes « a pour conséquence le fait que les sépultures, généralement découvertes isolément et de façon fortuite, ont rarement pu être fouillées dans les meilleures conditions... » (Lassalle, 1990a, p. 21-22). 5. Nous tenons à remercier ici tous ceux qui ont bien voulu relire ce texte et nous faire profiter de leurs remarques et plus particulièrement V. Bel, J.-L. Fiches, J. Guyon, M. Py et L. Sauvage.

6. Le terrain de ce jeu a été installé au XVII ${ }^{e}$ s. à l'emplacement qu'occupe ensuite, de 1850 à 1963 , le marché aux bestiaux, aujourd'hui remplacé par le centre Pablo-Neruda (Serre, 1989, p. 243-244). 


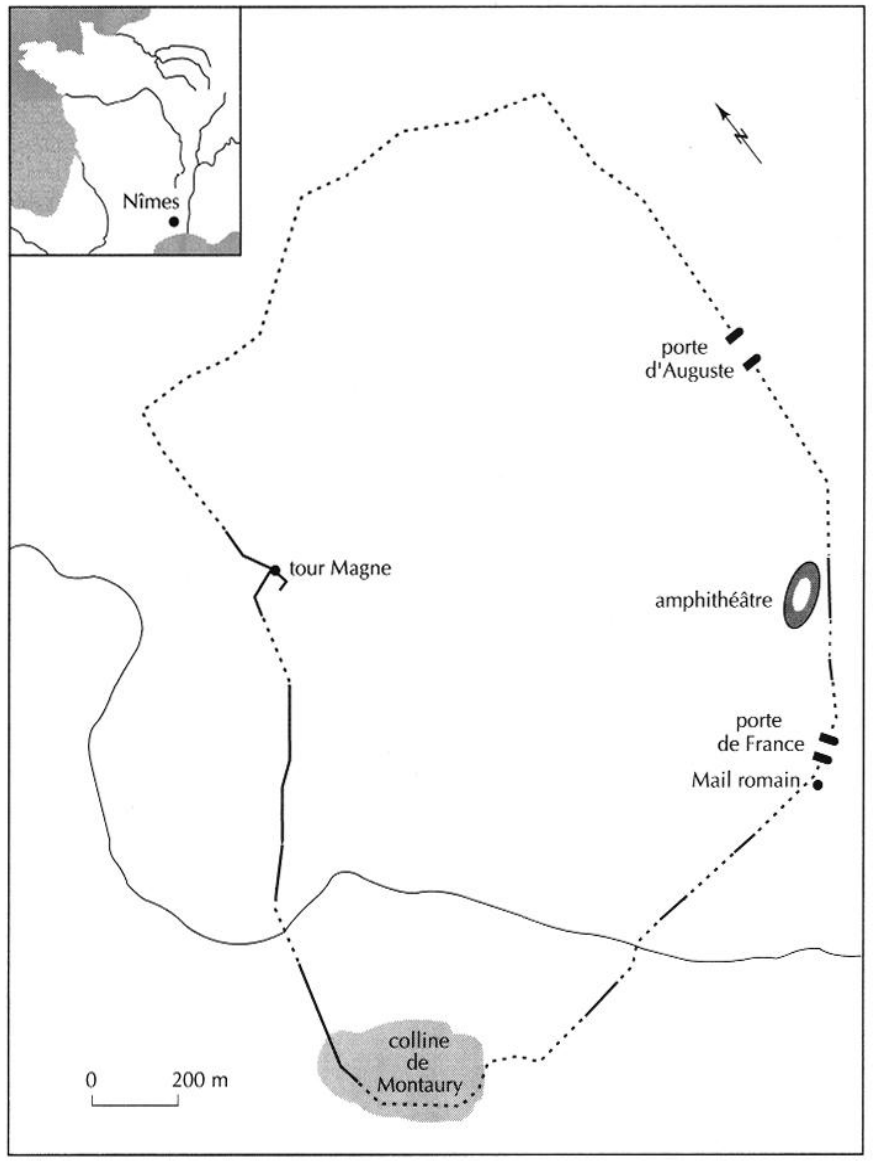

Fig. 1. Emplacement des tombes du Mail romain par rapport à l'enceinte gallo-rpmaine de Nîmes (d'après Varène, 1992).

Fig. 2. En bas à gauche, extrait cadastral au $1: 1000$ avec la localisation du site.

En bas à droite, extrait de plan de la ville de Nìmes, tiré d'un original au $1: 10000$ de J. Benoit.

1. Mail romain

2. Montaury

3. Cadereau

4. porte de France

5. porte du Cadereau

6. place Jules-Guesde

7. Jeu du mail

8. marché aux bestiaux

9. amphithéâtre

\section{Illustration non autorisée à la diffusion}

Plusieurs opérations archéologiques nîmoises récentes montrent qu'au ${ }^{\text {er }} \mathrm{s}$. avant J.-C., le secteur qui nous concerne est encore une portion d'espace champêtre située à environ $600 \mathrm{~m}$ au sud des limites de la ville et à $1 \mathrm{~km}$ de la source de la Fontaine ${ }^{7}$.

7. Le Mail romain se situe à $600 \mathrm{~m}$ au sud de deux fossés, traversant l'actuelle place J.-Guesde, interprétés comme les limites de la ville préromaine, au sud (Célié, 1990). Aucune découverte, pour le moment, ne
Cependant, les découvertes archéologiques montrent aussi que cette campagne, productrice de richesses pour les vivants, accueille la dernière demeure de certains (fig. 2). Ainsi, J. Bourrilly rapporte, d'après les manuscrits de A. Pelet, la découverte, au cours de fouilles exécutées en

paraît marquer un développement au-delà de cette ligne avant le dernier quart du $\mathrm{I}^{\text {er }} \mathrm{s}$. avant J.-C. Pour une première approche de la campagne précédant la ville au sein de la surface enclose par l'enceinte augustéenne, on se reportera à Poupet, Sauvage et Monteil, 1993. 


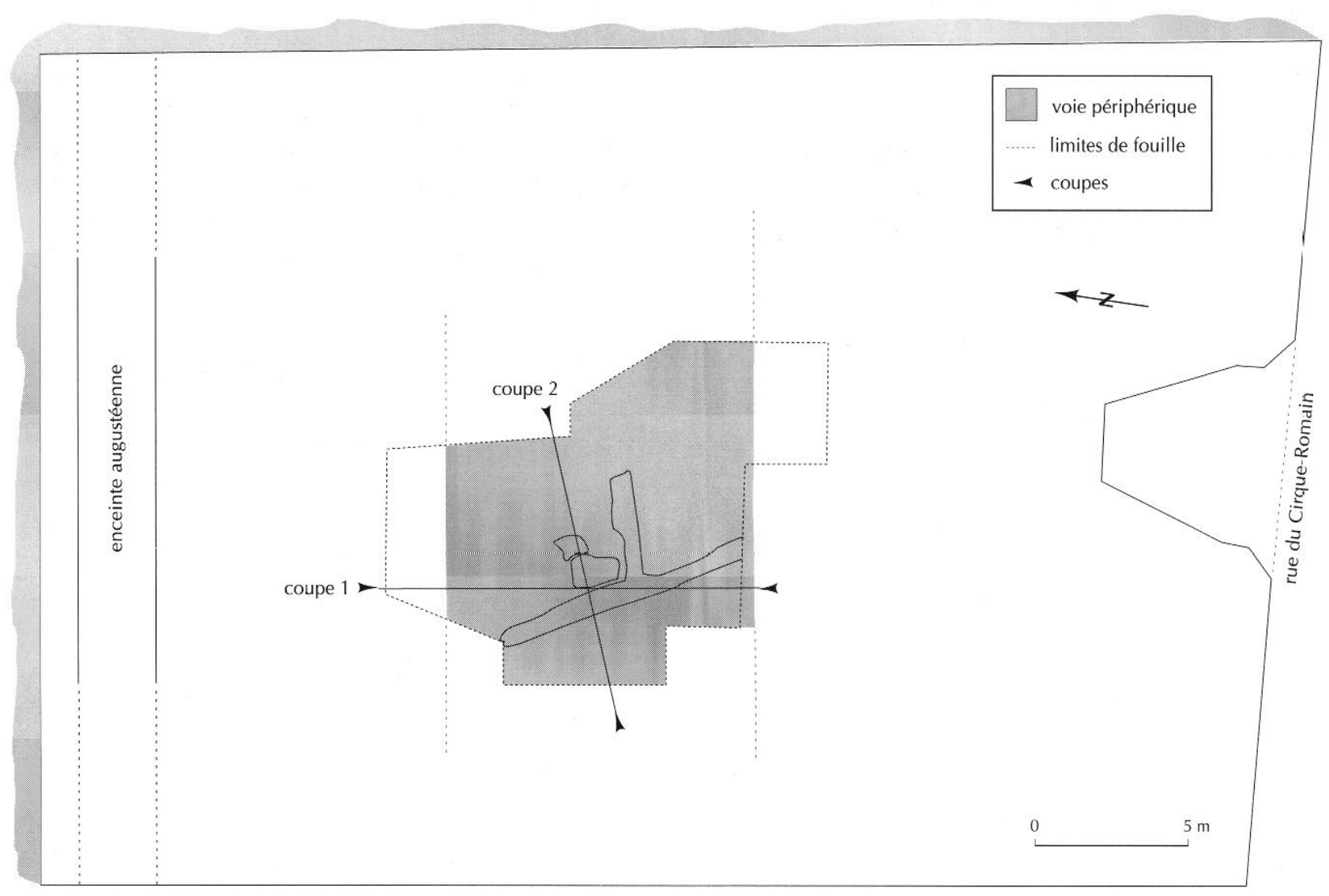

rue Dagobert

Fig. 3. Plan des vestiges : courtine, voie extra-muros el espace funéraire.

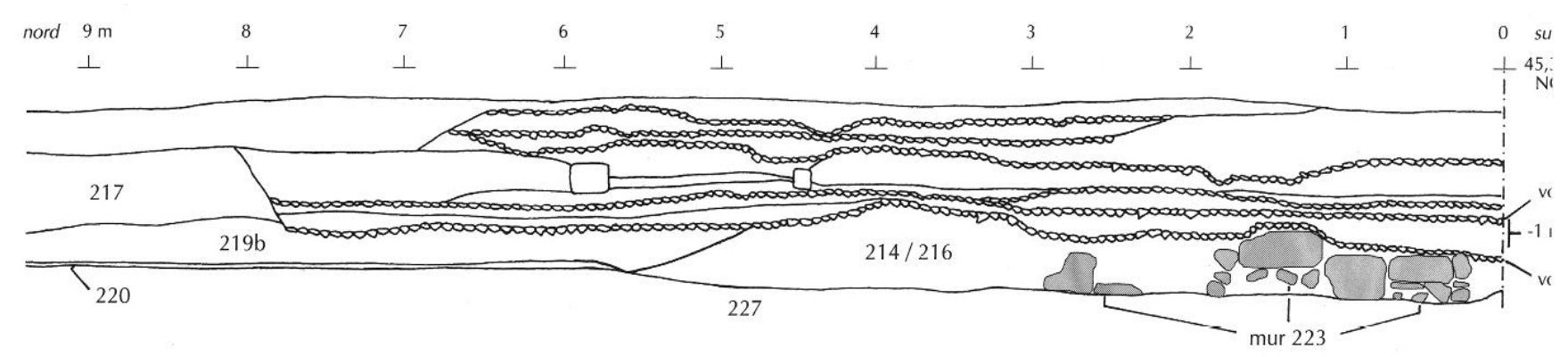

Fig. 4. Coupe sud-nord sur la voie et une partie de l'espace funéraire (coupe 1).

1840 sur l'emplacement de l'ancien Jeu de mail, de « fers de lance, longs étroits à douille et à sac (sic), deux amphores cinéraires, des coupes et une plaque de tôle de fer recourbée en demi-cylindre (arme ou bouclier) " (Bourrilly, 1912, p. 268). En 1963, à la suite du dégagement d'une portion du rempart romain, en préalable à la construction de bâtiments à l'emplacement du marché aux bestiaux, des fouilleurs clandestins ont découvert et fouillé une sépulture. En raison des conditions de la trouvaille, l'architecture et l'organisation de celle-ci ne sont pas connues, on sait seulement qu'elle "se trouvait sous la couche d'éclats de taille du rempart » (Lassalle, 1969). 
I.e mobilier a été restitué dans son intégralité, semble-t-il, au Musée archéologique de Nîmes et il a été étudié par M. Py (1981a, p. 173-177). Ce dernier date la tombe du troisième quart du $\mathrm{I}^{\text {er }} \mathrm{s}$. avant J.-C., alors que $\mathrm{G}$. Barruol et $\mathrm{G}$. Sauzade $(1969$, p. 64) la plaçaient à la tin du II" s. avant J.-C. Enfin, M. Bats (1990a, p. 282) propose de situer l'ensemble du mobilier dans les années 100-50 avant J.-C.

\section{LES DONNÉES ARCHÉOLOGIQUES}

\section{BRÈVE CHRONIQUE DE L'OCCUPATION DU SITE} (M. M.)

Le " sistre " a pu être observé en quelques points de la fouille. Il accuse un léger pendage nord-sud et est coté entre 43,45 et 43,80 m NGF. Il est recouvert par un paléosol brun rouge conservé en moyenne sur $0,50 \mathrm{~m}$. Ce dernier comprend quelques céramiques roulées qui semblent attester son anthropisation progressive dans le courant des II ${ }^{\mathrm{e}}-\mathrm{I}^{\mathrm{er}}$ s. avant J.-C. (mise en culture avec pratique de la fumure?). La première installation humaine d'importance s'avère cependant liée à la mise en place de l'espace funéraire (fig. 3).

Un peu plus tard, à l'époque augustéenne, le site est traversé par la courtine de l'enceinte ${ }^{8}$. On peut associer à la construction de cet ouvrage, généralement daté des années 16-15 avant J.-C. par l'inscription surmontant la porte d'Auguste, des niveaux de poussière de calcaire et d'éclats de taille reposant à même le sommet du paléosol (us 227), en périphérie du rempart (fig. 3 et 4). En d'autres points, ce même paléosol était recouvert par un mince cailloutis compact (us 220) sur l'interprétation duquel nous reviendrons.

Dans le même temps, extra-muros, une voie est installée à une dizaine de mètres de la courtine et parallèlement à celle-ci (fig. 3, 4 et 5). Sa mise en place condamne définitivement ce qui reste de l'espace funéraire, représenté sur la coupe 1 (fig. 4) par un de ses murs (mr 223) et le remblai 214/216. La première surface de roulement (vo 213), large de $11 \mathrm{~m}$, est installée sans réelle volonté de nivellement préalable de la zone d'implantation. I.e mobilier céramique recueilli comprend, entre autres, quelques

8. L'enceinte a pu être observée, sur environ $15 \mathrm{~m}$ de long, en limite nord de la parcelle. Objet d'une récupération massive, elle était seulement matérialisée par une excavation linéaire, à parois verticales, creusée dans le sistre et le paléosol sur une profondeur d'environ $1 \mathrm{~m}$. Sa destruction est intervenue, semble-t-il, dans le courant du XIV e s. exemplaires de sigillée du Sud de la Gaule (Haltern 2, 3 ou 8), des céramiques communes italiques et quelques productions locales (en particulier des coupes à pâte claire et engobe orangé) qui ont pu être mises en évidence dans des ensembles clos régionaux d'époque augustéenne (Genty, 1981, p. 113; Py 1981b, p. 96). L'ensemble de ces indices permet de proposer une installation dans le courant de la dernière décennie du $\mathrm{I}^{\mathrm{er}} \mathrm{s}$. avant J.-C. ou le tout début du I ${ }^{\text {er }}$ s. après J.C. ${ }^{9}$.

\section{L'ESPACE FUNÉRAIRE (Y. M., M. M., L. V.)}

\section{UN PETIT MONTICULE DE PIERRES ET DE TERRE}

Les vestiges de l'espace funéraire étaient recouverts par de très nombreux blocs et pierres calcaires bruts de taille, englobés dans une couche argileuse, de couleur rougeâtre (us 214/216); le tout épais, au plus haut, de $0,50 \mathrm{~m}^{10}$ (fig. 4). Ce niveau est antérieur aux aménagements augustéens et se présente sous la forme d'un petit monticule dont le sommet est localisé au-dessus des tombes et qui se poursuit en s'amenuisant au-delà des deux murs.

Il a livré une petite quantité de mobilier céramique, peu homogène, mais surtout plusieurs ossements, dont un crâne, appartenant à un cheval (cf. infra La faune).

$\mathrm{Au}$ vu de ce qui précède, il semble bien que cette couche ait un lien étroit avec l'ensemble funéraire et doive être interprétée comme le vestige d'un apport de pierres et de terre, plus ou moins limité par les murs, dans le but de constituer un " tumulus ", hypothèse sur laquelle nous reviendrons.

\section{UN AMÉNAGEMENT EMPIERRÉ}

Au-delà du tertre, vers le nord et donc vers l'enceinte augustéenne plus tardive, le paléosol était recouvert par un niveau de gravillon compact (us 220) (fig. 4). Bien que ce dernier n'ait pu ni être fouillé de façon extensive ni daté, on remarquera qu'il est antérieur (immédiatement ou non) aux grands travaux augustéens. Il est malheureusement impossible de l'interpréter avec certitude,

9. Cette voie originelle sera, par la suite, régulièrement entretenue. 10. Le sédiment est proche, pour sa fraction fine, du paléosol qui se rencontre partout ailleurs sur le chantier. Les blocs et pierres calcaires, très émoussés, sont de modules variés mais dépourvus de toute trace d'extraction ou d'équarrissage (à l'image de ceux qui constituent les murs). Ils semblent avoir été extraits du sistre. 


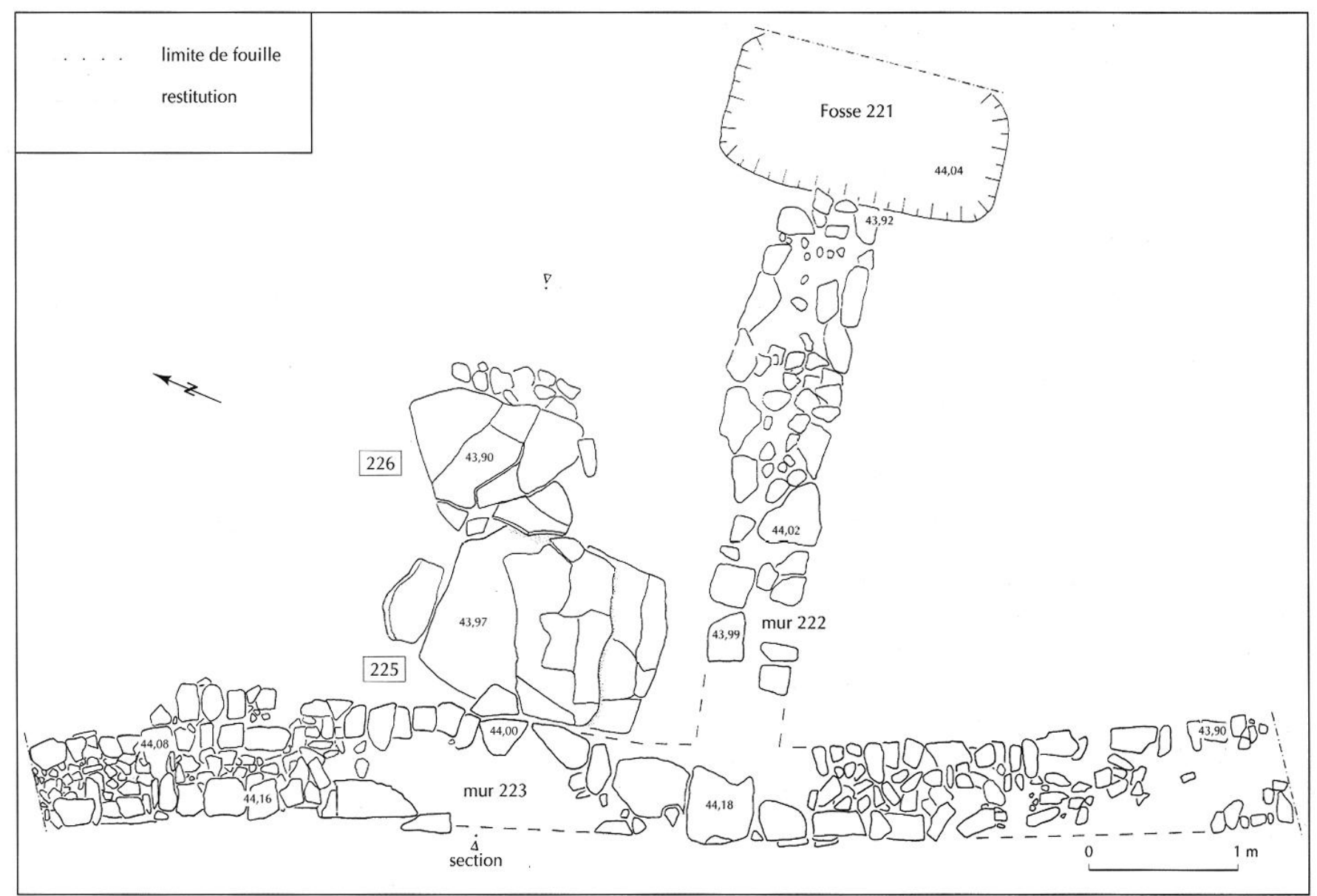

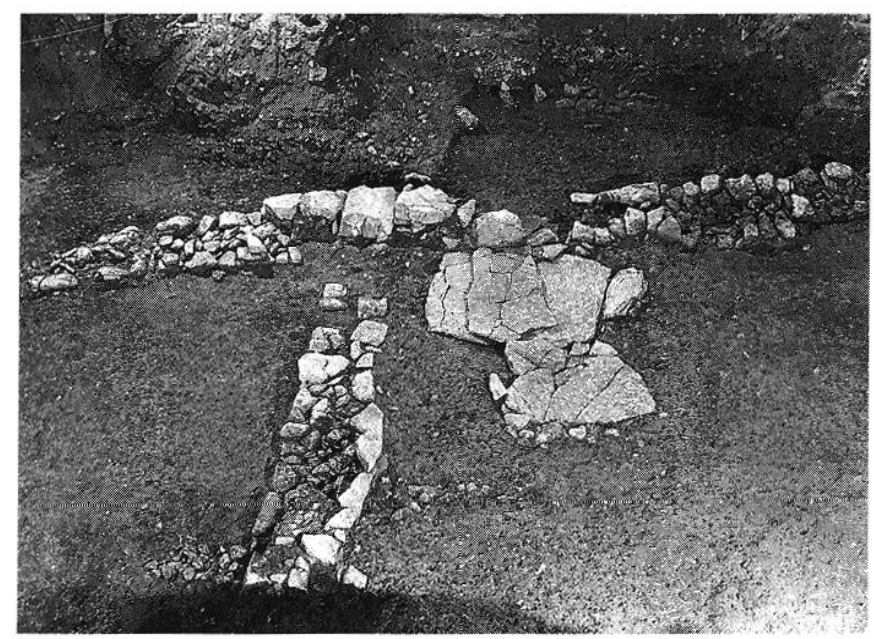

Fig. 6. Vue de l'espace funéraire, prise de l'est.

mais on peut émettre les trois hypothèses suivantes : résultat d'un piétinement répété (chantier de l'enceinte), aménagement empierré ponctuel lié à l'espace funéraire ou traces fugaces d'une voie préromaine.
Fig. 5. Plan général de l'espace funéraire.

\section{ÉLÉMENTS D'ARCHITECTURE}

Les vestiges funéraires se composent d'un groupe de quatre dalles horizontales situées dans l'angle de deux murs chaînés, plus ou moins perpendiculaires (fig. 5 et 6 ).

\section{Les murs}

Ils sont construits en blocs et pierres bruts de taille, extraits du sistre, agencés sans liant et conservés, au maximum, sur deux assises. Le mur 222, de direction est-ouest et d'une largeur comprise entre 0,60 et $0,80 \mathrm{~m}$, a été observé sur une longueur de $3,50 \mathrm{~m}$. Il est interrompu, à son extrémité est, par une fosse (fs 221) sans doute liée aux travaux augustéens. À l'ouest, il est chaîné avec un mur de direction nord-sud ( $\mathrm{mr} 223$ ), large de $0,60 \mathrm{~m}$ en moyenne et de même facture. Ce dernier a été suivi sur près de $8,30 \mathrm{~m}$ puis disparaît des deux côtés faute d'une 
bonne conservation. C'est dans l'angle de ces deux murs formant un $\mathrm{T}$ qu'ont été implantées deux tombes accolées. Celles-ci ont été numérotées 225 et 226, au sein d'une numérotation continue de tous les vestiges (faits et unités stratigraphiques) observés sur le site.

\section{L'installation des coffres}

Pour chaque tombe, une fosse au fond aplani est creusée depuis la surface du paléosol (us 227) et entame partiellement le « sistre" (fig. 7 et 8). Les deux coffres sont de dimensions un peu moins importantes que les fosses qui les contiennent ${ }^{11}$. Mais cette différence est surtout remarquable dans le cas du coffre 226. En effet, alors que l'espace compris entre les dalles et la paroi des fosses est généralement peu important - quelques centimètres de large comblés par un sédiment meuble proche du terrain naturel remanié et du sédiment colmatant les coffres -, celui existant à l'arrière de la dalle 7 mesure $20 \mathrm{~cm}$ de large à la base et $42 \mathrm{~cm}$ au sommet. Il se trouve rempli par de nombreux blocs auxquels se mêlent quelques gros fragments de poterie. Il semblerait que l'on ait réduit la taille de la chambre, à moins que toute la partie orientale n'ait été conçue d'emblée pour recevoir et caler un aménagement de surface destiné au repérage des incinérations. La superposition des différents relevés en plan indique que l'extrémité est de la fosse et de son comblement n'a pas reçu de couverture. Est-ce le fait du hasard ou un élément qui peut servir à conforter notre hypothèse?

En termes de chronologie relative, la première structure tombale mise en place est le coffre 225. La tombe 226 a été accolée peu après à la paroi ouest de la cellule précédente, ce qui a permis de faire l'économie d'une dalle ${ }^{12}$.

\section{Les couvertures}

La fermeture des coffres est assurée par la pose de dalles débordant largement de ceux-ci et qui sont semblables à

11. Tombe 225 dimensions extérieures du coffre (en $\mathrm{m}$ ) : $1,18 \times 0,90 \mathrm{x}$ 0,74 ; dimensions de la fosse : $1,20 \times 0,98 \times 0,85$.

Tombe 226 dimensions extérieures du coffre (en m) : $0,80 \times 0,65 \times 0,50$; dimensions de la fosse : $1,15 \times 0,78 \times 0,70$.

12. Tombe 225 dimensions intérieures $(\mathrm{en} \mathrm{m}):$ longueur $=0,88$, petite base $=0,54$, grande base $=0,64$.

Tombe 226 dimensions intérieures : longueur $=0,70$, petite base $=0,44$, grande base $=0,50$. Toutes les dalles sont en calcaire brut de détail, sans doute extraites des bancs superficiels de calcaire facilement délitable qui affleurent en zone de garrigue.

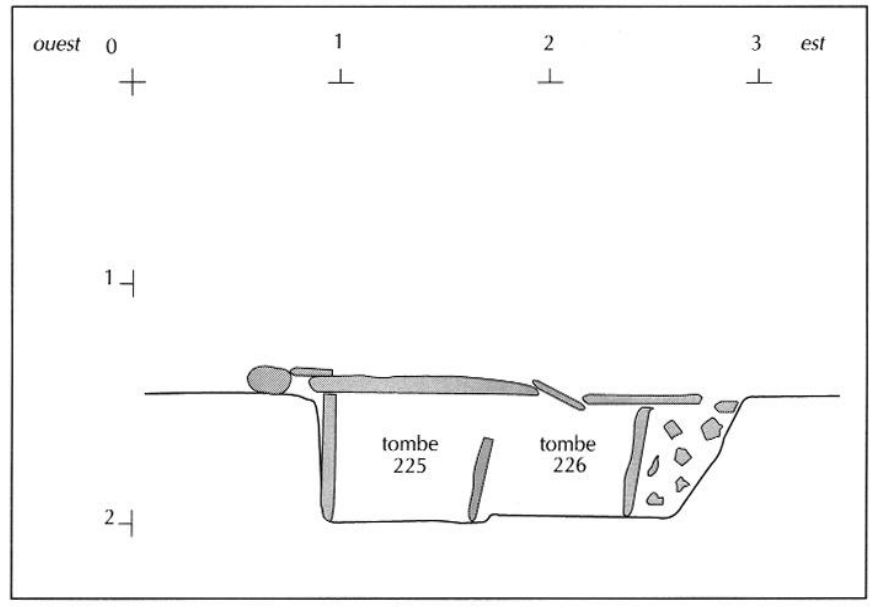

Fig. 7. Coupe ouest-est sur les deux coffres (coupe 2).

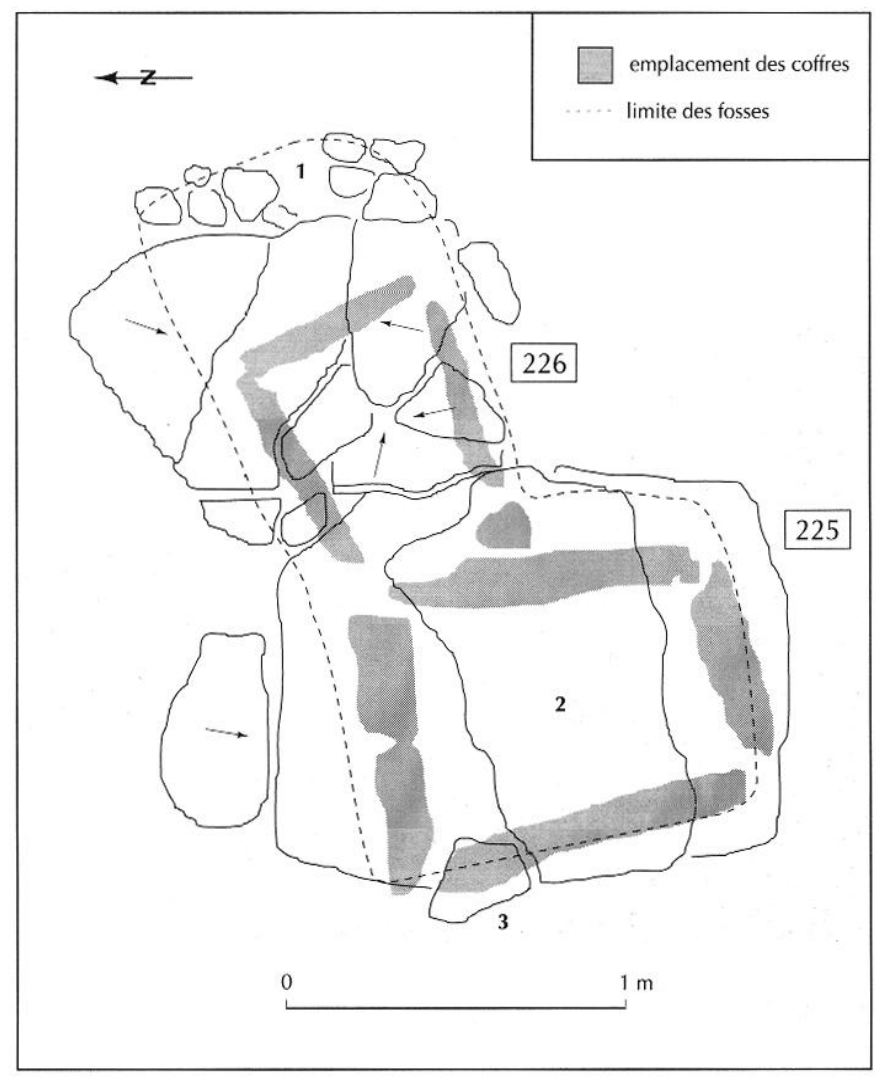

Fig. 8. Plans superposés des convertures, des coffres et des fosses. 1. emplacement supposé de la structure de signalisation

2. pointe de lance

3. umbo 
celles des côtés (fig. 8). Le coffre le plus grand (225) est fermé par deux dalles mises côte à côte et surmontées d'une troisième.

La position de ces dalles fournit un élément qui conforte la thèse de la contemporanéité des deux sépultures. En effet, toutes trois ont été organisées de façon à les faire déborder sur la tombe 226 mitoyenne dont elles recouvrent le tiers est ${ }^{13}$. Le complément de couverture est assuré par une dalle unique qui s'est fracturée en plusieurs morceaux sous le poids des terres constituant le tertre. Le point de rupture se situe exactement au centre du coffre et semble être dû au dénivelé entre la dalle couvrant la sépulture 225 et les parois du caisson qui se situent plus bas. Cette disposition, par son défaut d'étanchéité, a provoqué un remplissage plus rapide de la cavitë sous-jacente.

\section{LE CONTENU DES TOMBES}

Après la dépose des dalles de couverture, les deux coffres sont apparus - l'un au quart, l'autre entièrement - comblés par un sédiment argileux fin, lié à une lente infiltration. À l'exception de l'olpé $n^{\circ} 1$ de la tombe 225 , la totalité du mobilier était noyée dans le comblement (fig. 9 et 10 ).

\section{LES CÉRAMIQUES (M. M.)}

La définition typologique des vases décrits ci-dessous a été empruntée au récent Dictionnaire des céramiques antiques en Méditerranée nord-occidentale (Py dir., 1993) ${ }^{14}$.

\section{Tombe 225 (fig. 11)}

1. Cruche (hauteur : $24,5 \mathrm{~cm}$ ). Céramique tournée à pâte claire jaune. Bord en gouttière, anse trifide et fond annulaire. Lèvre ébréchée à l'opposé de l'anse et panse

\footnotetext{
13. Les deux tiers restants sont recouverts par une quatrième dalle. Les éléments de la couverture mesurent entre 1 et $1,10 \mathrm{~m}$ de long pour 0,60 à $0,80 \mathrm{~m}$ de large et 5 à $8 \mathrm{~cm}$ d'épaisseur.

14. Les abréviations utilisées correspondent aux catégories de céramiques suivantes : CAMP-A = céramique campanienne A (Py dir., 1993, p. 146-150); CAMP-B = céramique campanienne B (Py dir., 1993, p. 151$152)$; CL-REC = céramique à pâte claire récente (Py dir., 1993, p. 222243); CNI-LOR = céramique non tournée du Languedoc oriental (Py dir., 1993, p. 292-306); COM-IT = céramique commune italique (Bats in: Py dir., 1993, p. 357-362); SABL-OR = céramique commune sableuse oxydante ou réductrice (Raynaud in : Py dir., 1993, p. 548-553); A-ITA = amphore italique (Py dir., 1993, p. 53-55); COT-CAT = céramique grise de la côte catalane (Castanyer et alii in : Py dir., 1993, p. 391-397).
}

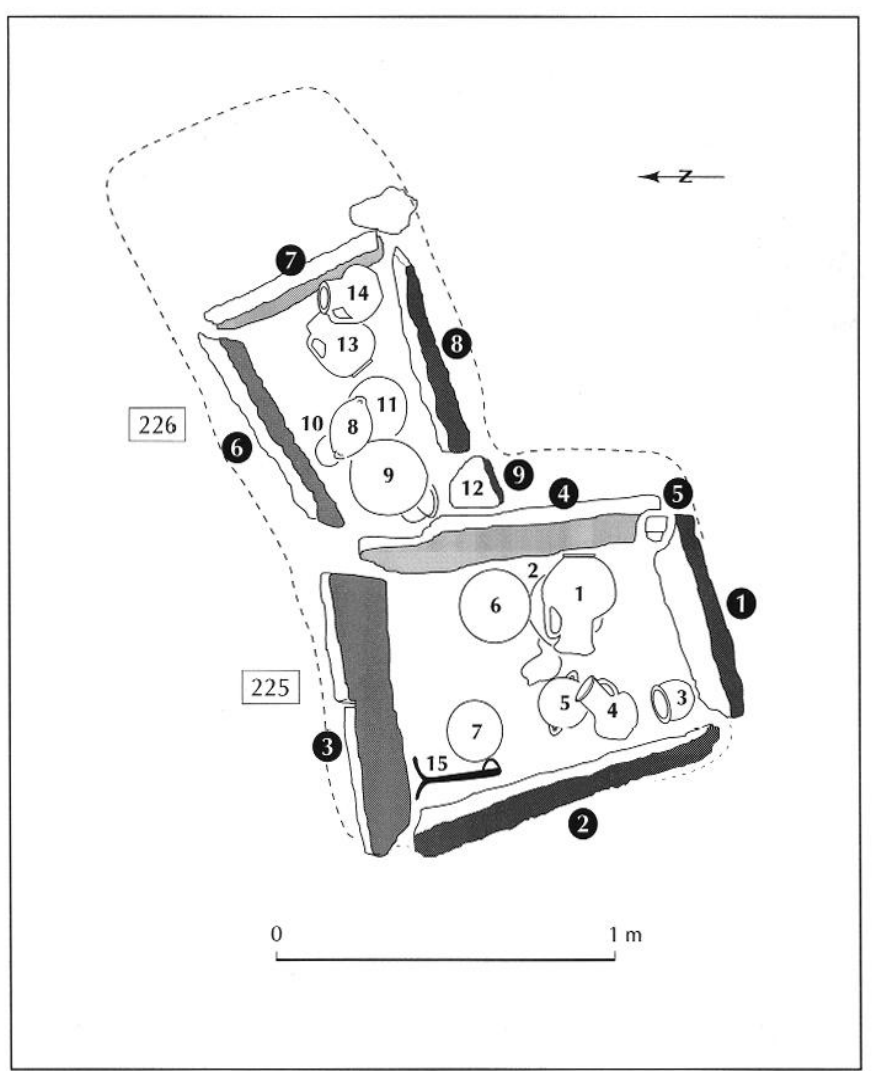

Fig. 9. Plan des tombes el des offrandes (le $n^{\circ} 2$ marque l'emplacement de l'umbo et le $n^{\circ} 15$ celui des strigiles) avec la numérotation des dalles.

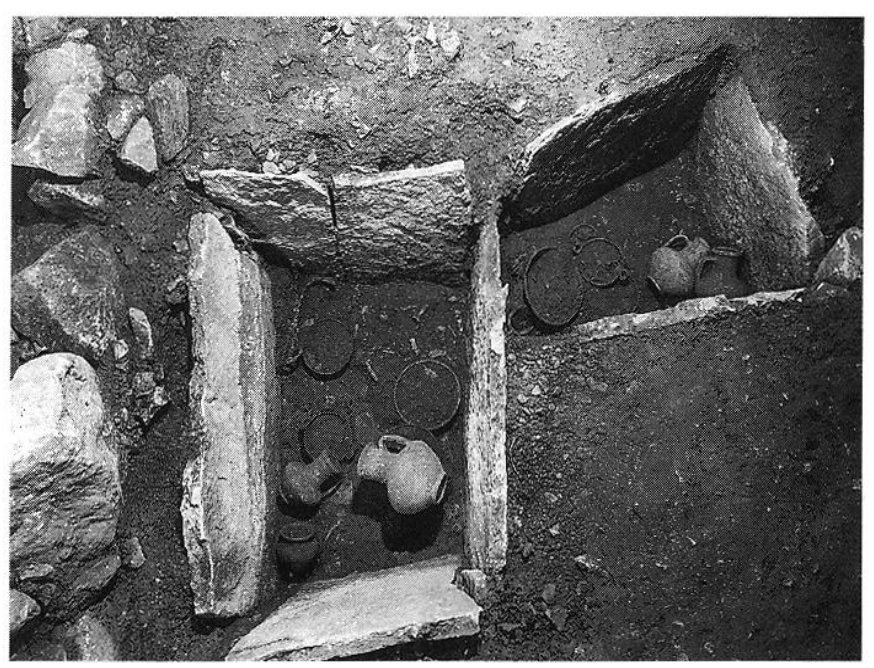

Fig. 10. Vue des deux coffres avec leur contenu, prise de dessus. 


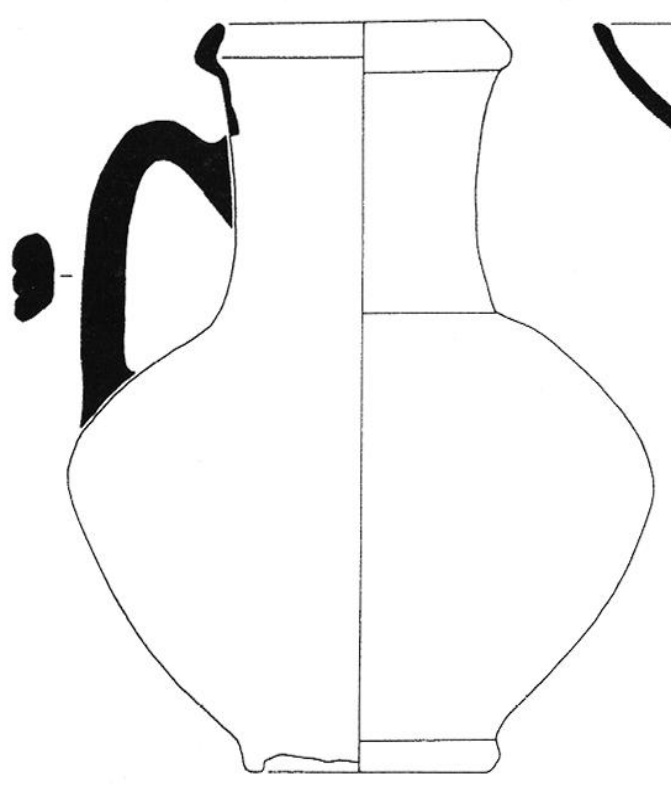

1

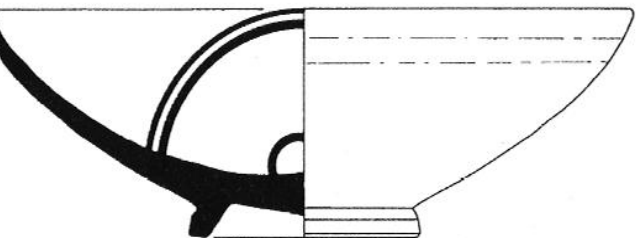

2

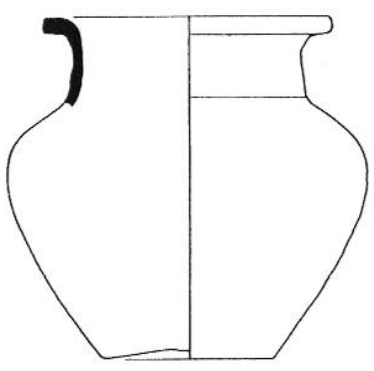

3

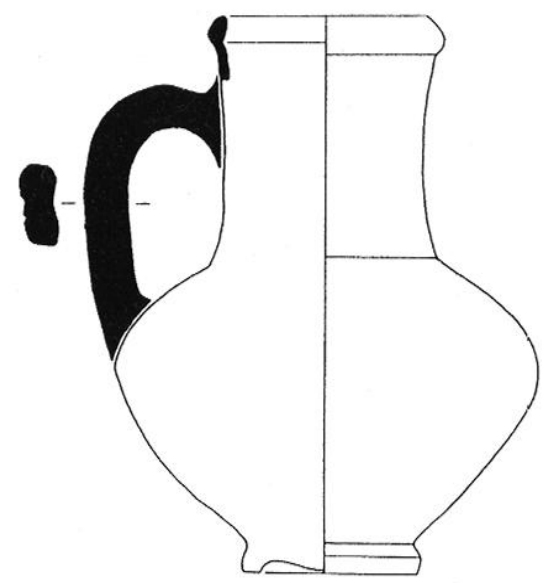

4 $\mathrm{cm}$
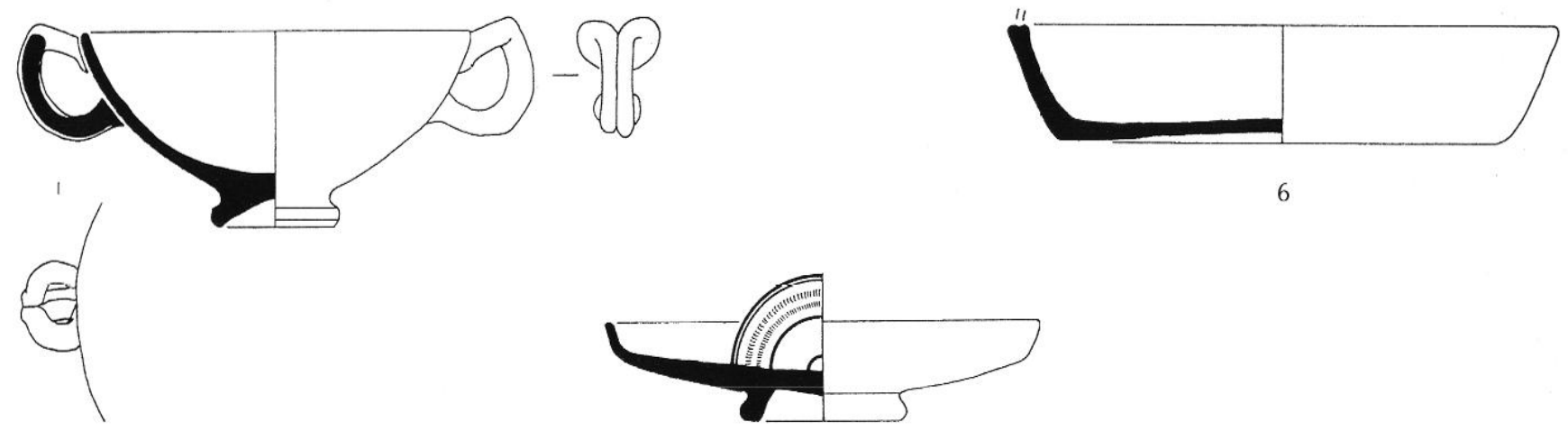

6

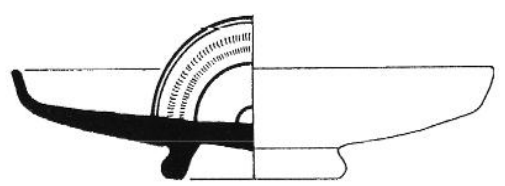

5

7

Fig. 11. Mobilier céramique de la tombe 225.

fissurée (suite à une chute?). Dépression digitée sur l'attache basse de l'anse. Cette pièce peut être rapprochée de la forme CL-REC 3a et est comparable, bien que de plus grande taille, aux n ${ }^{\circ} 4$ (fig. 11), 13 et 14 (fig. 12).

2. Coupe en Campanienne $\mathrm{A}$ tardive (diamètre moyen : 21,8 cm). Pâte rouge. Vernis noir, irisé, bien conservé, mais écaillé sur le bord, le fond et la panse. Pièce nettement déformée. Le fond est décoré d'un petit cercle central entouré de trois cercles concentriques rapprochés. Forme CAMP-A $27 \mathrm{Bb}$ (classification de Lamboglia).

3. Urne. Céramique tournée à pâte proche des communes modelées, orangé à beige gris; dégraissant très fin (mica), bien que ponctuellement marqué par des grains de calcite ou de quartz assez gros et par quelques points de chaux. Bord replié et col court. Fissure de retrait au séchage visible sur le fond. Ce vase est très bien tourné, bien que l'on note, sur sa panse, quelques traces d'enfoncement de doigts. Il pourrait être classé dans le groupe des céramiques communes sableuses oxydantes ou réductrices du Ianguedoc-Roussillon, mais il se rapproche davantage, par sa forme, des urnes récentes en céramique non tournée. Voir, en particulier, la série CNT-LOR U7 et comparer avec l'urne ${ }^{\circ} 12$ de la tombe 226 (fig. 12).

4. Cruche (hauteur : 17,9 cm). Céramique tournée à pâte claire jaune beige. Bord en gouttière, anse trifide et fond annulaire. Lèvre ébréchée à l'opposé de l'anse. 


$$
\text { OYANAIKOY }
$$
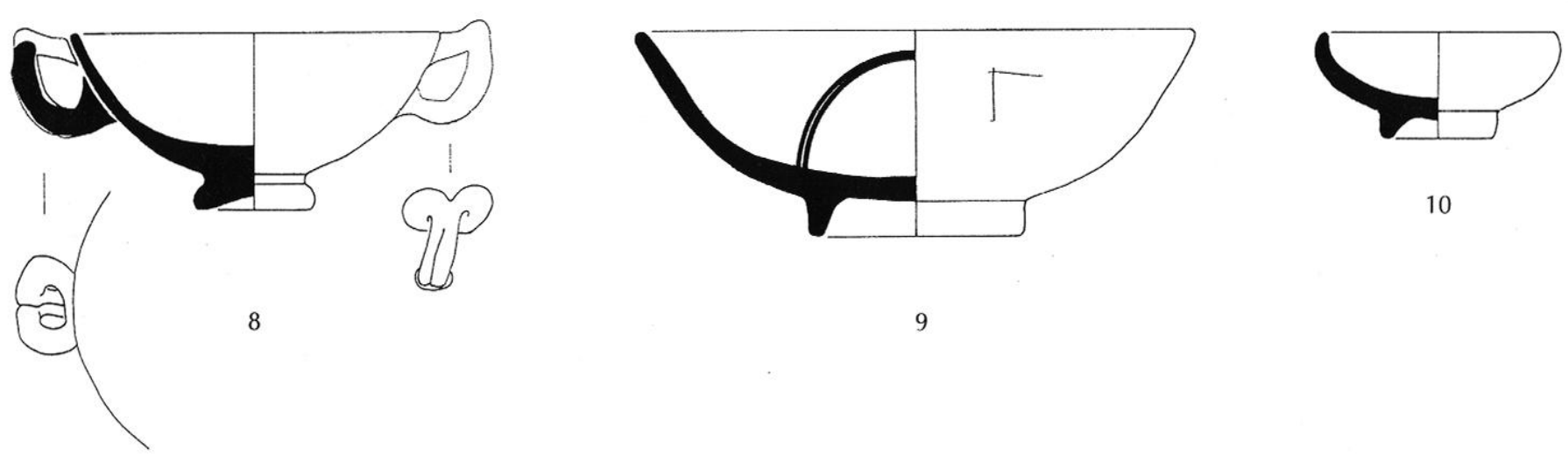

10

9

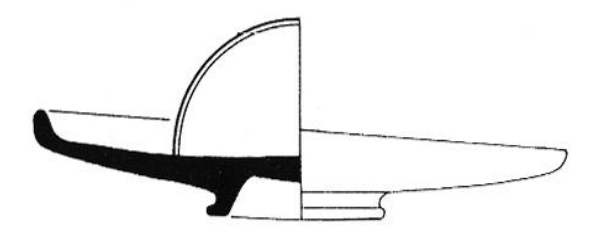

11

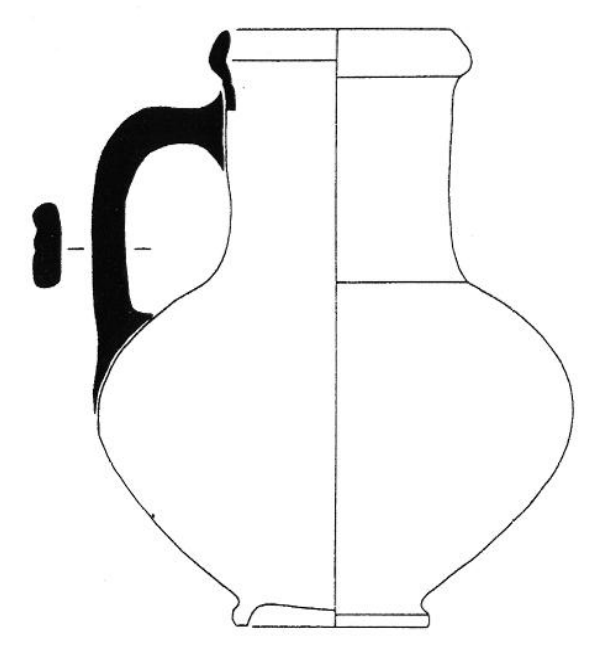

13

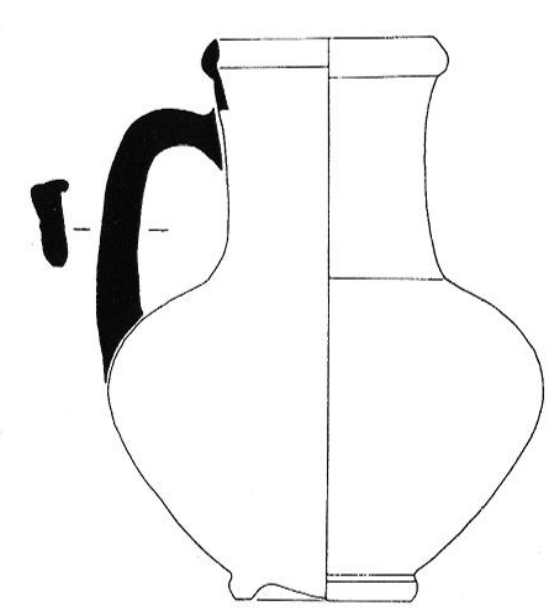

14

Fig. 12. Mobilier céramique de la tombe 226.

Desquamation de la partie du bord et du col situés à l'opposé de l'anse. À rapprocher de la forme CL-REC 3a et à comparer aux $n^{\circ} 1$ (fig. 11), 13 et 14 (fig. 12).

5. Bol à anses en boucle (diamètre : $14,4 / 14,7 \mathrm{~cm}$ ). Campanienne B à pâte jaune à jaune rosé. Vernis noir mat, très bien conservé à l'intérieur mais dégradé sur le bord et les anses et craquelé à l'extérieur. Identique au $n^{\circ} 8$ (fig. 12), ce bol est à rattacher à la forme CAMP-B 127 (classification de Pasquinucci).

6. Patina ou plat à feu (diamètre : $20,1 \mathrm{~cm}$ ). Céramique commune italique tournée, à pâte rouge brique et petites inclusions de mica et de quartz. Bord avec rainure en partie supérieure. L'extérieur du vase est très bruni et on note, sur le bord, quelques ébréchures ainsi que les restes lacunaires d'une pellicule de barbotine jaune clair. Forme COM-IT $6 c$.

7. Assiette en Campanienne B (diamètre : $16,5 \mathrm{~cm}$ ). Vernis noir mat, parfaitement conservé (aspect neuf?). Petit cercle central entouré de deux sillons concentriques limitant un espace guilloché. Très proche du $n^{\circ} 11$ (fig. 12), bien que légèrement plus petit. Forme CAMP-B 5 (classification de Lamboglia). 


\section{Tombe 226 (fig. 12)}

8. Bol à anses en boucle (diamètre : 13,2/13,7 cm). Campanienne $\mathrm{B}$ à pâte jaune beige. Vernis noir, partiellement irisé et dégradé sur le bord et les anses. Anses tordues. Identique au ${ }^{\circ} 5$ (fig. 11). Forme CAMP-B 127 (classification de Pasquinucci).

9. Coupe en Campanienne A (diamètre moyen : $21,7 \mathrm{~cm}$ ). Pâte rouge. Vernis noir irisé, très écaillé sur le bord et une partie du fond. Le bord présente également quelques ébréchures. Le fond est décoré de deux cercles concentriques très rapprochés. Forme CAMP-A 2943 (classification de Morel).

À l'intérieur, près du fond et parallèlement aux stries de tournage, un graffite en gallo-grec se développe. L'étude réalisée par M. Lejeune est reprise ici (Lejeune, 1990) : «Lettres de 6 à 7,5 mm d'un tracé régulier et élégant (...) ovavaıxov. Datif thématique en -ù (RIG I, p. 449 ; mais état antérieur -ùi de la finale en G-206 et G-208 à Nîmes). Nom Vanaicos, nouveau; souche (rare) Vano(Holder III 98) ; suffixe (rare; de celticité parfois contestée) -aico- (ibid. III 526). Désignation idionyme seul. (...) Vanaicos ne peut être que masculin. Les marques de propriété sur vaisselle sont presque toujours des noms abrégés; dans les rares exemples où le nom soit écrit en entier, et où le cas grammatical soit reconnaissable, il s'agit du nominatif exceptionnellement du génitif ( $R I G I$, p. 448). Le vase n'a donc sans doute pas été inscrit du vivant de Vanaicos mais à l'occasion de ses funérailles : le datif du défunt concurrence le nominatif dans la formulation des épitaphes (ibid. p. 447), dont nous avons ici un écho. " Un autre graffite, une incision représentant deux traits se recoupant à angle droit $(2 \mathrm{~cm}$ et $2,3 \mathrm{~cm})$, marque la panse, à proximité du bord. Cette lettre isolée peut être rapprochée des graffites 45 à 53 recensés par M. Py (1990a, doc. 293 et 294, $\mathrm{n}^{\circ} 45$ à 53).

10. Coupelle en Campanienne A (diamètre moyen : $9 \mathrm{~cm}$ ). Pâte rouge. Vernis noir, irisé et très dégradé. Pied et lèvre ébréchés. Forme CAMP-A 113 (classification de Morel).

11. Assiette en Campanienne B (diamètre moyen : $17,8 \mathrm{~cm})$. Pâte gris beige à chamois. Vernis noir mat, écaillé sur le bord. Fond décoré de deux sillons concentriques encadrant un guillochis. Déformé. Très proche du $\mathrm{n}^{\circ} 7$ (fig. 11). Forme CAMP-B 5 (classification de Lamboglia).

12. Urne. Céramique non tournée à pâte variant du beige au noir en passant par le brun rouge, avec quartz et calcite en dégraissant. Bord replié et col moyennement haut. Lissage de surface. Fin peignage sur le haut de la panse. Bord ébréché. Micro perforation sur la panse (volontaire ou liée à un éclat de dégraissant?). À rattacher à une étape de transition entre les série CNI-LOR U5 et U7.

13. Cruche (hauteur : 19,3 cm). Céramique tournée à pâte claire jaune. Bord en gouttière, anse trifide et fond annulaire. Lèvre ébréchée à l'opposé de l'anse. Traces de râpe sur la lèvre. Fissure sur la panse, parallèle au sens du tournage, avec grosse perforation due à une malformation ou à un impact. Cette pièce peut être rapprochée de la forme CL-REC $3 a$ et est comparable aux $n^{\circ} 1,4$ (fig. 11) et 14 (fig. 12).

14. Cruche (hauteur: $18,3 \mathrm{~cm}$ ). Céramique tournée à pâte claire jaune rosé. Bord en gouttière, anse trifide et fond annulaire. Lèvre ébréchée à proximité de l'anse. Trace d'impact sur la panse. Cette pièce peut être rapprochée de la forme CL-REC $3 a$ et est comparable aux $n^{\circ} 1$, 4 (fig. 11) et 13 (fig. 12).

\section{LE MOBILIER MÉTALLIQUE (M. F.)}

Il consiste en objets déposés à l'intérieur de la tombe 225 (paire de strigiles, éléments de boîtes ou de coffrets), dans les éléments de couverture de cette même sépulture (fer de lance) ainsi qu'au sommet du remplissage compris entre le bord de la fosse et la dalle 2 (umbo de bouclier). Aucun objet non céramique ne semble avoir été déposé dans le coffre 226, à l'exception d'un clou en fer (fíg. 14, $\mathrm{n}^{\circ} 14$ ) et d'un fragment informe en bronze (fig. 14, $\mathrm{n}^{\circ} 15$ ), tous deux peu caractéristiques, retrouvés dans le comblement de la fosse; la présence de ces objets à l'intérieur du coffre ne semble pas résulter d'un dépôt volontaire.

\section{Strigiles (fig. 13)}

1. Paire de strigiles en fer, en place sur leur anneau de suspension. Ces deux objets, identiques, appartiennent à un modèle gracile, étroit, dont la pointe forme avec le manche un angle proche de $90^{\circ}$; longueur totale $2,78 \mathrm{~cm}$, largeur de la ligula $1,45 \mathrm{~cm}$, largeur du manche $1,3 \mathrm{~cm}$. Ce dernier est constitué d'un simple repli ouvert, de forme rectangulaire. L'état de conservation ne permet d'observer ni décor, ni marque comme on en trouve assez fréquemment sur les exemplaires en bronze.

L'anneau de suspension est un simple tore filiforme replié sur lui-même pour former un anneau ouvert de $6,5 \mathrm{~cm}$ de diamètre environ; les extrémités, resserrées 


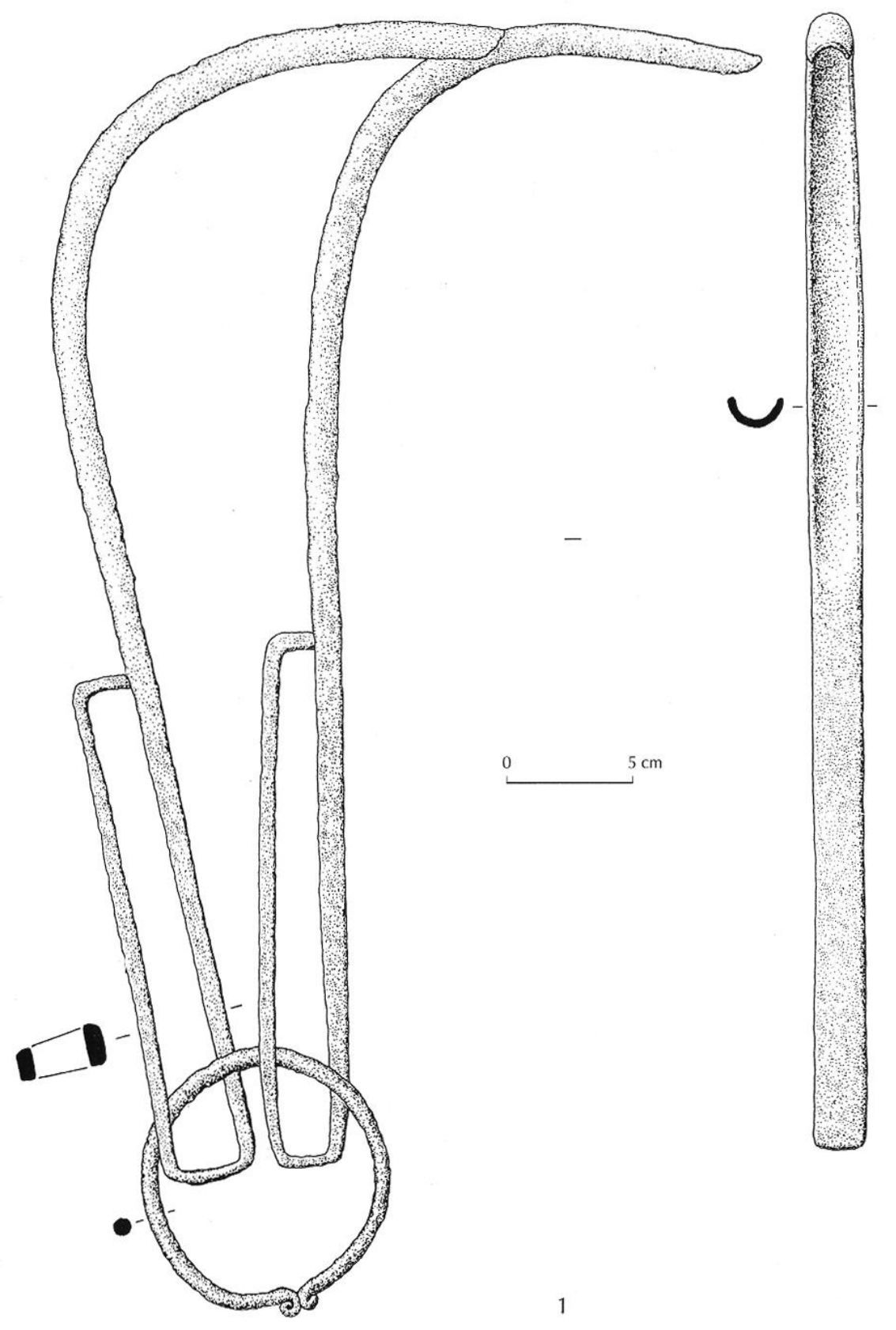

Fig. 13. Le trousseau de strigiles.

l'une contre l'autre sans qu'il cxiste aucun système de fermeture, sont simplement amincies et repliées en spirale vers l'extérieur. Ce système n'apporte ni la sécurité, ni la souplesse d'utilisation qu'autorisent les anneaux en bronze spécialement fabriqués pour cet usage (Ulbert, 1984, p. 71-77), du moins en contexte italique; mais on notera que plusieurs anneaux de suspension attestés dans la région sur des strigiles en fer ont été eux aussi fabriqués en fer, et ne comportent pas le système de fermeture des objets en bronze.

Éléments de fermeture de boîtes en bois (fig. 14)

2. Ensemble formé d'une entrée en tôle de bronze $(2,15 \times 3,3 \mathrm{~cm})$, perforée d'un orifice approximativement circulaire (diamètre : 1,35 à $1,5 \mathrm{~cm}$ ) prolongé par un 
appendice rectangulaire (longueur totale $2,1 \mathrm{~cm}$ ), au dos duquel subsiste encore une pointe de fixation (sur trois à l'origine) coulée en même temps que la plaque, et indiquant un support en bois d'au moins $1 \mathrm{~cm}$ d'épaisseur. En place sur cette plaquette, disposé perpendiculairement, un bouton en fer, en forme de tête de volatile aquatique, permettait de faire pivoter sur son axe longitudinal une tige de fer longue de $4,8 \mathrm{~cm}$. Cette tige se termine par une plaquette quadrangulaire percée de manière à pouvoir être introduite en force à l'extrémité de l'axe. Aux extrémités de la tige, donc au contact de l'entrée en tôle et de la plaquette en fer, se remarquent des empreintes ligneuses perpendiculaires.

3. Ensemble identique au précédent, quoique de dimensions légèrement inférieures (plaque en bronze : $1,85 \times 2,6 \mathrm{~cm}$; longueur de la tige $4 \mathrm{~cm}$ ); derrière la tôle de bronze, les traces ligneuses sont bien visibles sur une épaisseur de $1,35 \mathrm{~cm}$, mais la plaquette perpendiculaire à l'extrémité de l'axe est tordue.

Ces deux mécanismes, de même nature, semblent avoir été conçus pour pouvoir manœuvrer de l'extérieur, à l'aide du bouton en forme de tête de volatile, un système interne de blocage qui doit être la plaquette située à l'extrémité de l'axe. On peut envisager de placer les plaques en bronze sur le petit côté d'une boîte en bois dont le couvercle, à glissière, pourrait être maintenu en position fermée par la rotation des plaquettes placées aux extrémités des axes. Cette proposition conduit à restituer deux boîtes quadrangulaires identiques, mais de dimensions légèrement différentes.

\section{Divers (fig. 14)}

4-8. Ensemble de cinq petits clous en bronze, dont la tige systématiquement repliée à angle droit (et dans deux cas, avec la pointe également repliée dans l'épaisseur), indique un support épais de 5 à $6 \mathrm{~mm}$ environ. Les têtes plates, écrasées, étant de forme très irrégulière, il est difficile de voir dans ces objets des clous décoratifs; il s'agit plutôt de clous de fixation utilisés sur un support peu épais. Leur appartenance aux boîtes 2 et 3 est donc peu probable.

9. Aiguille en fer, tordue et brisée, longueur restituée : $10,3 \mathrm{~cm}$ environ. Simple tige filiforme effilée vers la pointe, et percée au sommet d'un chas de dimensions réduites.

10. Fragment de fil de bronze (longueur actuelle: $1,4 \mathrm{~cm})$, légèrement arqué.
11. Fragment d'un objet en fer (longueur actuelle : $2 \mathrm{~cm}$ ), non identifié.

\section{Armes (fig. 15)}

12. Umbo de bouclier en fer, longueur $21,3 \mathrm{~cm}$, largeur maximale $10,2 \mathrm{~cm}$; très bon état de conservation, même avant tout nettoyage. Profil en oméga, l'umbo croisant transversalement la spina verticale du bouclier; ailettes rectangulaires, assurant la fixation de l'umbo sur le bouclier au moyen de trois clous par ailette, dont aucun n'est conservé. La section transversale, bombée, permet d'observer les deux rebords épaissis, de forme triangulaire; la section des ailettes, en revanche, est plate, sans aucun renfort.

13. Pointe de lance en fer, longueur actuelle $21 \mathrm{~cm}$, très corrodée; ne sont conservées que la douille, longue d'environ $7,5 \mathrm{~cm}$, et la nervure centrale de l'armature; les ailettes et la pointe, plus fragiles, ont presque entièrement disparu. Cet état de conservation ne permet aucune comparaison avec les pointes de lance connues dans les tombes contemporaines du Languedoc oriental, où ces armes sont néanmoins fréquentes.

\section{LeS Restes hUMAINS (T. J., C. B.)}

Des restes épars isolés du matériel faunique de la tombe 225 ont été confiés à $\mathrm{Cl}$. Bouville, qui a identifié un fragment de diaphyse d'humérus, un fragment de diaphyse de fibula, un fragment de talus et un fragment de première phalange de pouce du pied. Les autres éléments, isolés par la suite, ont été reconnus par T. Janin qui a également accepté de réaliser l'étude d'ensemble ${ }^{15}$. Tous les éléments ont été retrouvés en place au fond des tombes 225 et 226 , derrière les dalles ou au cours du tamisage du comblement (fig. 16).

L.es os de la tombe 226 sont minuscules et appartiennent vraisemblablement à un sujet humain.

Tous les os de la tombe 225 sont humains. Le fragment de crâne montre une suture non synostosée. La base de la phalange distale du pouce du pied est soudée. Le sujet contenu dans la tombe 225 est donc de façon certaine un adulte, peut-être de stature gracile, probablement âgé de moins de 30 ans.

15. Claude Bouville, Laboratoire d'anthropologie, Faculté nord, Marseille, URA 184 du CNRS et Thierry Janin, doctorant, EHESS de Toulouse, chercheur associé de l'UPR 290 et du GDR 742 du CNRS. 

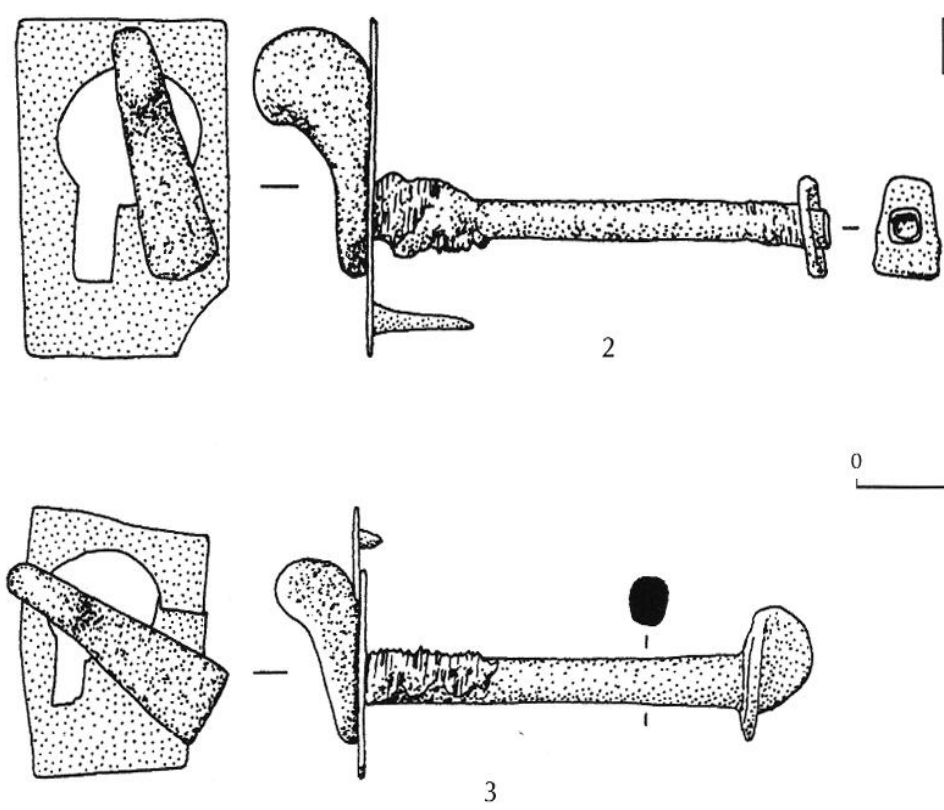

0
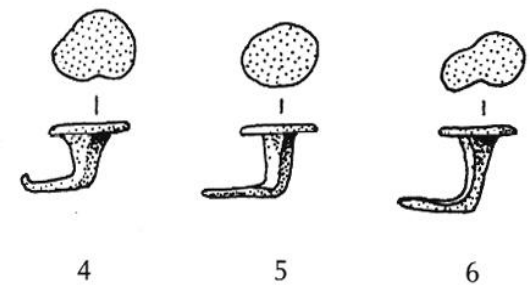

5

$3 \mathrm{~cm}$

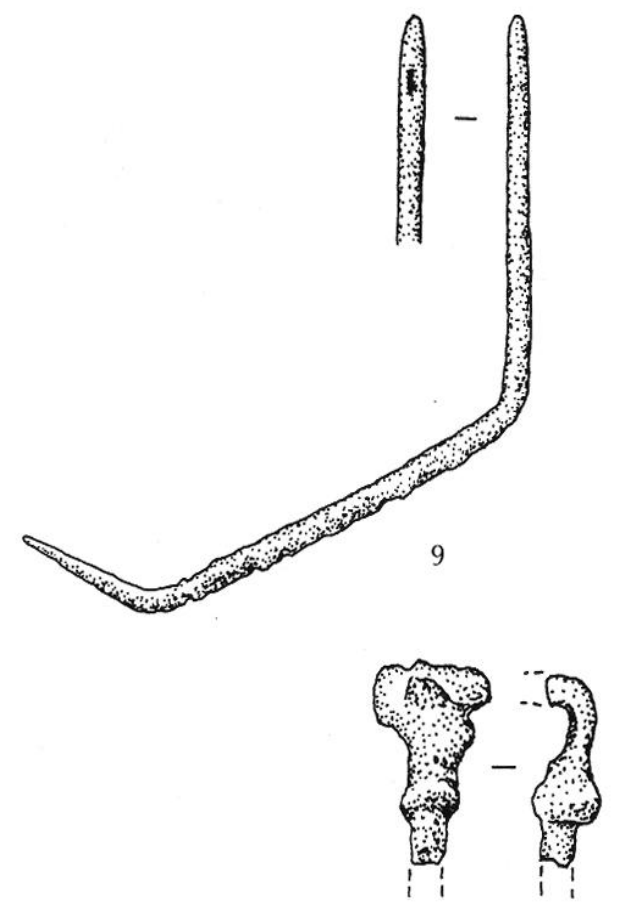

11

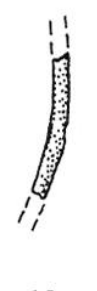

10
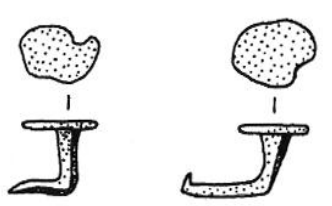

7

8

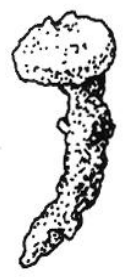

14

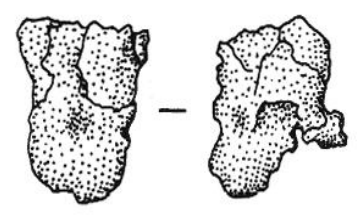

15

Fig. 14. Les éléments de fermeture de boîtes et les éléments divers.

Les os observés ont des couleurs qui vont du noir au blanc. Seul le sujet de la tombe 225 présente des ossements blanc crayeux, indiquant une température de crémation supérieure à $650^{\circ} \mathrm{C}$.
LA FAUNE (A. G.)

Les lots d'ossements étudiés proviennent des tombes 225 et 226 ct d'un assemblage baptisé 214/216 qui se 


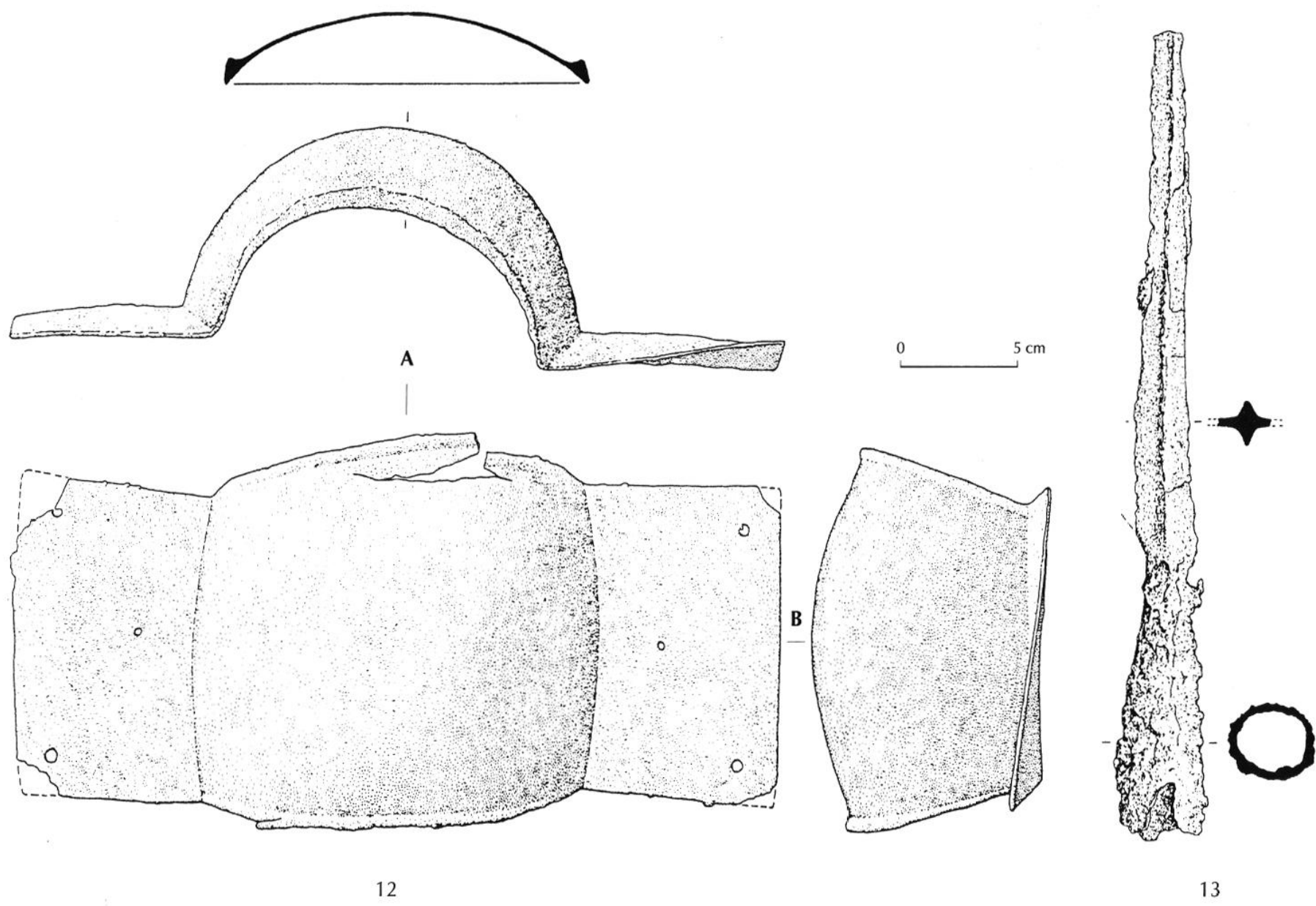

Fig. 15. Les armes.

situait au-dessus - c'est-à-dire dans le tertre -, sans que l'on puisse le rapprocher précisément de l'une ou l'autre des deux cellules.

Les numéros attribués aux fragments étudiés correspondent à ceux délivrés au cours de la fouille des tombes. Leur identification appliquée aux plans de détail fournis par les archéologues a permis de constater le profond bouleversement (éparpillement ou déplacement) des restes fauniques; il n'a donc pas été jugé utile de présenter les relevés originaux.

Tombe 225

\section{Ovi-caprinés}

La différenciation mouton chèvre s'est avérée impossible, le nombre minimum d'individus (NMI) corres- pondant à un individu trop jeune pour ce type de diagnose. On dénombre :

- un fragment d'épiphyse proximale de fémur droit (tête fémorale) et une extrémité distale (épiphyse non soudée) de fémur droit. Ces deux fragments pourraient correspondre à un seul et même os appartenant à un individu de moins de 18 mois;

- une épiphyse distale de tibia droit non synostosée et une extrémité proximale de tibia droit, épiphyse absente appartenant à un individu de moins de 12 mois.

À cela s'ajoute un calcanéum droit dont le sommet non soudé et l'état d'ossification indiquent un animal assez jeune.

On obtient donc au total cinq pièces pour un seul individu dont la patte arrière droite a fait l'objet d'une offrande. Aucune trace de découpe ou de décarnisation ne laisse supposer que ce gigot ait été consommé. 


\begin{tabular}{|l|c|c|}
\hline site & poids $\mathbf{( g )}$ & nombre \\
\hline dalles & & \\
\hline derrière dalle 1 & 0,3 & 2 \\
\hline derrière dalle 4 & 0,1 & 1 \\
\hline derrière dalle 7 & 0,5 & 5 \\
\hline derrière dalle 8 & 0,1 & 1 \\
\hline total & 1 & 9 \\
\hline tombe 226 & & \\
\hline fond & 0,5 & 5 \\
\hline tamisage & 1,1 & 10 \\
\hline total & 1,6 & 15 \\
\hline tombe 225 & & \\
\hline crâne & 2,8 & 1 \\
\hline humérus & 1,8 & 1 \\
\hline fibula & 2,1 & 1 \\
\hline talus & 0,9 & 1 \\
\hline PD hallux & 0,5 & 1 \\
\hline indéterminés & 2,4 & 12 \\
\hline total & 10,5 & 17 \\
\hline
\end{tabular}

Fig. 16. Tableau des ossements humains.

\section{Suidés}

Le dépôt est constitué d'une hémi-mandibule droite et d'un pied droit. Une deuxième phalange a également été retrouvée dans le vase $n^{\circ} 6$.

La demi-mandibule est entière : elle présente la première incisive définitive en place, la seconde étant en train de sortir au détriment de la lactéale présente. La dent I3 est absente. La canine, bien que cassée, est en place et indique qu'il s'agit d'un mâle. Les troisième et quatrième prémolaires définitives sont à peine usées ( $\mathrm{P} 2$ absente), de même que la deuxième molaire. Le bourgeon de M3 est visible mais toujours en place dans sa loge. Ces données nous permettent d'estimer l'âge de ce jeune mâle à 18 mois. Les traces de découpe sont visibles : marques du couperet qui a séparé la mandibule en deux, entre les deux premières incisives. On aperçoit la loge cassée de la dent Il gauche et le fond de la loge de la dent I2. Il s'agit là d'une découpe classique (Jourdan, 1976; Gardeisen, 1989) et ce, quelque soit la période. Signalons également deux stries parallèles et profondes d'environ $1 \mathrm{~mm}$ au niveau de la branche montante de l'apophyse coronoïde, côté interne, qui semblent indiquer que la joue a été entaillée sur le crâne complet pour faciliter l'opération d'extraction du condyle de la mandibule.

L'offrande du pied est constituée de quatre métatarses, d'une première phalange (doigt III), d'un sabot, des trois phalanges du cinquième doigt, du scaphoïde, du cunéiforme médial et d'un sésamoïde. Ces douze fragments s'apparentent au pied droit d'un porc qui aurait été coupé au niveau du tarse; cependant, les traces de découpe ne sont pas visibles. Ces pièces ont été trouvées éparpillées dans leur couche ce qui laisse supposer un certain nombre de remaniements. D'autre part, le décapage du fond de la tombe a permis de retrouver la phalangine et la phalangette du doigt IV qui appartiennent sans doute à ce pied. Les poulies, épiphyses distales non synostosées des métatarses, et les phalanges indiquent que l'animal devait avoir entre 13 et 24 mois, fourchette qui est d'ailleurs en concordance avec l'âge évalué de la mandibule. Rien ne permet d'affirmer toutefois, qu'il s'agit du même individu mais on constate une fois de plus que les animaux choisis ont rarement plus de 24 mois. On remarquera également qu'il n'y a pas de connexion visible avec la phalange provenant du vase.

\section{Oiseaux}

La présence d'un pigeon déposé entier est attestée par de nombreux restes. Chaque partie du corps est représentée sauf la tête; les phalanges et griffes ont pu être retrouvées au tamisage. Comme dans le cas du pied de porc, les ossements étaient dispersés. L'absence de trace de découpe ou de consommation porte à croire que ce pigeon a été déposé entier. L'état d'ossification indique un individu adulte.

\section{Poissons}

Les déterminations des pièces osseuses de poissons ont été effectuées par Myriam Sternberg.

Le décapage de la tombe 225 a révélé la présence de deux vertèbres de Scorpaenidae (genre scorpaena ?), c'est-àdire un poisson de la famille de la rascasse et une vertèbre de maquereau (Scomber sp.). Au fond de la tombe se trouvaient vingt-six vertèbres de Scomber $s p$. (maquereau) appartenant au même individu; on note l'absence de la tête (aucune pièce du neurocrâne et splanchnocrâne) et de la queue (absence du complexe urophore). Derrière la dalle 2 (ouest de la tombe) se trouvait une vertèbre de Mugilidae (muge) de très petite taille.

\section{Indéterminés}

Il s'agit de deux côtes et quatre épines vertébrales appartenant à de jeunes individus (ovi-caprinés?) et d'un bec d'oiseau. Ce dernier provient de derrière la dalle $n^{\circ} 4$. 
Une cinquième épine vertébrale a été trouvée dans le vase $n^{\circ} 7$. Les fragments osseux $n^{\circ} 4$ et 20 sont des esquilles dont l'une $\left(n^{\circ} 20\right)$, un fragment de diaphyse de tibia, présente des traces de découpe.

Signalons également la présence d'une esquille brûlée isolée et de quelques restes de lézard, souris, grenouille. On trouve d'ailleurs des traces de passage de ces petits animaux derrière les dalles 1,2 et 3 , ce qui confirmerait qu'ils sont bien intrusifs.

\section{Tombe 226}

\section{Ovi-caprinés}

Un seul fragment retrouvé : une poulie de métapode $\left(n^{\circ} 11\right)$. L'individu est jeune. Ajoutons à cela un cubonaviculaire droit provenant de derrière la dalle 8 et un talus, dalle 7 . Il ne semble pas y avoir de liaison évidente entre l'arrière des dalles et l'intérieur de la tombe.

\section{Suidés}

La pièce maitresse de cette tombe est un demi-crâne de porc femelle $\left(\mathrm{n}^{\circ} 19\right)$ dont la partie conservée est la moitié droite avec sa série de jugales supérieures en lactéales qui comporte :

- les trois incisives;

- la canine lactéale et la définitive dans sa loge;

- D2 peu usée ;

- D3 et D4 usées;

- M1 presque totalement sortie et à peine usée. Cette jeune femelle aurait été abattue entre 7 et 9 mois.

L'absence de la base du crâne ne permet pas de déterminer comment la tête a été séparée du reste du corps. Le seul fragment isolé est l'apophyse jugulaire droite $\left(n^{\circ} 12\right)$. Le reste, réuni sous le $\mathrm{n}^{\circ} 2$, correspond à un petit lot d'esquilles de très petite taille. La séparation longitudinale est typique et bien localisée au niveau des sutures nasale et palatine, frontale et pariétale.

La particularité de cette pièce réside dans le fait qu'elle présente une ouverture régulière entre les orbites, au niveau du frontal. Il s'agit d'ailleurs de la seule trace qui pourrait être d'origine anthropique. Les bords ne présentent pas de stries particulières et les cloisons osseuses situées sous le frontal ont été cassées (écrasées?) anciennement. Ce trou a sans doute été provoqué par le coup de masse asséné à l'animal lors de la mise à mort ou bien danı un second temps en boucherie, c'est-à-dire au

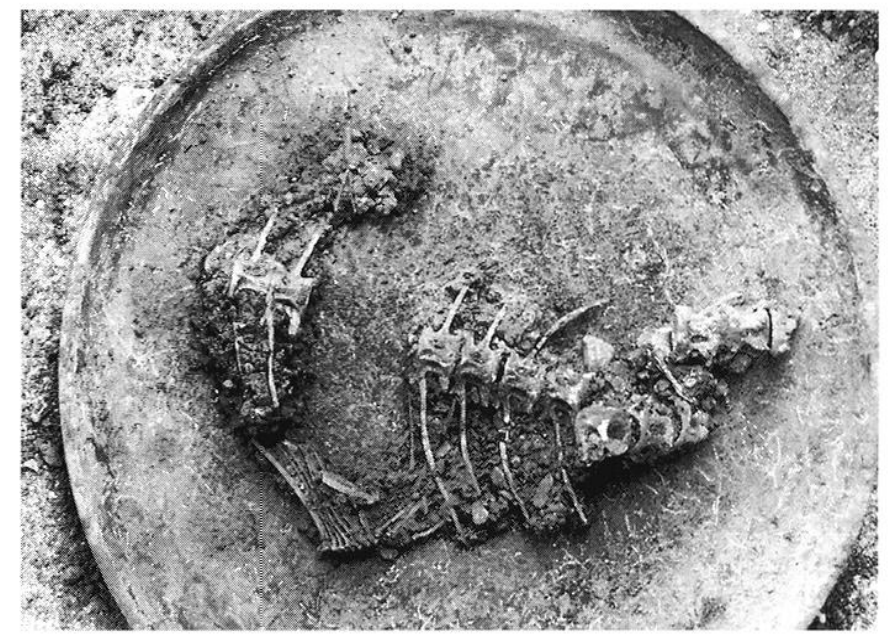

Fig. 17. Vue du plat contenant la rascasse.

moment de la préparation de l'animal. Le choc a entraîné la séparation du crâne en deux au niveau des sutures frontales. Cette hypothèse est renforcée par le fait que l'on ne voit pas de traces du passage du couperet dans le sens longitudinal.

Le matériel qui accompagnait cette pièce est constitué d'un fragment de coxal droit d'un très jeune individu (porc?), d'un fragment d'atlas, d'un cuboïde gauche $\left(\mathrm{n}^{\circ} 2\right)$ et d'une première phalange de doigt latéral $\left(n^{\circ} 5\right)$. Le reste ne sont qu'esquilles indéterminables $\left(n^{\circ} 6,8,9,10,12,13\right)$.

\section{Bovidés}

Les ossements recueillis sont très fragmentaires. Ce sont des vertèbres de jeunes dont certaines présentent des marques de couperet indiquant une découpe sagittale en particulier les $n^{\circ} 15$ (C7) et $n^{\circ} 16-17$. Les $n^{\circ} 14$ et 7 sont des fragments de vertèbres indéterminés anatomiquement et ne portant aucune trace particulière.

\section{Oiseaux}

La seule pièce déterminée est un humérus gauche de pigeon; malheureusement, les onze fragments suivants sont restés indéterminés du fait de leur mauvaise conservation et de leur juvénilité qui ne permettaient pas de reconnaître spécifiquement l'espèce. On constate toutefois que ces restes pourraient correspondre à un même oiseau un peu plus gros qu'un pigeon déposé entier (?). On dénombre : deux phalanges, un tarso-métatarse, une ulna $\left(\mathrm{n}^{\circ} 5\right)$, un humérus, un radius, un fémur, un tibia, un coracoïde et deux côtes. 


\section{Poissons}

Treize vertèbres d'un même individu ont été attribuées à un poisson de la famille des Scorpaenidae, genre scorpa (sous réserve), la rascasse. Il s'agit de la partie caudale de l'individu sans la queue (complexe urophore absent). Cet ensemble est le seul qui puisse être mis en relation évidente avec un récipient céramique puisqu'il a été découvert dans le vase $n^{\circ} 11$ (fig. 17).

\section{Niveau 214/216}

\section{Équidés}

Un crâne accompagné d'au moins dix vertèbres (et dixneuf fragments indéterminables) et de cinq côtes représentent les restes de cheval. Le crâne, beaucoup trop brisé et incomplet, n'a pu être remonté. Les restes osseux récoltés sont un rocher gauche cassé, un condyle occipital droit et un condyle temporal gauche (?). Par contre, les quatre séries de dents jugales ont été reconstituées (il ne manque que la P2 inférieure gauche). On note l'absence totale d'incisives et de canines. Les degrés d'usure et de croissance indiquent que ces dents appartiennent bien à un seul individu âgé d'un peu plus de quatre ans.

L'ensemble des autres restes (bovidés, ovi-caprinés, suidés), accompagnant le lot décrit ci-dessus, ont été déterminés mais ne méritent pas de description particulière. Ils sont, en effet, extrêmement fracturés, en très mauvais état de conservation et sans connexions apparentes.

\section{QUELQUES COQUIILAGES MARINS (F. B.-P.)}

Dans les refus de tamisage du comblement des tombes 225 et 226, nous avions noté la présence de nombreux coquillages de très petite taille dont l'origine marine paraissait probable.

Il s'agit de Cerastoderma edule L. : quelques fragments; et Berthella Plumula, Montagu, 1803 : treize exemplaires juvéniles ayant subi un début de fossilisation et dont la coquille a été engraissée par des eaux chargées en carbonate de calcium $(\mathrm{CO} 3 \mathrm{Ca})$; taille variant de 6 à $8,2 \mathrm{~mm}$ pour la longueur et de 4 à 4,5 mm pour la largeur.

Ces deux espèces vivent dans le même biotope : des eaux marines à des profondeurs ne dépassant pas $10 \mathrm{~m}$.

Ces coquillages ont dû être apportés, mêlés à des algues. Celles-ci ont servi, probablement, à envelopper les poissons déposés en offrande.
L'intérêt de ce site réside dans la présence de ces Berthella Plumula, Montagu, 1803, indices d'algues transportées sur des distances relativement importantes. Vu leur taille, ces coquillages ne sont découverts que par tamisage, le plus souvent à l'occasion des fouilles de tombes (Bérato, Dugas, Dutour, 1991, n. 5). Ces espèces démontrent l'utilisation d'algues sur des sites non maritimes et donc un transport de produits périssables entre le rivage et les localités de l'intérieur ${ }^{16}$.

\section{ANALYSES POLLINIQUES (B. T. M.)}

Lors de la campagne de fouille, une série de onze échantillons a été réalisée dans les deux tombes : neuf ont été prélevés dans des vases fermés et dans des plats de forme ouverte; deux autres proviennent du sol des tombes ${ }^{17}$.

Les échantillons A, B et $\mathrm{C}$ proviennent des vases de forme fermée 3 et 4 de la tombe 225 et 12 de la tombe 226. Les échantillons suivants proviennent des vases de forme ouverte : $\mathrm{D}, \mathrm{E}, \mathrm{F}$ des récipients 2,5 et 7 de la tombe $225 ; \mathrm{G}, \mathrm{H}$ et I des vases 8,9 et 11 de la tombe 226. Les deux derniers prélèvements ( $\mathrm{J}$ et $\mathrm{K}$ ) correspondent au sédiment de la tombe 225.

Par ailleurs, un spécimen de mousse « urbaine " a été recueilli à $10 \mathrm{~m}$ à l'ouest du site, sur un trottoir dans une fissure entre les dalles en béton, dont le spectre, qui représente la végétation actuelle, servira de comparaison avec ceux des échantillons fossiles.

Les préparations ont été réalisées au Centre de recherches archéologiques par R. Garzo que nous remercions vivement.

Le nombre de pollens comptés pour tous les échantillons varie de 188 à 416 . Le nombre de taxons oscille entre 10 et 25 pour les niveaux archéologiques et atteint 36 pour le spectre des mousses.

\section{Résultats obtenus}

Le sédiment $\mathrm{J}$ issu du fond de la tombe 225 est stérile, il correspond peut-être au sol primitif. Les spectres des sédiments archéologiques ont pratiquement tous la même composition. La représentation pollinique des arbres est très faible (entre 2 et $10 \%$ ). Le Pin (Pinus), grand pro-

16. Identification par M. Cl. Poizat, Faculté Saint-Jérome de Marseille. Remerciements à MM. M. Bourcier et P. Arnaud, Station marine d'Endoume-Luminy, URA 41, Marseille.

17. On comparera les résultats obtenus avec ceux, plus récents, de la fouille de la ZAC des Halles à Nîmes (Bui Thi Mai, 1993). 
ducteur de pollens, est le mieux indiqué, puis viennent le Chêne vert et le Chêne à feuilles caduques. Les autres essences figurent de manière discontinue.

Parmi les Herbacées, les Composées constituent la plus grande partie des spectres polliniques : elles sont principalement représentées par des Cichoriées (Liguliflores), des Anthémidées et des Carduacées (Tubuliflores). Les Chénopodiacées, les Graminées, les Plantains, les Ericacées ont été constamment rencontrées mais avec de faibles valeurs.

Les pollens de Céréales sont rares : un grain Secale et un autre d'Avena ont été reconnus dans le vase 3 de la tombe 225, un pollen de Céréale trouvé dans le vase 2 de cette même tombe n'a pas pu être identifié à cause de sa mauvaise conservation.

Les spectres de ce site correspondent à l'image d'une végétation totalement ouverte, très anthropisée, dont la nature exacte est masquée par la surreprésentation de Composées-Cichoriées (50 à 83,4\%), ce qui est dû probablement à une conservation différentielle.

Aucune différence n'est perceptible entre les spectres des récipients de forme ouverte et ceux des formes fermées ni du sol de la tombe. La recherche d'un apport particulier de nature végétale (offrande) est malheureusement restée vaine.

\section{Mousse actuelle}

Le spectre de la pluie pollinique actuelle diffère considérablement de ceux correspondants aux sédiments archéologiques.

Trois cent soixante-et-onze pollens et spores ont été dénombrés; trente-six taxons différents y figurent. Le taux AP/NAP de $71 \%$ démontre un paysage assez boisé. La strate arboréenne est représentée par des Pins $(26,2 \%)$, des Genévriers $(10,8 \%)$, des Chênes verts $(11,1 \%)$, des Chênes blancs à feuilles caduques $(8,7 \%)$, des Frênes (3,5\%), des Aulnes (4\%), des Saules et du Noisetier $(2,2 \%)$, ce qui correspond plutôt à la végétation régionale. Localement, il ne pousse pas d'arbres.

Les herbes sont essentiellement indiquées par les Graminées $(9 \%)$. Aucun pollen de Cichoriées n'a été rencontré.

\section{Comparaison avec la flore pollinique actuelle}

Bien que les spectres fossiles soient sans doute modifiés par les hautes fréquences de composées, il semble bien que la comparaison avec le spectre actuel indique qu'à l'époque romaine, le paysage était beaucoup plus pauvre en arbres que celui existant actuellement.

L'étude palynologique n'a donc pas permis de discerner d'éventuelles offrandes végétales mais elle permet, au moins, d'imaginer l'environnement immédiat de la tombe sous la forme d'une friche sans doute peu éloignée de champs cultivés.

\section{DATATION (M. M.)}

Rappelons, dès l'abord, que les tombes sont définitivement occultées au moment de la construction de l'enceinte augustéenne et de la mise en place du système de voirie périurbaine; événements qu'il faut placer dans le courant des deux dernières décennies du $\mathrm{I}^{\mathrm{er}} \mathrm{s}$. avant J.-C.

$\mathrm{La}$ datation du mobilier qu'elles contiennent tient compte des résultats les plus récents obtenus au cours de fouilles de sites d'habitat (Nages, le Marduel, Nîmes, Lattes...), mais également des comparaisons avec les tombes voisines datées de la même période. Pour ces dernières, nous nous référerons aux révisions chronologiques proposées par M. Bats dans un article récent (Bats, 1990a) ${ }^{18}$.

Une première approche chronologique peut être tentée au travers de l'architecture. En effet, dans son ouvrage sur Nîmes préromaine puis dans sa thèse, Michel Py signale que les premières tombes en coffre de dalles apparaissent, dans la région nîmoise, à la charnière $\mathrm{II}^{\mathrm{e}}-\mathrm{I}^{\mathrm{er}} \mathbf{s}$. avant J.-C., pour devenir de plus en plus fréquentes par la suite (Py, 1981a, p. 194 et Py, 1990a, p. 772). L'une des plus anciennes connue serait la tombe 1 de la nécropole des Colombes à Beaucaire (Dedet et alii, 1978, p. 83), dont la date d'enfouissement est de 100 avant J.-C.

\section{LES CÉRAMIQUES COMMUNES ET À PÂTE CLAIRE}

Les olpés à pâte claire $\left(\mathrm{n}^{\circ} 1,4,13\right.$ et 14$)$, à col large, bord en gouttière, panse ovoïde ou galbée, fond annulaire et anse verticale unique sont fréquentes dès le début du $\mathrm{I}^{\mathrm{er}}$ s. avant J.-C. sur les sites et dans les tombes du Languedoc oriental. On en rencontre, par exemple, sur le site de Nages (Py, 1978, p. 251) et sur celui de Lattes,

18. Les datations proposées à l'origine par les divers auteurs pourront être retrouvées dans Bats, 1990a ou dans les articles et ouvrages afférents. 
où ce type d'olpés apparaît dans la phase 125-75 avant J.-C. (Py, 1990b, p. 249). On notera également, sans rentrer dans un inventaire détaillé, la présence de cruches très proches de nos exemplaires dans la tombe 1 du quartier de Camplanier (Nîmes), datée de 100-25 avant J.-C. (Py, 1981a, fig. 54, ${ }^{\circ} 11$; fig. 57, n ${ }^{\circ} 7$ et 9 ) ou dans celle du marché aux bestiaux (Nîmes), datée des années 100-50 avant J.-C. (Py, 1981a, fig. 79, $\mathrm{n}^{\circ} 8$ et 10 ). Enfin, la fouille récente de la ZAC des Halles a livré deux fours à céramiques qui produisaient très vraisemblablement ce type de vases et dont la période d'activité couvre les années 5025 avant J.-C. (Sauvage, 1993, fig. 65).

L'urne $\mathrm{n}^{\circ} 12$, en céramique non tournée, pourrait se rattacher à la série des urnes récentes, dont les prototypes apparaissent vers 70 avant J.-C. (Py, 1978, p. 200) et qui, dès cette date, sont fréquemment finies au tour (Py, 1990b, p. 256). Certaines de ses caractéristiques (col moyennement haut, absence de peignage de la panse...) laissent cependant penser qu'il s'agit là d'un exemplaire de transition légèrement antérieur.

L'urne ${ }^{\circ} 3$, en apparence très proche par sa forme de la précédente, s'en distingue nettement. En effet, bien que quelques malfaçons soient perceptibles (traces d'enfoncements digités), il est clair que cette céramique a été non pas finie mais entièrement fabriquée au tour. Bien qu'il puisse s'agir d'une importation, nous pencherions plutôt pour une fabrication locale. À l'appui de cette hypothèse, il faut noter les caractéristiques de la pâte qui, bien que très épurée, contient encore quelques fragments de gros dégraissant, ainsi que les rapports typologiques indéniables que ce vase entretient avec les urnes non tournées dites récentes. Cette urne pourrait être rattachée au groupe des céramiques communes tournées à pâte sableuse qui n'apparaissent et ne sont diffusées qu'à compter des années 40-30 avant J.-C. (Py, 1990a, p. 588589). Cependant, la découverte des fours de la ZAC des Halles démontre l'existence d'une production locale tournéc à Nîmes dès les années 50-25 avant J.-C. et certains indices semblent indiquer la possibilité d'une fabrication antérieure (Sauvage, 1993). Il s'agit certes d'une fabrication de céramiques à pâte claire mais d'autres indices pourraient démontrer la présence d'ateliers locaux ayant pu façonner des urnes tournées dès le courant de la première moitié du $\mathrm{I}^{\text {er }}$ s. avant J.-C. Ainsi, deux exemplaires d'urnes, très proches d'ailleurs de la nôtre, découvertes dans la tombe de la rue Alphonse-de-Seynes, datable des alentours de 100 avant J.-C., sont finies au tour lent (Py, 1981a, fig. 68, n ${ }^{\circ} 6$ et 7 ).
Le plat à feu de la tombe $225\left(\mathrm{n}^{\circ} 6\right)$ trouve des parallèles à Olbia (Bats, 1988, p. 69 et 159, pl. 38, n ${ }^{\circ} 1087$ 1088), au Marduel où deux exemplaires sont recensés dans la phase 75-25 avant J.-C. (Py, Lebeaupin, 1986, fig. $46, n^{\circ} 14$ et 15 ) et à Lattes (Bats, 1990b, p. 355 et fig. 6-28, $\mathrm{n}^{\circ} 5$ ). Ce type de céramique se rencontre plus rarement en contexte funéraire. On note cependant, dans le mobilier perdu des tombes 12 et 21 des Marronniers à Beaucaire, trois plats en " céramique commune brune et rugueuse " qui pourraient être d'origine italique (Dedet et alii, 1978, p. 93) et un possible plat en céramique commune italique à vernis rouge interne (Dedet et alii, 1978, p. 108). Enfin, le dépôt de Sauveterre, tombe probable, a également livré des fragments d'un vase à vernis rouge interne (Barruol, Sauzade, 1969, p. 85). D'après les études les plus récentes, cette forme apparaît dans notre région dès le début du $\mathrm{I}^{\text {er }}$ s. avant J.-C. (Bats, in Py dir., 1993).

\section{LES CÉRAMIQUES CAMPANIENNES}

Le type des bols à anses en boucle en Campanienne B auquel appartiennent ceux des deux tombes du Mail romain ( $\mathrm{n}^{\circ} 5$ et 8$)$ a fait l'objet d'une étude spécifique en annexe de l'ouvrage de M. Py sur Nîmes préromaine (Py, 1981a, p. 211-217).

Après avoir donné un inventaire précis des découvertes de ce type de forme, l'auteur propose de les situer dans le I ${ }^{\text {cr }}$ s. avant J.-C. et surtout dans la seconde moitié de ce siècle, $y$ compris les environs du changement d'ère. Rappelons que les exemplaires de ce type sont assez fréquents dans les tombes nîmoises : tombe 1 du quartier de Camplanier (Py, 1981a, fig. 57, $\mathrm{n}^{\circ} 2$ et fig. 54, $\mathrm{n}^{\circ} 9$ ); tombe du marché aux bestiaux (fig. $79, \mathrm{n}^{\circ} 2$ ) et tombe 2 du quartier de Pissevin (fig. $67, \mathrm{n}^{\circ} 2$ ), toutes trois datées du $\mathrm{I}^{\mathrm{er}} \mathrm{s}$. avant J.-C.

I es trois coupes en Campanienne $\mathrm{A}\left(\mathrm{n}^{\circ} 2,9\right.$ et 10$)$ présentent des caractères qui les relient aux productions tardives du I ${ }^{\text {er }}$ s. avant J.-C. La coupe $n^{\circ} 2$, de forme I amb. 27 $\mathrm{Bb}$, couvre une large période chronologique puisqu'elle apparait vers 225 avant J.-C. pour ne disparaître qu'aux alentours de 25 avant J.-C. La coupelle Morel $113\left(\mathrm{n}^{\circ} 10\right)$, qui trouve un parallèle dans la tombe 1 du quartier de Camplanier (Py, 1981a, fig. 54, n ${ }^{\circ} 3$ et fig. 57, n5), n’apparaît que vers 125 avant J.-C. et disparait également avec l'arrivée des productions de sigillée italique et du Sud de la Gaule. Enfin, la coupe ${ }^{\circ} 9$ peut être rapprochée de la forme Morel 2943, datée des années 125-25 avant J.-C. (Py 
dir., 1993, p. 150). Un exemplaire proche pourrait être reconnu dans une Lamb. A 28c de la tombe 1 du quartier de Camplanier (Py, 1981a, fig. 57, $\mathrm{n}^{\circ} 1$ et 3). Les deux assiettes Lamb. B5 ( ${ }^{\circ} 7$ et 11) n'ont aucun parallèle dans les tombes nîmoises et sont couramment datées des années 150-25 avant J.-C. (Py dir., 1993, p. 152).

\section{PROPOSITION DE DATATION}

Ia première constatation qui s'impose est que le mobilier des tombes du Mail romain appartient, dans son ensemble, à la première moitié du $\mathrm{I}^{\mathrm{er}} \mathrm{s}$. avant J.-C. I.e mobilier céramique en Campanienne, aux caractères tardifs, ne peut guère être antérieur à 100 avant J.-C., ce qui est confirmé par les olpés à bord en gouttière ainsi que par le plat à feu. Il s'agirait donc là de la date d'apparition des objets les plus anciens et, donc, de la borne haute de notre intervalle chronologique. Il est par contre plus difficile de déterminer l'objet le plus récent, mais l'ensemble des caractères du mobilier céramique s'accorderait mal avec un enfouissement postérieur à 50 avant J.-C. Aussi, nous proposons de situer les deux tombes accolées du Mail romain entre les années 100 et 50 avant J.-C. avec, au vu de la durée d'utilisation des objets, tous usés ou ébréchés à l'exception d'une assiette Lamb. $\mathrm{B} 5\left(\mathrm{n}^{\circ} 7\right)$, un enfouissement probable dans la seconde moitié de cette période (75-50 avant J.-C.). On peut également ajouter que les armes et autres objets métalliques, faibles indicateurs chronologiques, peuvent parfaitement s'insérer dans cet intervalle.

\section{APPORT À LA CONNAISSANCE DES PRATIQUES FUNÉRAIRES}

\section{ORGANISATION GÉNÉRALE}

\section{L'ARCHITECTURE (M. M., L. V.)}

À l'image des autres tombes en coffre nîmoises, celles du Mail romain sont construites en dalles de calcaire froid d'origine locale. Ces dernières apparaissent brutes de taille bien qu'elles aient sans doute été légèrement retouchées par éclats (Py, 1990a, p. 770).

Leur mise en place, caractérisée par la construction de deux espaces distincts séparés par une dalle, ne connaît aucun parallèle dans le Languedoc oriental. Par contre, un exemple de structure construite remarquablement proche existe dans une nécropole récemment fouillée à Arsago Seprio, en Italie. Il s'agit de deux tombes en coffres ( 8 et 8 bis), également séparées par une " lauze " centrale, recouvertes par une dalle unique et datées de la seconde moitié du Ier s. avant J.-C. (Binaghi I.eva, 1987). On peut cependant noter, à Nîmes, le cas de la tombe 1 de Pissevin interprétée comme une tombe double par la présence de deux urnes identiques contenant chacune des armes (Py, 1981a, p. 149-151) et celui de la tombe de l'octroi de Beaucaire où la parité d'une partic du mobilier, même s'il n'y a qu'une seule épée, rend également plausible la possibilité de deux défunts (Py, 1981a, p. 141-148).

La présence de murs en évidente relation avec les tombes est également originale, aussi bien dans la région nîmoise que dans le reste de la basse vallée du Rhône. Le manque de temps, les conditions de fouilles et l'impact des destructions antiques nous ayant empêché de poursuivre au-delà des limites imparties, il est impossible de proposer un plan global de l'ensemble. Si l'on admet cependant que les murs étaient pourvus de retours, il faut restituer non pas un mais bien deux enclos accolés dont un seul a livré des vestiges funéraires ${ }^{19}$. Sur les $100 \mathrm{~m}^{2}$ environ qu'ils couvrent, seules deux tombes ont été observées. Faut-il donc imaginer des espaces funéraires vastes et peu densément occupés? Cette hypothèse pourrait être étayée par les fouilles menées par le $C^{\text {dt }}$ Vigne, dans sa propriété, qui avaient livré, sur une surface de $150 \mathrm{~m}^{2}$, une seule tombe préromaine et quatre tombes romaines (Vigne, 1899). En comparaison, la nécropole d'Agde a livré, en moyenne, 7,5 tombes pour $100 \mathrm{~m}^{2}$ (Nickels et alii, 1989).

D'autres observations ont trait au mode de signalisation de l'espace funéraire. Celui-ci devait déjà être nettement perceptible grâce aux murs qui l'entouraient. Mais il faut également rappeler que le coffre 226 est installé dans un creusement plus vaste que nécessaire. En effet, sa mise en place laisse subsister, à l'arrière de la dalle 7 , un espace, comblé par des blocs et des fragments de céramique, qui n'a jamais été recouvert. L'hypothèse, formulée plus haut, d'une fosse liée à la présence d'un élément de signalisation paraît séduisante. Celui-ci pourrait avoir

\footnotetext{
19. Une tombe, datée du troisième quart du Ier s. avant J.-C., a été récemment fouillée dans les garrigues, au nord de Nîmes. Construite en dalles de calcaire, elle s'inscrit dans l'angle d'un enclos quadrangulaire, dont les murs se poursuivent. Le fort état d'arasement du site n'a pas permis de confirmer la présence d'autres sépultures (Pène el alii, 1990, p. 168-169).
} 
eu la forme d'une stèle, inscrite ou non, récupérée, ou bien d'un poteau en matériau périssable ${ }^{20}$.

Enfin, le dernier document novateur est lié à la mise en évidence d'un monticule, constitué de pierres et de terre, surmontant les deux tombes. Cette observation, malheureusement amoindrie par la rapidité de la fouille, pose de nouveau la question de l'existence ou non de tertre funéraire. En effet, dans la région nîmoise, plusieurs sépultures, découvertes anciennement, ont été trouvées sous des " tas de pierres ", ce qui a conduit certains auteurs (Pothier, 1890; Barré de Saint-Venant, 1897; Bauquier, 1941; Barruol, Sauzade, 1969) à penser que les tombes arécomiques étaient fréquemment recouvertes de tumuli. Pour Nîmes, on rappellera les exemples :

- des tombes 1 et 2 de Camplanier situées « dans un clapier appartenant à M. Coulet » au quartier de Camplanier (Pothier, 1890; Barré de Saint-Venant, 1897, p. 497; Py, 1981a, p. 129);

- des tombes 1 et 2 des Fontilles (Mazauric, 1906, p. 1 ; Py, 1981a, p. 126);

- de la tombe 1 du quartier de Pissevin (Barré de Saint-Venant, 1897, p. 497; Py, 1981a, p. 149-151) découverte, au cours du creusement d'un fossé, dans un « galgal de pierrailles ».

Plus récemment, $\mathrm{P}$. Arcelin a pu observer certains indices, au-dessus de la tombe 27 de la nécropole de la Catalane aux Baux-de-Provence, qui pourraient évoquer la présence d'un tumulus de même constitution que le nôtre (Arcelin, 1980, p. 108).

Dans sa synthèse sur les tombes nîmoises (Py, 1981a, $p$. 129, n. 6) puis dans sa thèse (Py, 1990a, p. 772-774), M. Py conclut, au contraire, qu'il s'agit dans la plupart des cas de tas d'épierrements agricoles médiévaux et modernes localement appelés «clapas " - qui ensevelissent de façon fortuite les tombes. Il n'exclut pas cependant « que des tombes aient pu être signalées par un petit tas de pierres adjacent ». En l'absence d'« une fouille précise et complète », M. Py conforte son jugement en arguant du fait que les tombes en coffre de dalles étaient, au moment de leur découverte, comblées par de la terre : «ce qui s'expliquerait mal si elles n'avaient été couvertes que des

20. Plusieurs stèles funéraires en pierre, à sommet arrondi ou en forme de colonnes, sont recensées par M. Py (Py, 1990a, p. 772-777). Sur la nécropole de la Catalane, aux Baux-de-Provence, P. Arcelin a observé, à $1,10 \mathrm{~m}$ de la sépulture 27 (70-30 avant J.C.), une petite fosse remplie de pierres qu'il propose d'interpréter comme le calage d'un poteau en bois, d'un diamètre de 0,15 à $0,20 \mathrm{~m}$ de diamètre. Il suggère d'y voir une forme de signalisation de la sépulture (stèle en bois?) (Arcelin, 1980, p. 93). pierres sèches que l'on a retrouvées sur elles " (Py, 1990a, p. 772-774). Or, l'observation de coupes réalisées dans des tas d'épierrement agricoles de la garrigue nîmoise montre la non pertinence de l'argument. Il existe, à la base des " clapas ", une couche de sédiment plus ou moins fin qui provient du nettoyage puis de la désagrégation par les pluies des pierres calcaires. En outre, il n'est peut-être pas étonnant que des tas d'épierrement récents englobent des tumuli de pierre antiques. En effet, lors de l'épierrement manuel d'une parcelle, il paraît logique de grossir un tas préexistant s'il est situé à proximité.

En conclusion, nos observations permettent d'affirmer qu'un tertre recouvrait bien les tombes 225 et 226 et qu'il en était certainement de même pour d'autres tombes préaugustéennes.

\section{LE DÉPÔT FUNÉRAIRE (Y. M.)}

\section{Observations sur la tombe 225}

Au moment de l'ouverture du coffre 225 , seule l'olpé n ${ }^{\circ} 1$ était visible. Elle se trouvait en position couchée sur la terre d'infiltration ayant recouvert les autres céramiques. La hauteur moyenne du remplissage était de $8 \mathrm{~cm}$ dans la partie centrale. Elle était plus importante dans les angles car les dalles du caisson s'étaient disjointes, et plus particulièrement au sud-ouest (plus de $20 \mathrm{~cm}$ ) où la terre était accumulée en cône. Le nivellement central a pu se faire sous l'effet de l'eau.

Les observations réalisées au moment du dégagement des vases et lors de leur prélèvement nous ont permis de recueillir des informations sur leur position (fig. 18). C'est ainsi que l'on peut affirmer que les trois récipients fermés se trouvaient surélevés par rapport aux autres céramiques. Les supports qui ont servi à percher ces vases n'ont pas laissé de traces. Il pouvait s'agir de coussins ou de petits tabourets en osier ou en bois non cloués du type de ceux dont l'existence est attestée à la Lagaste et à Wederath ${ }^{21}$. C'est au moment de leur décomposition que

\footnotetext{
21. Un petit cabouret en bois sur lequel était déposé une partie du mobilier d'offrande a été observé à la I agaste au fond du puits funéraire 1 (Rancoule, 1980, p. 111-113 et fig. 53). Les restes d'un petit banc en bois, dont les pieds étaient constitués de différents éléments emboités, ont été mis au jour dans la sépulture 1311 de Wederath datée des environs de 100 avant J.-C. (Cordie-Hackenberg, 1989). La restitution du meuble (p. 195) est intéressante mais ne peut être replacée parmi le mobilier dans la reconstitution de la sépulture. En effet, si des éléments carbonisés de ce support ont pu être observés dans le coffre, c'est parce
} 


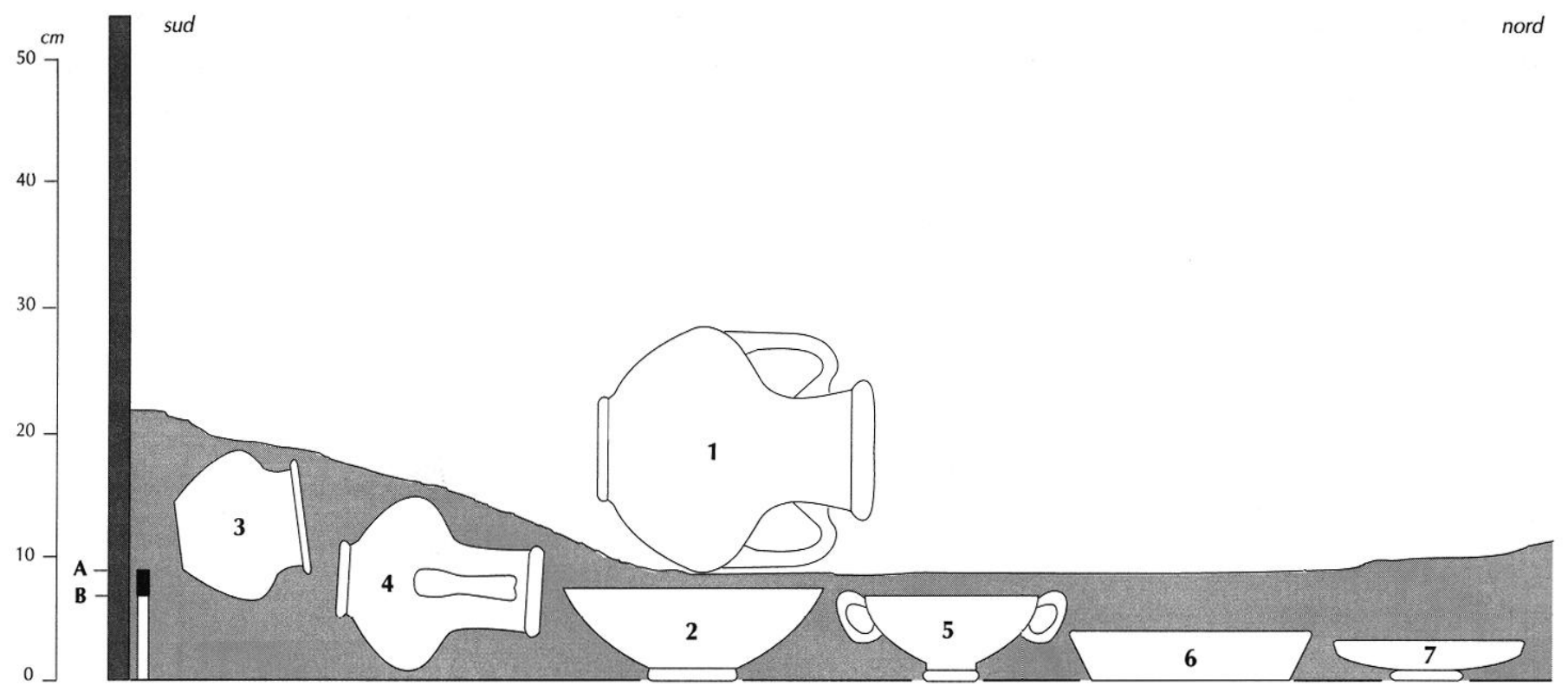

Fig. 18. Schéma de positionnement des vases de la tombe 225 (échelle réelle pour les ordonnées, développement fictif du coffre vers le nord).

les céramiques ont chuté. La restitution présentée sur la figure 18 permet de constater que le remplissage du coffre avait déjà commencé lorsque l'olpé $\mathrm{n}^{\circ} 4 \mathrm{et}$, plus tard, l'urne $n^{\circ} 3$ sont tombées. La cruche $n^{\circ} 1$ a basculé dans l'assiette $n^{\circ} 2$ à un moment où le comblement était achevé, ce qui laisse supposer que le support qui la recevait était constitué d'un matériau plus résistant et qui s'est désagrégé plus tard.

À partir des altitudes relevées, nous pouvons estimer la surélévation minimale de chacune des trois céramiques :

- olpé $\mathrm{n}^{\circ} 1: 8 \mathrm{~cm}$ (fig. 18, point $\mathrm{A}$ );

- urne $\mathrm{n}^{\circ} 3: 6 \mathrm{~cm}$ (fig. 18, point B) ;

- olpé $\mathrm{n}^{\circ} 4: 2 \mathrm{~cm}$.

Les formes ouvertes, elles, reposaient toutes les quatre sur le fond de la fosse dans la partie centrale. Il semblerait que l'angle nord-est ait volontairement été laissé libre. On peut penser que certaines offrandes n'étaient pas déposées dans les assiettes et que cet espace leur était réservé. Dans cette hypothèse, la demi-mandibule de porc, retrouvée à même le sol, n'aurait pas subi de déplacement. Le reste du dépôt alimentaire consistant en une patte de porc, un pigeon et un poisson déposé au nord du

qu'ils ont été recueillis avec les restes du défunt sur le bûcher après la crémation. Pour une période plus récente (IVe $s$. après J.-C.), on peut aussi signaler l'existence d'un support en plomb surélevant une assiette dans la tombe 61 de la nécropole des Clapiès à Villeneuve-lès-Béziers (Hérault) (Manniez, 1989, p. 16). coffre ${ }^{22}$, a souffert du passage d'animaux fouisseurs peu après la fermeture du coffre ${ }^{23}$.

Dans le même secteur se trouvait la paire de strigiles et le petit mobilier de bronze. La pointe de lance était prise entre deux des dalles de couverture alors que l'umbo de bouclier se trouvait dans la partie supérieure du comblement de la fosse, au niveau de la dalle $n^{\circ} 2$ (fig. 9 ).

\section{Observations sur la tombe 226}

On constate une accumulation des céramiques dans la partie ouest du caisson, or il est impossible de les replacer toutes côte à côte sur le fond. D'après les observations de fouille, les vases $n^{\circ} 8$ et 9 se trouvaient renversés vers le sud et recouvraient de façon très nette les pièces $n^{\circ} 10,11$ et 12. Une telle disposition ne peut s'expliquer, là encore, que si l'on admet que la coupe et le bol à anses étaient surélevés. La position comparable dans laquelle ils ont été observés laisse penser qu'ils ont chuté en même temps, ce qui conforte l'hypothèse d'un support commun en matériau périssable (petit tabouret aux pieds non cloués ou

22. On retrouve un cas d'association pigeon poisson dans une tombe à incinération d'Apt qui contenait une assiette sigillée (Dumoulin, 1963, p. 18).

23. Ces restes ont été dispersés dans la partie nord du coffre. On a d'ailleurs retrouvé de nombreux os de lézards, de grenouilles et de petits rongeurs lors du tamisage des terres des tombes 225 et 226 . 


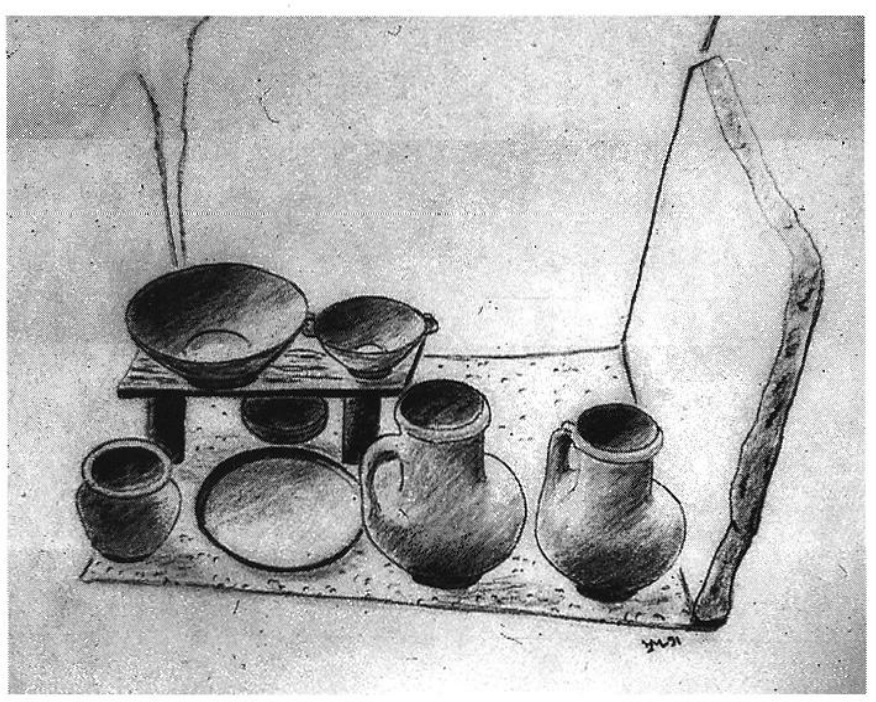

Fig. 19. Essai de restitution de la tombe 226, vue du sud.

planche posée sur deux rondins de bois comme dans notre restitution, fig. 19). Les deux cruches étaient placées côte à côte dans l'angle sud-est. À l'opposé l'espace laissé libre était, de toute évidence, occupé par d'autres offrandes (alimentaires, florales ou vestimentaires) déposées dans des corbeilles, de la vaisselle en bois ${ }^{24}$ ou bien à même le fond de la structure tombale. Dans ce coffre, les restes fauniques sont un élément de crâne de porc, un poisson - déposé dans le plat $\mathrm{n}^{\circ} 11$ - et un volatile aux ossements dispersés.

\section{LE « VIATIQUE » DÉPOSÉ}

\section{LES VASES : OBJETS DE LA VIE QUOTIDIENNE OU OBJETS FUNÉRAIRES? (Y. M.)}

La similitude presque parfaite des formes céramiques rencontrées dans chacune des deux tombes n'est pas le fait du hasard (fig. 11 et 12). Au-delà de l'aspect utilitaire - ces vases sont d'abord des contenants -, transparaît la valeur sociologique du dépôt qui est l'expression de la mentalité de l'entourage des disparus ${ }^{25}$. En effet, si le choix de ces deux lots de vaisselle a été réalisé dans un

24. Ia tombe 324 de Wederath, contemporaine de celle évoquée plus haut, a livré les restes calcinés sur le bûcher, de récipients en bois du type bols, saladiers et assiettes (Cordic-Hackenberg, 1989, p. 193).

25. Cette homogénéité pourrait être, d'après A. Daubigney, un critère à retenir pour conforter l'hypothèse de sépultures familiales "...où l'on attend plutôt, même avec des écarts, des mobiliers de qualité analogue..." (Daubigney, 1982, p. 130). souci d'égalité apparente - il s'agit certainement de services complets - les petites différences qui les distinguent (vases 1 et 6 de plus grande taille que les récipients 13 et 10) sont des indices qui s'ajoutent à d'autres (inégalité de la taille des coffres, de la quantité des offrandes alimentaires au vu des restes) et qui soulignent, en fait, la différence de statut des défunts.

Les céramiques offertes sont toutes des formes complètes et utilisables au moment de leur dépose. Les observations réalisées sur ce mobilier s'accordent avec celles faites sur celui d'autres sépultures antiques, qu'ils s'agisse d'incinérations (Bel, 1993, p. 280) ou bien d'inhumations (Manniez, 1992, p. 27). Elles ont permis de constater que certaines pièces avaient déjà servi avant d'arriver dans les coffres (lèvres des exemplaires 4, 6, 9, 10,12, 13 et 14 ébréchées, vernis des vases 5 et 9 écaillé). Les formes étudiées, connues dans les niveaux d'habitat, appartiennent à des services de table constitués de pièces que l'on rencontre plus fréquemment dans des sépultures que dans l'habitat ${ }^{26}$. Il s'agit, comme dans les autres nécropoles, de vaisselle de présentation (Bats, 1990a, p. 273 et 279; Guichard, Vaginay, 1993, p. 241). Le seul « intrus » est le plat à feu $n^{\circ} 6$, que l'on retrouve parfois dans de tels contextes. Même si l'on note qu'il y a eu sélection du mobilier, et ce dans le but d'offrir ce qui devait avoir le plus de valeur, esthétique ou marchande, les vases, pas plus que les objets en métal, n'ont eu à notre avis de spécificité funéraire.

\section{ÉTUDE DU MOBILIER MÉTALUIQUE (M. F.)}

Alors que la céramique des tombes 225 et 226 dénote un souci évident de composer deux dépôts analogues, le mobilier métallique a bénéficié ici d'un traitement entièrement différent. Il n'est attesté que dans la tombe 225 , à l'exception des armes qui n'ont pas été déposées dans les coffres, mais à l'extérieur.

Plusieurs aspects de ces dépôts doivent être envisagés : tout d'abord, leur nature et leur signification quant à la date des enfouissements, à la nature du ou des défunts; d'autre part, leur signification culturelle dans le contexte local et régional.

Deux ensembles sont clairement à distinguer : d'une part, les strigiles, l'aiguille à coudre et les boîtes de la

26. Les céramiques à vernis noir sont, en proportion, beaucoup plus nombreuses dans les tombes que dans les niveaux d'habitat (Py, 1990a, p. 780). 
tombe 225 ; d'autre part, l'umbo et le fer de lance déposés sous ou contre les dalles de couverture des tombes.

\section{Strigiles}

À l'intérieur du premier lot, l'association des strigiles en paire est une constante : $55 \%$ des découvertes funéraires de strigiles effectuées dans le Sud de la Gaule, selon un inventaire récent ${ }^{27}$, consistent en paires. Le pourcentage est plus élevé à la fin de la République que sous le principat, où on observe une dispersion des données : les strigiles isolés se multiplient, mais également les ensembles de trois à six strigiles, inconnus précédemment. Cette constante, certainement liée à l'utilisation des objets (par exemple, raclage avec puis sans huile), se retrouve en Italie : le fait qu'elle soit respectée en Gaule, notamment au I ${ }^{\text {cr }}$ s. avant J.-C., traduit sûrement une utilisation conforme à l'usage classique.

Du point de vue géographique et chronologique, la diffusion des strigiles en Gaule du Sud est clairement liée à la première phase de romanisation de la basse vallée du Rhône. Ce phénomène, on le sait, cst apparu dans la zone directement soumise à l'influence marseillaise, là où les sociétés indigènes étaient familiarisées depuis longtemps avec les usages sociaux et les modes de vie méditerranéens. Ce n'est certes pas un hasard si la plus ancienne découverte de strigile en Gaule a été effectuée à Marseille même, dans l'un des ensembles funéraires de la rue Tapis-Vert (V ${ }^{e}$ s. avant J.-C.) (Chabot, Féraud, 1959, p. 77, fig. 16).

Par la suite, il faut attendre la création de la Provincia pour voir apparaître, à titre d'abord exceptionnel, ces ustensiles tout à fait étrangers aux traditions indigènes.

La répartition des strigiles antérieurs à l'époque augustéenne met bien en évidence le caractère très localisé de ces découvertes : tous les strigiles de la fin de l'Âge du Fer ont été découverts sur la rive droite du Rhône, sur le territoire qui deviendra plus tard celui de la cité de Nîmes. Il est particulièrement frappant de constater l'absence de tout objet de ce type dans les tombes des Alpilles, pourtant nombreuses et récemment étudiées, alors que ces tombes livrent fréquemment d'autres indices de romanisation précoce (notamment l'usage de vaisselle italique en bronze). La plus grande concentration se retrouvant dans la nécropole des Marronniers à

27. Feugère, 1993, p. 131. Pour l'Âge du Fer dans la région nîmoise, cf. Py, 1990a, p. 773, doc. 264.
Beaucaire, il semble bien que ces deux faciès funéraires correspondent à l'expression locale d'un même phénomène, l'influence romaine se manifestant à l'est et à l'ouest du Rhône par des emprunts différents.

En ce qui concerne la dëtermination sexuelle, le dépôt de strigiles dans une tombe ne semble pas pouvoir être utilisé comme élément significatif. Si l'interrogation sur les caractéristiques sexuclles des mobiliers funéraires est beaucoup moins avancée pour l'époque romaine que pour d'autres périodes ${ }^{28}$, signalons néanmoins qu'en Lombardic et dans le Piémont, pour une période contemporaine de nos sépultures nîmoises, cinq tombes sur six ayant livré des strigiles sont considérées, sur d'autres critères relatifs au mobilier funéraire, comme masculines (Bolla, 1991, fig. la et 1b).

\section{Aiguille}

La présence d'une aiguille en fer, dans cette même structure, connaît peu de parallèles, que ce soit dans le sud de la Gaule ou plus largement dans le monde grécoromain ${ }^{29}$. Une aiguille en bronze, malheureusement non conservée, faisait partie du mobilier de la tombe XIV de la nécropole de la Catalane ( ${ }^{\mathrm{cr}} \mathrm{s}$. avant J.-C.), aux Bauxde-Provence (Arcelin, 1973, p. 188).

Sur environ 1500 sépultures du Haut-Empire recensées dans la même région, on ne peut guère citer que six exemples d'aiguilles déposées dans la tombe avec les objets personnels du défunt (Feugère, 1993, p. 148).

La présence de ces objets induit pour les sépultures concernées une présomption de caractère féminin, mais cette hypothèse n'est confirmée que dans un cas (Apt), par l'association avec quatre épingles à cheveux.

\section{Boîtes en bois}

Les systèmes de fermeture de petites boîtes en bois, quant à eux, posent tout d'abord un problème d'identification. Les éléments conservés ne permettent guère de restituer la forme de l'objet, qui peut avoir été un contenant de la taille de nos plumiers modernes. La proposition la plus

28. Comme le haut Moyen Âge, où elle s'est généralisée depuis quelques décennies. Pour les tombes à strigiles du Midi de la Gaule, voir les associations funéraires dans Feugc̀re, 1993, p. 131.

29. Il est vrai qu'il s'agit, de toutes façons, d'un objet peu répandu (quoique ancien) dans la Protohistoire méridionale : Tendille, 1982, fig. 4; Py, 1990a, p. 457-460, doc. 110. Contrairement à l'exemplaire nîmois, tous ces objets sont en bronze. 
simple consiste à voir dans ces boîtes une variante précoce du modèle quadrangulaire, à couvercle à glissière, dont le type est attesté à Nîmes même, en os et en ivoire, un siècle plus tard (Béal, 1984, B VIII). Quand on peut déterminer leur fonction, les boîtes de ce type contiennent des parures ou des objets de toilette ${ }^{30}$; elles appartiennent de toute façon au mundus muliebris. D'origine hellénistique, les boîtes et coffrets pourvus d'un système de fermeture apparaissent en Italie du Sud, dans les riches contextes funéraires de Tarente, dès le début du $\mathrm{II}^{\mathrm{e}} \mathrm{s}$. avant notre ère ${ }^{31}$, un peu plus tard semble-t-il en Italie du Nord ${ }^{32}$

La Gaule interne, de son côté, n'a pas ignoré l'usage de ces coffrets : on en rencontre dans quelques tombes ségusiaves et trévires, souvent associés à des clés de taille relativement importante. Les plus anciennes attestations, datées de la transition C2/D1, témoignent peut-être d'une influence romaine consécutive à la conquête de la Provincia, ou aux contacts juste antérieurs. À Roanne (nécropole 3, ensemble 55), les éléments en fer indiquent qu'un coffret doit avoir contenu de petits anneaux en os, attribuables à des éléments de parure ${ }^{33}$. À Wederath, on observe des restes de coffrets similaires dans une autre tombe LT C2/D1 ( $\left.{ }^{\circ} 276\right)$ ainsi que dans une tombe LT D1 $\left(n^{\circ} 207\right)$, dans laquelle il est également intéressant de noter la présence d'au moins une aiguille à coudre ${ }^{34}$.

\section{Faciès de la tombe 225 à travers le mobilier métallique}

L'association de deux boîtes et d'une aiguille dans la structure $225 \mathrm{du}$ Mail romain constitue une forte présomption pour y voir la tombe d'un sujet de sexe féminin.

Cette présomption est cependant modérée par la présence des strigiles, dont on ne sait pas encore si l'usage, en Gaule romanisée, est réservé ou non à l'un ou l'autre sexe. En revanche, la position des armes, à l'extérieur des coffres, peut être utilisée comme argument en faveur de l'hypothèse féminine. C'est à ces objets qu'il convient maintenant de nous intéresser en détail.

\footnotetext{
30. Béal, 1984, n³67 (bijoux) ; Vaulina et Wasowicz, 1974, p. 142, nº3 (peigne et miroir).

31. De Juliis et alii, 1986, p. 365-366, cat. $n^{\circ} 336 ; 456 ; 462, n^{\circ} 3 ; 504, n^{\circ} 12$ 32. Par exemple une tombe d'Ancône (Ulbert, 1984, pl. 69, 2).

33. Tombe ITT C2/D1, renseignement V. Guichard.

34. Haffner, 1971, pl. 48 (tombe 207) et 67 (tombe 276), associée aux parures?
}

\section{Les armes}

Des deux éléments rapportés à des armes, aucun ne témoigne de la présence d'un objet complet : le bouclier comportait, au minimum, des clous à large tête assurant la fixation de l'umbo, et la lance est généralement pourvue, à l'opposé de l'armature, d'un talon également en fer, non retrouvé ici. Il s'agit donc d'éléments ayant fait l'objet d'un dépôt secondaire, peut-être après la crémation où les objets complets ont pu accompagner le corps d'un défunt.

Du point de vue typo-chronologique, tout d'abord, l'umbo à ailettes rectangulaires est une forme classique de La Tène C et D1 ; s'il se retrouve dans toutes les phases du sanctuaire de Gournay-sur-Aronde en Picardie (Rapin, 1988), le site gaulois où on en connaît à ce jour le plus grand nombre, il faut noter sur ce site l'absence de tout exemplaire à trois clous par ailette. Les armes de ce type sont assez nombreuses dans les tombes de Nîmes et dans les environs. Citons ici, pour un objet identique, la tombe 1 de Camplanier (Py, 1981a, fig. 55, 7), et d'un modèle voisin, les deux exemplaires de l'octroi de Beaucaire ( $\mathrm{Py}$, 1981a, fig. 64, 8 et 9); un autre umbo, sans doute analogue, est conservé au musée de Nîmes ${ }^{35}$. Des umbones en oméga tout à fait semblables à celui du Mail romain (ailettes rectangulaires, trois trous pour les clous de fixation), le plus souvent hors contexte, font partie de l'abondant mobilier de la nécropole préromaine d'Ensérune ${ }^{36}$.

Le fer de lance, on l'a vu, est trop corrodé pour autoriser la moindre comparaison; sa présence est fréquente dans les tombes nîmoises (Py, 1981a, fig. 58, 64, 66, 87 et 88 ), où épée, lance et bouclier semblent constituer la panoplie typique de l'armement indigène. L'occurrence de chaque type d'arme dans les tombes préaugustéennes du Languedoc oriental ne semble pas pouvoir déboucher sur une analyse exploitable, dans la mesure où beaucoup d'armes, détériorées sur le bûcher, ne sont attestées dans le dépôt secondaire de la sépulture que par un élément ou fragment incomplet. Si l'épée est retrouvée dans quatorze cas sur dix-huit, la lance apparaît dans treize cas et le bouclier dans neuf cas seulement (fig. 20).

35. Py, 1981a, fig. 88,5 ; voir aussi l'exemplaire non conservé (à moins que ce ne soit le même) de la tombe du Jeu de mail découverte en 1840 (Py, 1981a, p. 123).

36. Au Musée national d'Ensérune ; voir Jannoray, 1955, p. 232 ; également Gallet de Santerre, 1980, pl. 4l, en bas; pour une forme plus ancienne de cet $u m b o$, dans la tombe 163 de la nécropole d'Ensérune (début du III ${ }^{\mathrm{e}}$ s. avant J.-C.), voir Rapin, Schwaller, 1987, p. 175, fig. 13. 


\begin{tabular}{|l|c|c|c|c|}
\cline { 2 - 5 } \multicolumn{1}{c|}{} & \multicolumn{4}{c|}{ arme attestée } \\
\hline tombe & épée & lance & bouclier & autre \\
\hline Nîmes, octroi de Beaucaire & $\bullet$ & $\bullet$ & $\bullet$ & $\bullet$ \\
\hline Nîmes, Camplanier 1 & $\bullet$ & $\bullet$ & $\bullet$ & \\
\hline Ste-Anastasie & $\bullet$ & $\bullet$ & $\bullet$ & \\
\hline Ste-Cécile & $\bullet$ & $\bullet$ & $\bullet$ & \\
\hline Calvisson & $\bullet$ & $\bullet$ & & \\
\hline Nîmes, Pont biais & $\bullet$ & $\bullet$ & & \\
\hline Nîmes, Fontilles & $\bullet$ & $\bullet$ & & \\
\hline Nîmes, Pissevin 1 & $\bullet$ & $\bullet$ & & \\
\hline Ambrussum, Pont romain & $\bullet$ & $\bullet$ & & \\
\hline Nîmes, Ch.-Grézan & & $\bullet$ & & \\
\hline Nîmes, Jeu de mail & & $\bullet$ & $\bullet$ & \\
\hline Nîmes, Mail romain & & $\bullet$ & $\bullet$ & \\
\hline Ambrussum, Sablas & & $\bullet$ & $\bullet$ & \\
\hline Nîmes, Rue A.-de-Seyne & $\bullet$ & & $\bullet$ & \\
\hline St-Siffret & $\bullet$ & & $\bullet$ & \\
\hline St-Dionisy & $\bullet$ & & & \\
\hline Nîmes, Ch.-Ranquette & $\bullet$ & & & \\
\hline Nîmes, Ch.-Valdegour & $\bullet$ & & & \\
\hline
\end{tabular}

Fig. 20. Combinaison d'armes dans les tombes préromaines de la région nîmoise.

\section{Interprétation}

Les éléments les plus significatifs de ce mobilier sont donc, d'une part, l'association des objcts ct, d'autrc part, leur position dans le dépôt funéraire. Tout à fait remarquable est, ici, la position externe des armes par rapport au mobilier céramique et au reste des objets personnels. Dans le contexte nîmois, cette particularité ne connaît qu'un autre parallèle, rue Alphonse-de-Seynes, où amphore et épées ont été déposées dans le loculus, mais à l'extérieur de la tombe proprement dite, recouverte d'une grande dalle calcaire (Py, 1981a, p. 153). L'impossibilité physique de faire tenir l'amphore dans une fosse trop peu profonde ne peut pas être avancée pour expliquer la présence de l'épée en dehors de la tombe, ce que confirment dans un contexte un peu différent les fouilles du Mail romain.

Une hypothèse permettrait de concilier les éléments issus de la fouille et ceux qui découlent de l'analyse du mobilier. On a depuis longtemps remarqué que les tombes préaugustéennes de Nîmes sont remarquablement peu nombreuses; leur rareté et, d'autre part, leur mobilier toujours abondant permettent de supposer que nous n'avons là que les tombes de personnages relativement privilégiés. D'autre part, la proportion à peu près égale de tombes avec et sans armes ne permet de consi- dérer celles-ci que comme un marqueur du sexe masculin. L'expression " tombes de chefs ", si on tient donc à l'employer, ne peut s'utiliser à bon escient à Nîmes que pour toutes les tombes connues, avec (tombes masculines) ou sans armes (tombes féminines?).

La combinaison de deux facteurs, l'un social, l'autre sexuel, a-t-elle entraîné ici un paradoxe que les organisateurs de l'enfouissement auront cherché à résoudre à leur manière? Pour autant qu'on le sache, le pouvoir politique et social devait être exercé, dans les sociétés locales préaugustéennes, par des hommes exclusivement : c'est tout naturellement qu'ici, comme ailleurs, le symbole de ce pouvoir s'est fixé sur une catégorie d'objets masculins, les armes. Il est possible que la probable défunte du Mail romain se soit retrouvée en possession d'une charge normalement assumée par un homme, mais que dans des circonstances particulières elle était la seule à pouvoir exercer. En associant les armes à sa sépulture, mais sans vouloir les placer à l'intérieur du coffre, les proches ont pu vouloir exprimer une réalité sociale, tout en respectant la personnalité de la défunte.

\section{ESSAI D'INTERPRÉTATION DES RESTES FAUNIQUES (A. G.)}

Chacune des espèces n'est guère représentée que par un scul ou rarement par deux individus. Le matériel provenant des tombes se trouve dans un bon état de conservation, il correspond à des dépôts d'offrandes funéraires représentés soit par un animal entier (pigeon), soit par des parties découpées à cet effet (pied ou gigot) qui n'ont, a priori, pas été consommés. On constate que ces morceaux sont souvent des parties droites et que les bêtes sélectionnées sont jeunes. Leurs restes sont bien conservés en dépit de leur caractère juvénile.

À l'inverse, tous les os provenant du tertre 214/216 sont en mauvais état, fracturés, cassés. Ils correspondent davantage à de véritables déchets de boucherie et de consommation tels que l'on peut en trouver dans les habitats ou les dépotoirs. On fera exception du cheval dont la présence ici est sans doute davantage liée au culte funéraire qu'à une offrande alimentaire.

Ces trouvailles d'offrandes animales, en particulier de crânes ou mandibules, sont fréquentes pour cette époque, surtout dans le cas du porc : tombe 1 du quartier de Camplanier à Nîmes, tombe de la Cigale (Py, 1981a, p. 131 et 179); tombe de la gare de Nages (Columeau, 1980). À chaque fois, la prédominance des jeunes individus est flagrante. 
Dans le cas du Mail romain de Nîmes, le choix des animaux est classique. Seuls les animaux domestiques sont représentés mais les trouvailles de sanglier sont fréquentes (si l'on considère que la différenciation porc/sanglier ne pose pas de problème) comme à la nécropole des Colombes à Beaucaire (Duday, 1974). On sait aussi que ces populations ne dédaignaient pas l'apport carné de gibier tels que cerf, chevreuil, lièvre, sanglier.

\section{LES OFFRANDES AUIMENTAIRES : UNE SPÉCIFICITÉ SYMBOLIQUE? (Y. M.)}

Elles comprennent d'abord le dernier repas offert par les proches aux disparus. Elles se composent de nourriture solide dont il nous a été possible de retrouver des restes, mais certainement aussi de liquides contenus dans les olpés ainsi que des mets divers qui n'ont pas laissé de trace ${ }^{37}$. Si la plupart des aliments étaient déposés dans les récipients en céramique, comme le poisson retrouvé dans le plat 11 de la tombe $226^{38}$, d'autres ont dû être placés dans de petites corbeilles en osier, sur des supports en matériaux périssables, sur un tapis d'algues ${ }^{39}$ ou encore à même la fosse. La mise en évidence d'espaces vides dans les tombes semble bien, nous l'avons vu plus haut, en être la preuve.

Le soin porté au prélèvement des vases mais aussi de tout le sédiment contenant les restes, a permis d'aboutir à une identification précise de la faune et des poissons. Il est intéressant de constater que chaque tombe a reçu un poisson et un oiseau, données qui témoignent d'une certaine équité et qui vont dans le sens de la contemporanéité des deux dépôts. Mais il convient d'ajouter un pied de suidé et un gigot d'ovi-capriné dans le coffre 225 qui accentuent, là encore, cette volonté de privilégier un défunt et non l'autre.

\footnotetext{
37. Dans certaines tombes, les vases ont parfois été déposés vides, comme le note M. Py (1990a, p. 782), en particulier la tombe 12 des Marronniers à Beaucaire, où huit plats campaniens étaient empilés et la tombe 1 des Colombes, dans la même ville, où cinq vases étaient posés les uns dans les autres au moment de la découverte (Py, 1990a, p. 772). 38. Ce poisson, de la famille de la rascasse, a fait l'objet d'une préparation particulière : seule la partie caudale sans la queue a été déposée dans ce vase.

39. La présence, dans les deux coffres, de minuscules coquillages marins ne peut s'expliquer que par celle d'algues. Ces algues qui ont certainement servi à conserver les poissons durant leur transport jusqu'à l'enclos funéraire, si elles n'ont pas été déposées dans les coffres, ont été placées
} au-dessus.
Sans que nous soyons en mesure de le percevoir, le caractère purement symbolique des offrandes est peutêtre à rechcrcher dans toutes les pièces que nous venons d'évoquer. Il s'exprime de façon nette dans la présence de morceaux qui nous semblent être de moindre qualité : une hémi-mandibule droite d'un jeune suidé dans la tombe 225 et un demi-crâne droit d'une femelle de même espèce dans le coffre 226 .

Outre la jeunesse des animaux sélectionnés (ovi-capriné de moins de 18 mois, suidé d'environ 18 mois, porc femelle de 7 à 9 mois), il faut noter le choix manifeste des parties droites des pièces. Cette pratique, qui est peut-être liée à la valeur mystique accordée par les populations celtiques au porc avait déjà été observée sur d'autres sites de la région ${ }^{40}$.

Les éléments fauniques ponctuels, retrouvés au contact des dalles, à l'extérieur des coffres et même dans le remplissage ${ }^{41}$ sont certainement, comme dans l'exemple de la tombe de la gare de Nages, des témoins du repas funéraire pris par les proches à proximité des tombes (Py, 1990a, p. 782).

\section{UNE OFFRANDE ÉQUINE (L. V.)}

L'unité stratigraphique constituant le tertre est très pauvre en mobiliẹ archéologique. Cependant, elle a livré des ossements fauniques (crâne et vertèbres en probable connexion), mêlés de façon intime au sédiment, appartenant à un équidé de quatre ans et qui n'ont rien à voir avec la constitution d'un dépôt de déchets culinaires. $\mathrm{Si}$, les conditions de la découverte n'ont pas permis une observation fine de l'agencement des restes, il nous a été possible de constater a posteriori que le crâne reposait, peu ou prou, au-dessus de la jonction des deux tombes. Les techniques de fouilles ainsi que la destruction partielle $\mathrm{du}$ tertre à l'époque romaine nous interdisent de savoir si le corps de l'équidé a étć enscvcli cn totalitć ou partiellement, sous forme de cadavre décharné ou charnu. Enfin, le contexte stratigraphique nous incline à penser qu'il ne

\footnotetext{
40. Voir Py, 1990a, p. 782. Il est possible qu'elle interfère avec le rite typiquement romain, évoqué par Cicéron, du sacrifice d'une truie associé à la cérémonie de l'ensevelissement et au banquet se déroulant aux abords de la tombe. L'imprécision des sources anciennes ne nous permet pas de dire si ces offrandes constituaient une partie de la cena réservée au défunt ou si elles pouvaient correspondre à " une communion sacrificielle entre les lugentes et la mort " (Cicéron, Leg. 2, 57; Scheid, 1984, p. 129).

41. Une vertèbre de muge derrière la dalle 2 , deux vertèbres de rascasse et une vertèbre de maquereau dans le comblement de la tombe 225 .
} 
s'agit pas là d'un enfouissement sanitaire postérieur à l'utilisation de l'espace funéraire.

Le récent recensement synthétique de P. Méniel, portant sur quatre cents sépultures de vingt nécropoles, réparties en quatorze sites du second Âge du Fer et de la période romaine, montre, pour la Protohistoire, l'absence de tombes équines en Europe occidentale mais aussi la rareté des restes de chevaux en contexte funéraire (Méniel, 1993).

En Europe centrale, par contre, B. Jovanovic note, pour La Tène moyenne et récente, au moins cinq occurrences de tombes équines dans la région habitée aux $\mathrm{II}^{\mathrm{e}}$ $\mathrm{I}^{\text {er }}$ s. avant J.-C. par les Scordisques (Jovanovic, 1984, p. 84). Concours de circonstances dû à l'état de la documentation ou liens réels entre les informations, A. Duval a noté que, parmi les différents lieux d'origine que proposent les auteurs antiques pour les Volques, Justin écrivait qu'ils vivaient, à l'origine, au confluent DanubeDrave, à proximité des Scordisques avec lesquels ils pourraient former une même famille (Duval, 1993, p. 304). Pour certains, l'ensevelissement de chevaux entiers ou morcelés semble une pratique particulièrement courante chez les peuples de cavaliers (Alexandrescu, 1983).

Pour l'époque romaine, si S. Lepetz souligne l'existence de quelques tombes équines (notamment en Champagne où une découverte ancienne en a révélé cinq), il note la rareté et le polymorphisme des dépôts : animaux entiers accompagnés de vases mais qu'il n'est pas possible de rapprocher de sépultures humaines; crâne ou patte associés à un défunt (Lepetz, 1993, p. 40). V. Bel, enfin, a observé sur le sol de la nécropole à SaintPaul-Trois-Châteaux des restes d'équidés au-dessus de plusieurs sépultures à incinération (Bel, 1993, p. 279).

Confrontés à une observation aussi lacunaire et isolée que la tombe équine du Mail romain, il est seulement possible de rappeler que les études portant sur la religion des populations de la Gaule, ont insisté sur la place tenue par le cheval dans les préoccupations religieuses et notamment sur son rôle probable d'animal psychopompe (Benoit, 1948). On remarquera également que, dans la région nîmoise, la plupart des chenets identifiés se rapportent au cheval (Py, 1990a, p. 798).

\section{LES DÉFUNTS (Y. M.)}

\section{LA PRÉSENCE SYMBOLIQUE DES MORTS}

Au moment de la fouille des coffres, aucun élément flagrant ne nous renseignait sur la présence de défunts inci- nérés, la rareté des charbons de bois allant de pair avec celle des restes humains. Cependant, quelques os découverts au fond des deux caissons et le tamisage systématique de toute la terre ont permis de mettre en évidence, pour la tombe 225, dix-sept fragments ayant appartenu à un individu adulte et, pour la tombe 226, quelques esquilles indéterminées ${ }^{42}$. Fouillés en d'autres temps et dans des conditions moins favorables, ces indices ténus auraient pu passer inaperçus ${ }^{43}$ et rien, hormis les offrandes, n'aurait alors permis d'attribuer à ces coffres une vocation funéraire. Ce qui peut surprendre ici c'est le paradoxe qui fait que l'on ait pris autant de soin à aménager les cellules et à organiser des lots importants d'offrandes alors que les morts sont, pour ainsi dire, absents. Ia présence des défunts est plus symbolique que réelle. C'est ce que suggère, à ce propos, M. Py (1990a, p. 778) ${ }^{44}$. Cette récupération très sélective des cendres nous amène à nous poser des questions sur les raisons d'un tel choix. Que sont devenus les autres ossements non prélevés? Sont-ils restés sur le bûcher? Ont-ils été éparpillés à ses abords ou en un autre lieu? Il semble, en tous cas, peu probable qu'ils aient été enterrés ailleurs. Cette façon de concevoir la mort révèle une forme de pensée qui se détache très vite du côté matériel que constitue la crémation pour privilégier l'aspect spirituel que peut induire la croyance en une survie dans l'au-delà. Disposer des offrandes dans un coffre, c'est d'abord rendre hommage au défunt mais c'est aussi et surtout, dans les exemples qui nous intéressent, permettre à l'âme de vivre dans sa nouvelle demeure ou bien de commencer son voyage ${ }^{45}$.

42. Si les restes de la tombe 225 sont exploitables du point de vue de l'anthropologie, il n'en est pas de même pour ceux de la tombe 226. Dans les deux cas, leur éparpillement dans le fond des coffres, dans leur comblement et, à l'extérieur, dans les niveaux supérieurs du comblement de la fosse d'installation des tombes, laissent penser qu'ils ont été dispersés dans et autour des réceptacles.

43. C'est ce qui a pu se produire dans le cas de certaines découvertes anciennes où l'absence de restes humains peut être la conséquence des méthodes de fouille ou des conditions d'observation (Py, 1990a, p. 778). 44. Pour la période étudiée, ces exemples ne sont toutefois pas isolés. $M$. Py en signale quatre pour la région nîmoise (Py, 1990a, p. 778) ainsi que P. Arcelin, aux Baux-de-Provence (Arcelin, 1980, p. 109). Pour les périodes plus anciennes des observations identiques ont été faites sur les sites de l'Aude (Rancoule, 1989, p. 47).

45. Ce double aspect du devenir de l'âme est évoqué par M. Py (1990a, p. 778). F. Cumont considère que « le sépulcre n'est donc pas un lieu de passage que l'âme traverse sans s'y fixer pour se rendre dans un autre monde; il reste à jamais sa résidence " et il cite en exemple une inscription qui dit « ceci est notre demeure certaine, celle que nous devons habiter " (Cumont, 1949, p. 26). Il est possible que cette notion de voyage corresponde à une croyance plus récente et qu'elle soit davantage perceptible dans les sépultures livrant un dépôt de monnaie(s). 


\section{UNE LIAISON PAR-DELÀ LA MORT}

C'est peut-être cet état d'esprit qui a conduit les proches des défunts à aménager une communication entre les deux coffrcs. La dallc mitoyenne $n^{\circ} 4$ a, en effet, été retaillée dans sa partie haute et il semble que cette échancrure, placée justement à cet emplacement, ne soit pas le simple fait du hasard. Si l'on a permis aux morts de rester en communication dans l'au-delà, c'est sûrement qu'un lien terrestre les unissait déjà ${ }^{46}$. Celui-ci a pu être autre que familial mais, comme le souligne A. Daubigney pour d'autres sites, les données anthropologiques sont ici trop insuffisantes pour connaître les rapports qui pouvaient exister entre les défunts ${ }^{47}$.

\section{À PROPOS DU SEXE ET DU STATUT DES DÉFUNTS}

Les rares fragments d'os humains retrouvés dans les coffres 225 et 226 ne nous donnent pas d'informations sur leurs occupants, si ce n'est que l'un deux est un adulte. Il nous faut donc tenter de tirer partie de tout ce qui, dans la tombe ou dans son environnement immédiat, est à même de nous éclairer indirectement. Le mobilier céramique et la faune ne nous sont pas d'une grande aide. $\mathrm{Au}$ contraire, les diverses pièces métalliques mises au jour près ou dans la tombe 225 (l'umbo de bouclier, la lance et la paire de strigiles) ${ }^{48}$, souvent considérées comme des attributs masculins, sont autant d'indices qui pourraient laisser croire que le défunt était un homme; encore qu'on pourrait attribuer à ces objets une fonction purement apothropaique. L'étude du petit mobilier, prenant également en compte des éléments de fermeture de coffrets ou de boîtes, la présence d'une aiguille, la position extérieure des armes et la non spécificité sexuelle des strigiles remet en question ces données et conduit à proposer d'attribuer la tombe 225 à une femme de rang social élevé. Cette hypothèse est plausible mais chacun des argu-

46. Si tel est le cas, ce fait souligne et accentue la croyance en une survie de l'âme, idée que l'on perçoit peut-être moins nettement dans le geste assez. stéréotypé du dépôt d'offrandes, surtout lorsqu'on imagine que celui-ci a perdu peu à peu sa signification originelle.

47. Ces rapports pouvant être des rapports de dépendance (Daubigney, 1982, p. 130).

48. On a souvent considéré ces sépultures à armes comme celles de chefs, mais leur nombre est trop élevé ( $50 \%$ de celles connues en Languedoc oriental). La présence de ce type de mobilier, dans les tombes masculines entre le $\mathrm{V}^{\mathrm{e}}$ et le $\mathrm{I}^{\mathrm{er}} \mathrm{s}$. avant J.-C., ne nous renseigne pas sur le statut social de leur propriétaire. Il est, en effet, difficile d'admettre que tous les hommes étaient des guerriers (voir Py, 1981a, p. 27).

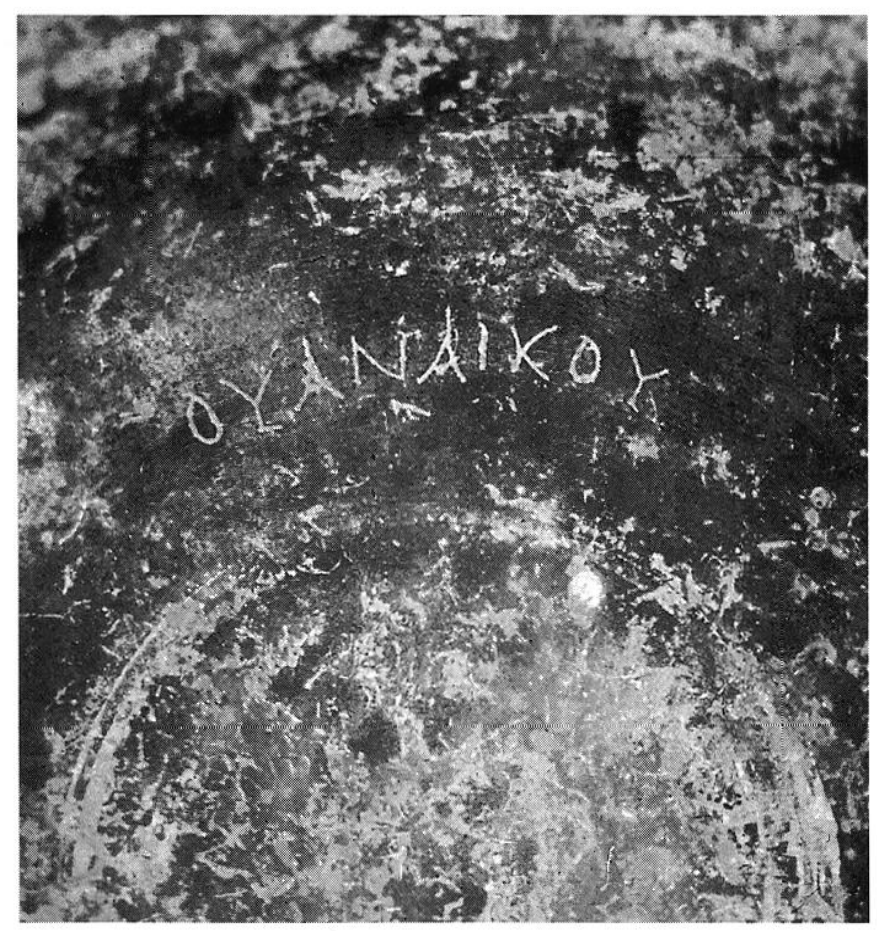

Fig. 21. Vue de détail du graffite.

ments présentés pourrait être aisément contrecarré. L'exemple de la sćpulture protohistorique de SaintAntoine à Castelnau-de-Guers (Hérault), tombe d'un enfant de 12-15 ans accompagné d'armes, montre bien la relativité de toute discrimination sexuelle et/ou sociale basée sur le mobilier et non sur une analyse anthropologique (Houlès, Janin, à paraître). Il semble donc bien difficile de conclure sur l'identité de l'occupant de ce premier coffre.

Aucun objet comparable à ceux de la précédente tombe n'existe pour le coffre 226. Nous serions tentés, pour plusieurs raisons (taille du caisson 226 plus petite, communication entre les deux cellules funéraires, absence de mobilier métallique), de penser que nous avons affaire à la sépulturc d'un proche du premier défunt dont la position sociale ne serait pas aussi importante. Là encore, les hypothèses sont bien fragiles.

Par contre, la présence d'un graffite, gravé à l'intérieur du vase $n^{\circ} 9$, mentionnant le nom Vanaicos nous renseigne davantage (fig. 21). Cet anthroponyme, d'origine celtique, transcrit au datif en alphabet grec, fait référence de façon indéniable, selon $\mathrm{M}$. Lejeune, à un individu de sexe masculin. Les inscriptions complètes sont rares sur la vaisselle. Habituellement on ne les rencontre que sous forme abrégée. Toujours d'après M. Lejeune, 
" le vase n'a pas été inscrit du vivant de Vanaicos mais à ses funérailles. Le datif du défunt, en effet, concurrence le nominatif dans la formulation des épitaphes dont nous avons ici un écho" (Lejeune, 1990, p. 176). Cette information est intéressante à double titre : elle nous permet, d'une part, de connaitre l'identité du défunt et elle souligne, d'autre part, au travers d'un message, l'idée d'un hommage spécialement rendu au disparu.

\section{LES TOMBES PRÉAUGUSTÉENNES DE NÎMES}

\section{PROPOSITIONS DE RÉVISION (L. V.)}

Les informations qui suivent ont pour but de compléter l'inventaire des tombes préaugustéennes réalisé par M. Py (1981a, p. 121-195) en rectifiant certaines propositions de datation ou en affinant certaines localisations (fig. 22).

\section{LA TOMBE DES Trois PILIERS}

Cette tombe (fig. 22, K) est connue par une reproduction graphique d'un album de dessins que possède le Musée archéologique de Nîmes et qui porte le titre "Ville de Nîmes, inscriptions romaines et objets trouvés pendant les années 1883-1887 ». Sous le $\mathrm{n}^{\circ} 120$, se trouve le dessin d'un vase légendé « tombe trouvée dans le mazet du Sieur Compan, en face les Trois Piliers, en 1886 ». M. Py voit dans ce dessin " un petit dolium, au bord échancré, rempli de vases parmi lesquels un plat qui pourrait être campanien »et, par comparaison avec la tombe du chemin de la Ranquette ainsi que par le fait de sa situation au centre d'une zone riche en découvertes de tombes protohistoriques, propose d'attribuer cette sépulture à l'époque préromaine (Py, 1981a, p. 125-126). Or, un article de A. Aurès et G. Maurin (1887) reprend cette découverte et fournit une liste exhaustive du mobilier archéologique, liste qui permet d'affirmer que cette tombe est postérieure au milieu du $\mathrm{I}^{\text {er }} \mathrm{s}$. après J.-C. ${ }^{49}$.

\footnotetext{
49. Inventaire du mobilier : une urne " fracturée (de) poterie rouge" avec, certainement son couvercle à bouton (voir dessin dans Py 1981a, fig. 53), une "fiole lacrimatoire en verre ", des "petits vases en terre", une lampe en terre cuite représentant un " homme assis et dans une attitude désolée ", deux monnaies de bronze de Claude, un "bracelet assez grossier ", six « épingles à cheveux * (Aurès, Maurin, 1887).
}

\section{LA TOMBE DU QUARTIER DES OULES}

Cette sépulture (fig. 22, 33) a été signalée par A. Michel (1885) comme ayant été découverte " dans les fouilles d'une propriété appartenant à $\mathbf{M}$. Cabane, longeant la route d'Uzès, à la montée de Calvas ». Elle est également étudiée par J. Bourrilly (1912, p. 268), qui précise qu'elle est située « au quartier des Oules", ce qui revient à confirmer les informations de A. Michel puisque le chemin des Oules n'est autre que le nom médiéval du chemin d'Uzès. Enfin, ce document est repris par A. Blanchet (1941, p. 97) puis par M. Py (1981a, p. 123-125). Ce dernier la positionne assez loin de la ville, à proximité des actuels chemin de Calvas et route d'Uzès (Py, 1981a, fig. 1, point 33). Or, une recherche conduite au cadastre montre qu'il existe un seul " Cabane ", prénommé " Emery ", possédant, en 1863, la parcelle de terre T 2349p et, en 1865, la maison cadastrée $\mathrm{T} 2349$, au $\mathrm{n}^{\circ} 14$ de la rue Watt. Plus récemment, un "Cabane Louis " acquiert et augmente, en 1888 , une construction dans la parcelle $\mathrm{T} 2349$, au $\mathrm{n}^{\circ} 1$ de la rue Fulton. Les deux maisons s'avèrent de forme très proche, mais nous retenons la parcelle actuelle $\mathrm{DN}$ 159 comme lieu de la découverte car la date de son inscription dans le registre est la plus proche de celle donnée par A. Michel. Ainsi, de fortes présomptions pèsent pour désormais situer cette tombe à proximité des rues Watt, Fulton et de la Biche, soit à environ $450 \mathrm{~m}$ de l'enceinte augustéenne.

\section{LA TOMBE DE MONTAURY}

Pour cette tombe décrite (fig. 22, 31), avec les circonstances de sa découverte, par M. Py (1981a, p. 126-127), nous proposerons simplement une localisation légèrement différente appuyée par des recherches cadastrales. En effet, son positionnement n'est possible qu'au travers des mentions suivantes : «trouvée sur le versant sud de la colline de Montaury » (Bourrilly, Mazauric, 1912, p. 565) et, à l'occasion de la découverte d'une sépulture romaine au même emplacement, par le rappel de cette tombe placée « plus près du rempart romain " et dont le mobilier a été recueilli par « M. Rochat dont le mazet était très voisin de là » (Mazauric, 1917, p. 43). Nos recherches montrent qu'il n'existe pas de propriétaire du nom de " Rochat ", mais qu'il en existe un du nom de «Rojat ». Les deux patronymes étant presque homophones, nous avons recherché les propriétés de ce dernier. David Rojat possède un mazet (NN 739) et deux parcelles (NN 669 et 


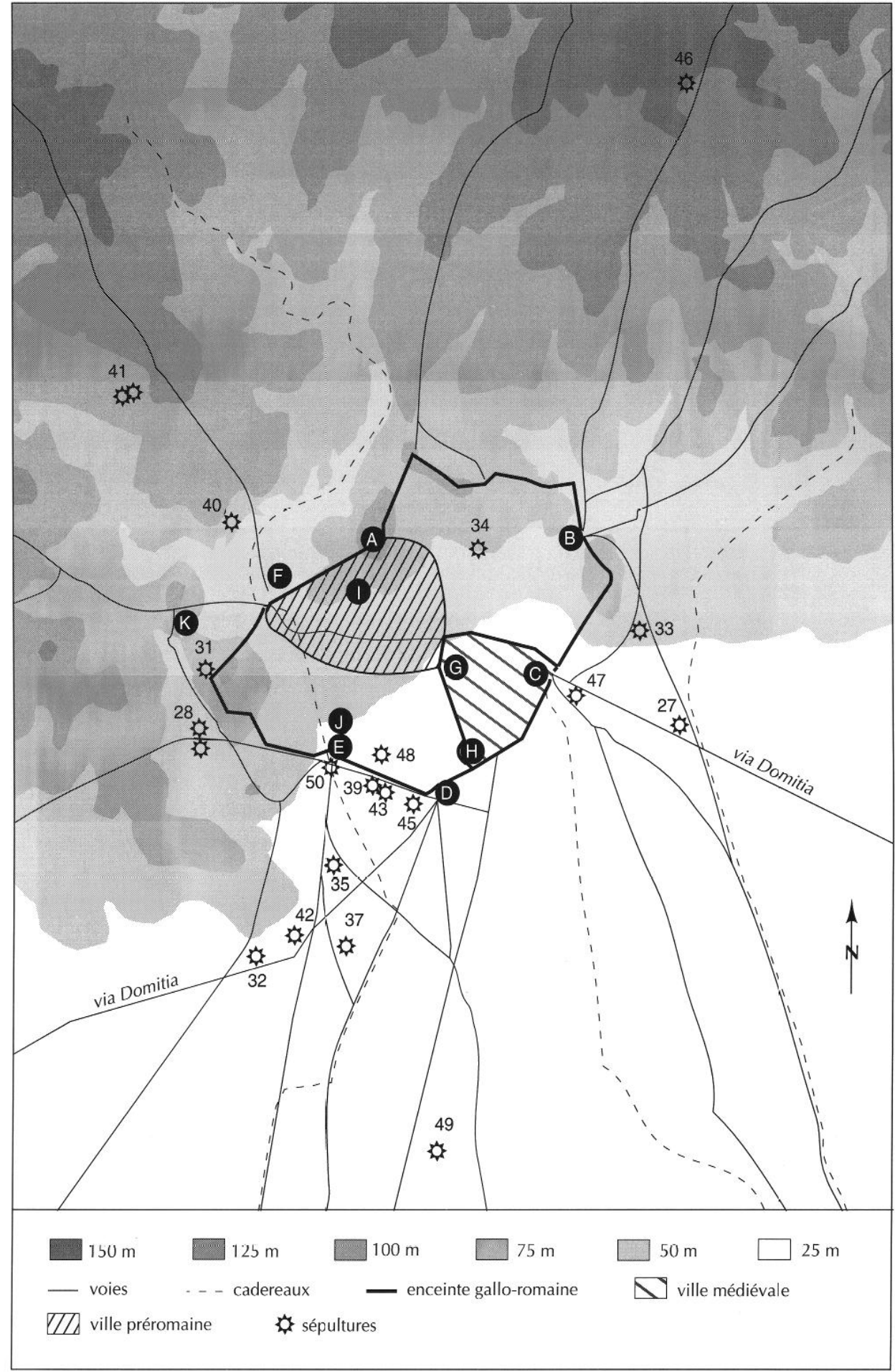

Fig. 22. Plan de la ville de Nîmes avec localisation des sépultures préromaines. La numérotation reprend celle de $P y$, 1981a, fig. 1, complétée. I es points de découverte cités dans le texte sont:

A. tour Magne

B. porte de l'enceinte

C. porte d'Auguste

D. porte de France

E. porte du Cadereau

$\boldsymbol{F}$. porte de l'enceinte

G. maison Carrée

H. amphithéâtre

I. source de la Fontaine

$J=e x 30$ : trouvailles de la rue SainteAnne

$K=$ ex $44:$ tombe des Trois-Piliers

27. octroi de Beaucaire

28. Pissevin

31. Montaury

32. chemin de Montpellier

33. quartier des Oules

34. rue de la Lampèze

35. rue A.-de-Seyne

37. chemin de la Ranquette.

39. marché aux bestiaux

40. la Cigale

41. Camplanier

42. Pont-Biais

43. Jeu de mail

45. Mail romain

46. terres de Rouvière

47. Carmes

48. la Placette

49. Viol du Plan

50. «Jean-Lasserre "

670) qui encadrent le rempart romain. Ces informations nous conduisent donc désormais à situer cette tombe sensiblement plus au nord que sur le plan de M. Py (1981a, fig. 1, point 31).

\section{LES TROUVAILLES DE LA RUE SAINTE-ANNE}

Le problème de la découverte présumée funéraire de la rue Sainte-Anne (fig. 22, J) est évoqué par M. Py, sur la 
base d'une mention de F. Mazauric en 1907 (Py, 1981a, p. 189-190). F. Mazauric écrit en effet, dans les Mémoires de l'Académie de Nîmes, qu'à l'occasion de la construction d'une maison à l'enclos Cabane (rue Sainte-Anne), il a pu noter que, sous "un dur béton romain (...) les couches inférieures recélaient une sépulture gauloise entourée de dalles, autour de laquelle les ouvriers ont recueilli, entre autres débris, une belle coupe apode à large base du type rosé à glaçure noire, un curieux chenet en terre cuite, à tête de bélier, et quelques fragments de vases en verre... " (Mazauric, 1907a, p. 355). M. Py juge cette découverte suspecte (absence de connexions avérées entre dalles et mobilier), d'autant plus que le quartier recèle de nombreuses traces d'habitat (Py, 1981a, p. 189-190). Cette suspicion est encore plus affirmée lorsqu'on s'aperçoit que la version publiée de $\mathrm{F}$. Mazauric diffère curieusement de celle qu'il expose dans son manuscrit (Mazauric, 1907b, p. 64-65). Dans celui-ci, il note que « le glacis (aire d'une maison romaine) s'arrête à quelques mètres de la rue Sainte-Anne. Là, presque sous le chemin, on remarque une accumulation de blocs irréguliers. On y a découvert un squelette entier recouvert d'une dalle. La partie couverte de pierrailles (sic) s'étend de ce côté à plus de $2 \mathrm{~m}$ (...). Les fragments de poterie celtique y sont très abondants. Nous avons pu acquérir d'un ouvrier un très joli vase en terre rosée à peinture noire (...) sorte de coupe apode assez élégante, analogue à celles que l'on trouve dans les sépultures arécomiques de la Tène III (...). [Le lendemain], le terrassier Roulle nous a également remis un curieux objet en terre cuite rouge représentant un chenet gaulois à tête de bélier (...). Celui-ci a été trouvé tout à côté du vase précédent. Il est certain d'après l'examen des débris recueillis jusqu'à maintenant que cet emplacement était occupé par des maisons gauloises dès la fin de l'époque gauloise ". La comparaison de ces deux textes, bien que longue, permet, à notre avis de définitivement rayer cette découverte de la liste des tombes préaugustéennes de Nîmes.

\section{INFORMATIONS RÉCENTES (L. V.)}

Les données inédites qui suivent, bien que parfois lacunaires, méritaient, à notre avis, d'être signalées en attendant une étude plus poussée. Elles complètent, en effet, le groupe des tombes préaugustéennes nîmoises, même si elles apportent peu d'éléments décisifs pour renouveler sa lecture (fig. 22).

\section{L'ENSEMBLE DU VIOL DU PLAN}

C'est à la faveur des décapages linéaires réalisés, par L. Vidal, en préalable à la construction du nouveau palais des congrès au sud de Nîmes, au lieu-dit Viol du Plan, que deux probables structures funéraires ont été observées, mais non fouillées (fig. 22, 49). La plus nette, très bouleversée, peut être sûrement assimilée à une tombe comme en témoigne le maigre mobilier recueilli (fragments d'olpés à pâte claire, d'urne en céramique commune modelée, de plats en campanienne, d'objets métalliques) et la présence de quelques esquilles d'os humains brûlés. Datable du I ${ }^{\text {er }}$ s. avant J.-C., cette sépulture pourrait avoir été contenue dans un coffre ou tout au moins recouverte par une dalle

\section{L'ARME ISOLÉE DU SITE « JEAN-LASSERRE »}

Une opération de sauvetage réalisée en 1989, à l'angle des rues du Cirque romain, de l'abattoir et de l'avenue G. Pompidou, a livré les vestiges d'une porte monumentale de l'enceinte augustéenne mais aussi ceux d'une voie nord-sud datée de la fin du II ${ }^{\mathrm{e}}$ s. avant J.-C. C'est aux abords immédiats de cette dernière, partiellement détruite par un fossé est-ouest daté du V $\mathrm{V}^{\mathrm{c}}$ s. après J.-C., qu'un reliquat de petite fosse a livré une épée de fer pliée datable du II ${ }^{\mathrm{e}}$ ou du $\mathrm{I}^{\mathrm{er}}$ s. avant J.-C. (Monteil, 1990c) (fig. $22,50)$. Cette découverte très ponctuelle pourrait marquer l'emplacement d'une tombe, à l'image des découvertes plus anciennes du Jeu de mail (Py, 1981a, p. 123).

\section{L'INHUMATION DU SITE « JEAN-LASSERRE "}

On peut également signaler, dans le cadre de cette même opération, la découverte d'une inhumation, très mal conservée et dépourvue de mobilier, installée dans les remblais supportant la voie de la fin du $\mathrm{II}^{\mathrm{e}}$ s. avant J.-C. Son étude a été conduite par T. Janin et devrait être intégrée dans une future publication du site. Il semble difficile d'affirmer qu'il s'agit là d'une tombe au plein sens du terme.

\section{LA tombe de la Placette}

Cette découverte fortuite a été faite par des entrepreneurs en maçonnerie, à l'occasion du creusement d'une cave au n ${ }^{\circ} 3$ de la Placette (parcelle EX-984) (Midi Libre du 21.08.1993) (fig. 22, 48). Le mobilier récupéré et une 
visite des lieux ont permis à M. Monteil et Y. Manniez d'attester l'existence d'une tombe en loculus, datable du début du $\mathrm{I}^{\mathrm{cr}} \mathrm{s}$. avant J.-C., à laquelle on peut rattacher au moins : une grande urne en céramique non tournée avec engobe blanc (imitation des productions celtiques?), une petite urne en céramique non tournée et à panse peignée, un vase à balustre celtique de forme CELT $3 b$, un bol en campanienne A (Lamb. 28b), une amphore italique Dressel 1A, une épée ployée avec son fourreau, un fragment de lance et des fragments d'umbo.

\section{LA TOMBE DES CARMES}

Un repérage a été conduit, en 1989, en préalable au projet d'aménagement de la ZAC du «Forum des Carmes » (parcelle HA 1007), situé entre les rues P.-Sémard et Séguier. Les tranchées réalisées ont permis d'observer, parmi plusieurs sépultures gallo-romaines, une tombe en loculus très détruite (fig. 22, 47). Seuls un fragment de médaillon de lampe orné d'une rosace et deux plats Lamb. A36 tardifs ont pu être recueillis et datent la sépulture de la seconde moitié du Ir s. avant J.-C. (Vidal, Célié, 1989).

\section{LA TOMBE DES TERRES DE ROUVIÈRE}

Une fouille de sauvetage a permis de relever, au centre d'un petit vallon situé au nord de Nîmes en zone de garrigue, quatre murs formant un enclos (fig. 22, 46). Dans un des angles se trouvait une tombe à incinération en coffre de dalles contenant cinq vases et des offrandes alimentaires. Cet espace funéraire est datable de la seconde moitié du ${ }^{\text {er }}$ s. avant J.-C. (Pène et alii, 1990).

\section{LES DÉCOUVERTES FUNÉRAIRES DU SUD-OUEST DE LA VILLE (M. M.)}

Dans sa synthèse sur les sépultures préaugustéennes découvertes aux alentours immédiats de Nîmes, M. Py note une nette concentration des tombes des $\mathrm{II}^{\mathrm{e}}-\mathrm{I}^{\mathrm{er}} \mathrm{s}$. avant J.-C. dans les garrigues à l'ouest du site et dans la plaine au sud-ouest (Py, 1981a, p. 193) (fig. 22). Le premier groupe comprend des ensembles funéraires isolés, souvent plus récents que ceux découverts en plaine, et qui peuvent être révélateurs d'une mise en exploitation, par une partie de la population, des bassins de garrigue; installation provoquée par la mise en place du cadastre Nîmes A et par le respect de certaines traditions (Fiches,
1989, p. 221). On peut également ajouter que certaines de ces tombes se retrouvent à proximité de voies de communication : ce qui est le cas de la tombe de Pissevin proche de l'antique via Anagia (Py, 1981a, p. 193) ${ }^{50}$.

Il en est de même pour plusieurs des tombes situées en plaine, au sud-ouest de l'agglomération. Ainsi, la position remarquable de la tombe isolée de la rue Alphonsede-Seynes par rapport au ruisseau du Cadereau, a-t-elle été notée par J.-L. Fiches (Fiches, 1989, p. 220). On peut ajouter que cet axe naturel était doublé d'une voie comme le démontre la découverte, au cours d'une fouille de sauvetage ("Jean-Lasscrre "), d'une voie sur talus, datée de la fin du $\mathrm{II}^{\mathrm{e}} \mathrm{s}$. avant J.-C. ou du début du $\mathrm{I}^{\mathrm{er}} \mathrm{s}$. avant J.-C., et de direction nord-sud (Monteil, 1990a; 1990c). Cette voie, qui pourrait être assimilée à un tronçon de la via Domilia, peut être poursuivie vers le sudd ${ }^{51}$. En effet, au XIX ${ }^{e}$ s., les travaux de prolongement du cours Neuf (actuel boulevard Jean-Jaurès) jusqu'à la route de Montpellier, et la création contemporaine de nombreuses rues perpendiculaires, ont entraîné la mise au jour de plusieurs tombes. F. Germer-Durand souligne ainsi l'impact archéologique de cet aménagement, consistant en « une voie secondaire, latérale au Cadereau, et qui, descendant du nord au sud, allait aboutir à la voie Domitienne, représentée aujourd'hui par le chemin vieux de Montpellier. C'est sur les bords de cette voie, dont l'empierrement est parfaitement reconnaissable, que se trouvaient un certain nombre de sépultures qui apparaissaient à chaque instant sous la pioche des terrassiers» (Germer-Durand, 1873, p. 94-101). Le positionnement sur le cadastre napoléonien de ces découvertes, réalisé par I. Vidal, permet d'assimiler cet axe à la rue de la Galère (actuelle rue H.-Espérandieu). Le quartier environnant a livré plusieurs tombes du Haut-Empire, mais quelques éléments rendent également probable l'existence de tombes préaugustéennes, dont celle de la rue A.-deSeynes (Vidal, 1990). Ce rappel du rapport indéniable

50. Celle de Montaury (Py, 1981a, p. 193), relocalisée plus au nord par L. Vidal, ne peut plus être considérée comme proche de la via Anagia. 51. En 1989, à l'angle de l'avenue G.-Pompidou (anciennement du Cadereau) et des rues du Mail et de l'Abattoir, une opération de sauvetage programmé (résidence Jean-Lasserre) a permis de mettre en évidence cette voie masquée, à la fin du $\mathrm{I}^{\mathrm{er}} \mathrm{s}$. avant $\mathrm{J}$.-C., par une vaste place jouxtant une porte de l'enceinte augustéenne identique en plan à la porte d'Auguste (Monteil, 1990a, 1990c; Varène, 1992, p. 179). Plusieurs arguments, qu'il serait trop long de développer ici, permettent de conclure que ce tronçon de voie ainsi qu'un autre découvert lors de la fouille de la ZAC des Halles (Monteil, 1993) font partie intégrante de la voie Domitienne créée aux lendemains de la conquête. 
entre quelques tombes et les routes n'exclut cependant pas les hypothèses de nécropoles, dont seuls quelques éléments nous seraient parvenus, ou de « front pionnier » lié à de nouvelles formes d'appréhension du territoire, dès le deuxième quart du II ${ }^{\mathrm{e}} \mathrm{s}$. avant J.-C. (Fiches, 1989, p. 220 et 229) ${ }^{52}$.

D'autres tombes ne semblent cependant pas, au premier abord, entretenir de quelconque relation avec le réseau viaire. Il en est ainsi de celles du Jeu de mail et du marché aux bestiaux (Py, 1981a, p. 123 et 173-177), auxquelles on peut ajouter les tombes du Mail romain et l'arme isolée de Jean-Lasserre. Ces quatre points de découverte forment une sorte de semis linéaire parallèle à l'enceinte augustéenne et se trouvent, dans le cas du Mail romain comme dans celui du marché aux bestiaux, condamnés par des ensembles associés aux travaux de construction de la courtine ou de la voirie périphérique. J.-L. Fiches n'exclut pas que ces découvertes aient fait partie d'une nécropole, dans laquelle il rangerait également " les céramiques d'interprétation incertaine de la rue Sainte-Anne (Py, 1981a, p. 189)"(Fiches, 1989, p. 221). Nous avons évoqué plus haut cette dernière observation dont nous pensons qu'elle doit désormais être définitivement exclue du groupe des tombes préaugustéennes.

On peut également remarquer que ces tombes sont les plus proches, en plaine, de l'agglomération d'époque républicaine, tout en étant hors des murs augustéens, si l'on exclut la découverte de la rue de la Lampèze ${ }^{53}$. Il est alors tentant d'émettre l'hypothèse selon laquelle une partie du tracé de l'enceinte, en plaine, se surimpose à une limite forte et antérieure, marquée par un jalonnement d'espaces funéraires, indiquant peut-être la présence d'un pomcrium républicain ${ }^{54}$. Bien entendu, cette proposition reste très fragile, mais surtout, elle est désormais rendue caduque par la découverte fortuite et récente d'une tombe à la Placette, à près de $150 \mathrm{~m}$ vers le nord par rapport à l'enceinte augustéenne. Bien que cette dernière soit peut-être légèrement plus ancienne, il paraît désormais difficile de retenir cette idée à moins que l'on

\footnotetext{
52. Notons également que l'axe nord-sud marqué par la voie du Cadereau ne constitue qu'un des éléments d'une patte d'oie à laquelle il faut ajouter les voies matérialisées par les rues H.-Revoil et par le chemin de la Ranquette, également bordées de tombes. Le rapport entre les tombes du chemin de Montpellier et celle de l'octroi de Beaucaire avec la voie Domitienne mérite aussi d'être souligné (Fiches, 1989, p. 220). 53. La tombe du chemin de la Lampèze reste éminemment suspecte, voir Py, 1981a, p. 127.

54. Sur la définition et la fonction du pomorium, voir Magdelain, 1976.
}

imagine un lent glissement, dans le temps, du pomørium du nord vers le sud. Cette découverte accrédite par contre l'hypothèse d'une nécropole en limite sud-ouest de la ville du I ${ }^{\text {er }}$ s. avant J.-C. ${ }^{55}$. Cependant, le semis des quatre ensembles funéraires cités plus haut pourrait rester malgré tout un des arguments à verser au dossier de l'existence d'une limite antérieure à l'enceinte augustéenne peut-être une voie traversant la nécropole ${ }^{56}$-, reprise par cette dernière, du moins pour le tronçon compris entre le Cadereau et la porte de France. Cet axe de recherche, qui reste à développer, est intimement lié à l'étude de la structuration de l'espace nîmois à l'époque républicaine et à ses répercussions sur l'organisation augustéenne.

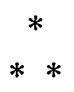

Bien d'autres champs de réflexion pourraient être ouverts dans le cadre de l'étude des tombes préaugustéennes nîmoises. Récemment, J.-L. Fiches a repris le dossier pour la cité de Nîmes dans son ensemble et a opéré une distinction entre tombes isolées, rattachées à une nouvelle forme d'appréhension du territoire par une couche de paysans guerriers tributaires, et tombes regroupées dans des nécropoles articulées ou non autour d'axes viaires (Fiches, 1989). Une étude du mobilier non céramique dans les tombes de Gaule méridionale de cette période et plus tardives a également permis de soulever de nouvelles questions (Feugère, 1993).

Par rapport au premier de ces articles, les tombes du Mail romain modifient peu la répartition spatiale observée, et cela compte tenu, bien sûr, d'une documentation qui ne reflète, à Nîmes comme ailleurs, que la géographie des trouvailles identifiées comme étant des tombes. Elles donnent seulement plus de poids à la portion de plaine situé au sud de la ville ( $43 \%$ des découvertes). Par contre, cllcs accontuent l'espace vide correspondant au bassin du Petit Vistre. Cette zone, particulièrement humide comme le montrent encore quelques toponymes cadastraux -

\footnotetext{
55. Il est intéressant de noter que cette nécropole, si l'on tient compte de la découverte de la Placette, débuterait à seulement quelques mètres des dernières traces de la "ville verte ", limitée, au sud, par la rue Bigot (Benoit, 1981, p. 81-83). Ces linéaments cadastraux marquent, comme l'a noté en plusieurs occasions J.-L. Fiches, la reprise d'un cadastre rural républicain bien attesté dans la Vistrenque (le "Nîmes $A$ "). Ils seraient cependant mis en place postérieurement à nos tombes. Pour la ville à l'époque républicaine, voir Christol, Goudineau, 1988.

56. On serait tenté de rapprocher le niveau de gravillons observés à proximité du tertre d'une telle voie (cf. supra Un aménagement empierré).
} 
Haute et Basse-Magaille, Creux des Canards -, peut avoir eu un caractère répulsif. Ce même secteur est aussi, pour l'époque impériale, une zone vierge de découvertes sépulcrales (Vidal, 1990). Ce n'est pas le seul élément de continuité qui caractérise la répartition des tombes républicaines et des tombes impériales. En effet, la permanence de certaines localisations montre que quelques contraintes peuvent avoir un enracinement dans le passé qui n'est pas dû à la seule géologie. C'est ainsi qu'on peut aisément remarquer que, pour le Haut-Empire, l'implantation des tombes se fait, de façon principale, en fonction de la trame de la voirie; trame qui remonte, pour l'essentiel, aux II ${ }^{\mathrm{e}}$ et $\mathrm{I}^{\mathrm{er}}$ s. avant J.-C.

On rappellera, cependant, le caractère ponctuel de la documentation : on ne dispose en fait que d'une vingtaine de tombes de la période préaugustéenne pour la ville de Nîmes. Si cette constatation a surtout pour but de relativiser tout essai de synthèse, elle nous oblige également à nous interroger sur la relative pauvreté du sous-sol nîmois en la matière? Faut-il associer rareté des exemples et richesse du mobilier pour y voir les tombes de personnages relativement privilégiés ${ }^{57}$ ? Peut-être, mais il faut bien alors imaginer d'autres modes d'enfouissement,

57. On peut citer, à ce propos, l'exemple de la nécropole d'Agde, plus ancienne, où on a noté des exemples de " tombes à simple ossuaire placées dans la dépendance topographique des tombes à urnes avec vases d'accompagnement " (Nickels et alii, 1989, p. 409-410). peut-être moins facilement perceptibles, pour les individus de rang social moindre. Ne peut-on pas également mettre cette lacune au compte de la profondeur de ces tombes par rapport au sol actuel et à la moindre urbanisation récente des secteurs qui les livrent?

Enfin, notre étude des deux tombes du Mail romain apporte aussi de nouvelles informations sur les structures et les rites funéraires (tumulus, enclos, nature des offrandes...) tout en posant de nouveaux problèmes, en particulier ceux liés aux rapports sociaux. Les progrès les plus nets, à Nîmes, pourraient être fournis par la fouille extensive d'un espace funéraire du type de celui que l'on commence ici à entrevoir : observer la tombe dans son enclos, analyser les rapports entre sépultures voisines au sein d'un même ensemble, reconstituer plus précisément les gestes de l'ensevelissement; autant de pistes prometteuses que la fouille du Mail romain ne permet que d'esquisser, mais dont la poursuite s'avère indispensable à la compréhension de la société locale.

M. FeUgìre, A. GARDEISEN, Y. MANNIEZ, M. MONTEII. et L. VIDAL avec la collaboration de F. Brien-Poitevin, Bui Thi Mai, M. Lejeune et M. Sternberg 


\section{Bibliographie}

\section{AllXANDREscu A.-D.}

1983, Tombes de chevaux et pièces du harnais dans la nécropole gète de Zimnicea, Dacia, 27, 1-2, p. 67-68.

ARCFIIN P. et Ch.

1973, La nécropole protohistorique de la Catalane aux Baux-de-Provence, RAN, VI, p. 91-195.

\section{ARCELIN P.}

1980, Nouvelles observations sur la nécropole préromaine de la Catalane aux Baux-de-Provence (Bouches-du-Rhône), Bulletin de l'École Antique de Nimes, 15, p. 91-109.

Auris A., MaUrin G.

1887, Découvertes archéologiques pendant l'année 1886, Mémoires de l'Académie du Gard, p. 194.

\section{BARRÉ DE SAINT-VENANT J.}

1897, Les derniers Arécomiques, Traces de la civilisation celtique dans la région du Bas-Rhône, spécialement dans le Gard, Bulletin Archéologique du Comité des Travaux Historiques, p. 489-531, pl. X-XI.

Barruol, G., SAuzade G. 1969, Une tombe de guerriers à SaintLaurent-des-Arbres, Gard, contribution à l'étude des sépultures du $\mathrm{I}^{\mathrm{er}} \mathrm{s}$. av. J.-C. dans la basse vallée du Rhône, Rivista di Studi Liguri, 35, p. 15-89 (Hommages à F. Benoit, 3, 1972).

BATS M.

1988, Vaisselle et alimentation à Olbia de Provence, Paris, CNRS, 272 p. (18 suppl. à la RAN).

1990a, Tombes et nécropoles de Narbonnaise aux II -I $^{\text {er }}$ s. av. J.-C. : problèmes de datation et de chronologic, in: J.-A. Duval, J.-P. Morel et Y. Roman (dir.), Gaule interne et Gaule méditerranéenne aux $I I^{e}$ et $I^{e r} s$. av. J.-C. : confrontation chronologique, Paris, CNRS, p. 269-290 (21e suppl. à la $R A N)$.

1990b, Mobilier céramique, le faciès culturel, in: M. Py (dir.), Fouilles dans la ville antique de Iattes, les ilots 1, 3 et 4nord du quartier Saint-Sauveur, I attes, p. 351-356 (I attara, 3).

BAUQUIER $\mathrm{H}$.

1941, L'occupation préromaine du terroir nîmois : mise au jour d'une sćpulture arécomique rue Alphonse de Seyne, Le Vieux Nîmes, 17, p. 3-12.

BÉAL J.-C.

1984, Les objets de tabletterie antique du Musée archéologique de Nîmes, Nîmes, 120 p. (Cahiers des Musées et Monuments de Nîmes, 2).

BEL V.

1993, Les dépôts de vases dans les tombes : les données de l'époque romaine, in : Les Celtes en Normandie. Les rites funéraires en Gaule (III - $^{\text {rr }}$ siècle avant J.-C.), Rennes, p. 279-283 (6' suppl. à la $R A O)$.

\section{BENOIT F.}

1948, Les mythes de l'outre-tombe. Des chevaux de Mouriès aux chevaux de Roquepertuse, Préhistoire, X, p. 137210.

BENOIT J.

1981, Nîmes : études sur l'urbanisme antique. Problèmes de méthode et résultats, Bulletin de l'École Antique de Nîmes, 16, p. 69-90.

Bérato J., Dugas F., Dutour O.

1991, Tombes protohistoriques de GrosPed aux Arcs-sur-Argens, Documents d'Archéologie Méridionale, 14, p. 125141.

BINAGHI L.EVA M.-A.

1987, Arsago Seprio (Varese). I.ocalità
S. Ambrogio, via Roma. Necropoli celtica, Notiziario 1987,

Soprintendenza Archeologica della Lombardia, p. 38-40.

\section{BI.ANCHFT A.}

1941, Forma Orbis Romani, Carte archéologique de la Gaule romaine. Le Gard, $223 \mathrm{p}$.

\section{BOLLA M.}

1991, Considerazioni sulla funzione dei vasi in bronzo tardorepubblicani in Italia settentrionale, in : M. Feugère et Cl. Rolley (dir.), La vaisselle tardorépublicaine en bronze, Actes de la tableronde CNRS de Lattes, 1990, Dijon, p. 143-153 (Centre de recherches sur les techniques gréco-romaines, 12).

Bonnet A., MÉnil.tet F., PALOC $\mathrm{H}$. 1973, Carte géologique de la France au 1/50 000 : feuille de Nimes, $\mathrm{n}^{\circ} 945$ et notice de 40 p., Paris, BRGM.

BoURrilliy J., MAzauric F.

1912, Statistique des enceintes préhistoriques et protohistoriques du département du Gard, Congrès Préhistorique de France 1911, Nîmes, p. 541-610.

BOURRILLY J.

1912, La protohistoire, Nîmes et le Gard, Nîmes, p. 255-284.

\section{Bui THI MaI}

1993, Étude palynologique, in : M. Monteil (dir.), Les fouilles de la Z.A.C. des Halles à Nîmes (Gard), Nîmes, p. 233-236 (1 ${ }^{\mathrm{er}}$ suppl. au Bulletin de l'École Antique de Nîmes).

\section{CÉlIÉ M.}

1988, Le Mail Romain (Nîmes), Rapport de sauvetage urgent, Archives du Service régional de l'archéologie du Languedoc-Roussillon, $10 \mathrm{p}$.

1990, Fouilles de la place Jules-Guesde, in : Archéologie à Nîmes, 1950-1990. 
Bilan de 40 années de recherches, catalogue de l'exposition, Nîmes, p. 90-93.

Chabot L., FÉraud J.

1959, La nécropole de la Rue Tapis-Vert à Marseille, Cahiers Ligures de Préhistoire et d'Archéologie, p. 63-86.

Christol M., Goudinenu C.

1988, Nîmes et les Volques Arécomiques au I ${ }^{\text {er }}$ s. avant J.-C., Gallia, 45, p. 87103.

\section{COlumeau Ph.}

1980, La faune de la tombe de la gare de Nages, in : M. Py, Une sépulture du II ${ }^{e}$ s. av. J.-C. à Nages (Gard), $R A N$, XIII, p. 223-224.

\section{CORDIE-HACKENBERG R.}

1989, Eine latènezeitliche

Doppelbestatung mit Holzmöbel, Grab 1311, in: A. Haffner (dir.), Gräber Spiegel des Lebens.

Totenbrauchtum der Kelten und Römer, Mayence, p. 187-196.

CUMONT F.

1949, Lux Perpetua, Paris.

DAUBigney A.

1982, Tombes et signes hiérarchiques en Champagne protohistorique : problèmes, in: Archéologie et rapports sociaux en Gaule, Protohistoire et Antiquité, Actes de la table-ronde CNRS de Besançon, p. 123-154.

Dedet B., Michelozzi A., Py M., Raynaud Cl., Tendille C.

1978, Ugernum, Protohistoire de Beaucaire, Caveirac, 156 p. (ARALO, 6).

DE JULIIS E.-M. et alii

1986, Les ors hellénistiques de Tarente, catalogue de l'exposition, Tarente, Paris.

DUDAY H.

1974, Études des restes osseux provenant des Colombes à Beaucaire, in : B. Dedet, A. Michelozzi, M. Py, La nécropole des Colombes à Beaucaire (Gard), RAN, VII, p. 118.

DUMOULIN A.

1963, Notes sur les nécropoles gallo- romaines d'après les récentes découvertes, Provence historique, XII, p. 16-19.

Duval A.

1993, Les dépôts funéraires : documents ethnographiques?, in: Les Celtes en Normandie. Les rites funéraires en Gaule (III--Ir siècle avant J.-C.), Rennes, p. 299-309 (6 $6^{\mathrm{e}}$ suppl. à la $\left.R A O\right)$.

\section{FEUGÈRE M.}

1993, L'évolution du mobilier non céramique dans les sépultures antiques de Gaule méridionale ( $\mathrm{II}^{\mathrm{c}}$ siècle av. J.-C. - début du Ve siècle ap. J.-C.), in: M. Struck (dir.), Römerzeitliche Gräber als Quellen zu Religion, Bevölkerungsstruktur und Sozialgeschichte, Mayence, p. 119-165 (Archäologische Schriften des Instituts für Vor- und Frühgeschichte der JohannesGutenberg Universität Mainz, 3).

FICHES J.-L.

1989, Tombes et monuments lapidaires dans l'espace rural arécomique (III ${ }^{\mathrm{e}}$ $\mathrm{I}^{\mathrm{er}}$ siècles avant notre ère), in : Mélanges P. Lévêque, 2, Anthropologie et société, Paris, Les Belles Lettres, p. 207-235.

FISCHER B.

1990, Les relations entre les Arvernes et le Midi méditerranéen à travers la numismatique, Revue Archéologique du Centre de la France, 29, 1, p. 63-66.

\section{GALLET DE SANTERRE $\mathrm{H}$.}

1980, Ensérune, Les silos de la Terrasse Est, 164 p. (39e suppl. à Gallia).

\section{GARDEISEN A.}

1989, Le castrum du Rocher des Vierges à Saint-Saturnin, Étude de la faune du dépotoir, Anthropozoologica, 10, p. $48-50$.

GENTY P.-Y.

1981, Une fosse augustéenne à comblement homogène, rue Saint-laurent à Nîmes, Bulletin de l'École Antique de Nîmes, 16, p. 101-113.

GERMER-DURAND E.

1873, Découvertes archéologiques faites à Nîmes et dans le Gard pendant l'année 1872, Mémoires de l'Académie $d u$ Gard, p. 68-111.

1876, Découvertes archéologiques faites à Nîmes et dans le Gard pendant l'année 1872, Mémoires de l'Académie $d u$ Gard, p. 68-111.

GUICHARD V., VAGINAY M.

1993, Les mobiliers funéraires en Gaule aux $\mathrm{II}^{\mathrm{e}}$ et $\mathrm{I}^{\mathrm{er}}$ siècles avant $\mathrm{J}$.-C.

Reflexions méthodologiques, in : Les Celtes en Normandie. Les rites funéraires en Gaule (III - Fr $^{\text {r }}$ siècle avant J.-C.), Rennes, p. 231-243 (6 $6^{\mathrm{e}}$ suppl. à la $R A O)$.

HAFFNER A.

1971, Das keltisch-römische Cräberfeld von Wederath-Belginum, 1. Teil. Gräber 1428, ausgegraben 1954/1955, Mayence (Trierer Grabungen und Forschungen, VI, 1).

HOUI.̇s N., JANIN T.

à paraître, La sépulture protohistorique de Saint-Antoine à Castelnau-deGuers (Hérault), RAN.

JANNORAY J.

1955, Ensérune. Contribution à l'étude des civilisations préromaines de la Gaule. méridionale, Paris (Coll. EFR, 181).

JOURDAN L.

1976, La faune du site gallo-romain et paléo-chrétien de la Bourse (Marseille), Paris, CNRS, 338 p.

JOVANOVIC B.

1984, Les sépultures de la nécropole celtique de Pécine près de Kostolac (Serbie du Nord), Études Celtiques, 2l, p. 63-93.

LASSALLE V.

1969, Rapport d'activités de l'année 1969, Archives du Service régional de l'archéologie du LanguedocRoussillon.

1990a, Nîmes préromaine, in : Archéologie à Nîmes, 1950-1990. Bilan de 40 années de recherches, catalogue de l'exposition, Nîmes, p. 19-23. 
1990b, Les nécropoles du Haut Empire, in : Archéologie à Nîmes, 1950-1990. Bilan de 40 années de recherches, catalogue de l'exposition, Nîmes, p. 31-34.

LLJEUNE M.

1990, Compléments gallo-grecs, Études celtiques, 22, p. 175-179.

\section{LEPETL S.}

1993, Les restes animaux dans les sépultures gallo-romaines, in : A. Ferdière (dir.), Monde des morts, monde des vivants en Gaule murale ( $I^{\text {r }}$ s. av. J.-C. Ve s. ap. J.-C.), Actes du colloque ARCHEA/AGER, Orléans 7-9 férrier 1992, Tours, p. 34-44.

\section{MAGDELAIN}

1976 , Le pomorium archaïque et le mundus, Reoue des Etudes Latines, p. 71-109.

\section{MANNIE7, Y.}

1989, La nécropole des Clapiès à Villeneuvelès-Béziers (Hérault), Rapport de fouille programmée, archives du Service régional de l'archéologie du Languedoc-Roussillon, $36 \mathrm{p}$.

1992, I a córamique gallo-romaine tardive de la nécropole des Clapiès à Villeneuve-lès-Béziers (Hérault), Études sur l'Héraull, nouvelle série 7, p. 27-33.

\section{MAZAURIC F.}

1906, Recherches et acquisitions, manuscrit conservé au Musée archéologique de Nîmes.

1907a, Recherches et acquisitions, année 1907, Mémoires de l'Académie. du Card, 1908, p. 295-378.

1907b, Recherches et acquisitions, manuscrit conservé au Musée archéologique de Nîmes.

1917, Recherches et acquisitions, manuscrit conservé au Musée archéologique de Nîmes.

MÉNIEL P.

1993, Les animaux dans les pratiques funéraires des Gaulois, in: Les Celtes en Normandie. Les rites funéraires en Gaule (III'-IT siècle avant J.-C.), Rennes, p. 285-290 (6 $6^{\mathrm{e}}$ suppl. à la $R A O)$.

Michil. A.

1885, Découvertes faites à Nîmes ou aux environs pendant l'année 1884 , Mémoires de l'Académie du (arard, p. 30.

\section{MONTEIL M.}

1989, Le Mail Romain (Nîmes), Rapport de sauvetage programmé, Archives du Service régional de l'archéologie du L anguedoc-Roussillon, $120 \mathrm{p}$.

1990a, Nouvelles données sur l'enceinte. augustéenne el les voies à Nîmes, mémoire de maîtrise d'histoirc P.-A. Février (dir.), université de Provence, Aix-en-Provence.

1990b, Fouille «I.e Mail Romain ", in : Archéologie à Nîmes, 1950-1990. Bilan de 40 années de recherches, cataloguc de l'exposition, Nîmes, p. 107-109.

1990c, Fouille «Jean-Lasserre ", in : Archéologie à Nîmes, 1950-1990. Bilan de 40 années de recherches, catalogue de l'exposition, Nîmes, p. 110-111.

1993, Voirie, collecteurs et urbanisme, in: M. Monteil (dir.), Ies fouilles de la Z.A.C. des Halles à Nîmes (Gard), Nìmes, p. 137-166 (1 ${ }^{\text {er }}$ suppl. au Bulletin de l'École Antique de Nîmes).

Nickeis A. (G. MARChAND, M.

SCHWALLER collab.)

1989, Agde, la nécropole du premier âge du Fer, Paris, CNRS, 498 p. (19 suppl. à la $R \wedge N)$.

PÈnf. J.-M. (I. I AAFAYE collab.)

1990, "La Rouvière Sud II ». Fouille de sauvetage, in : Archéologie à Nîmes, 1950-1990. Bilan de 40 années de recherches, catalogue de l'exposition, Nîmes, p. 168-169.

\section{POTHIFR E.}

1890, Sépultures préromaines trouvées dans les environs de Nîmes, Mémoires đe l'Académie de Nîmes, p. 1-10.
Poupet P., Sauvage L., Monteil. M.

1993, La campagne avant la ville, in : M. Monteil (dir.), Les fouilles de la Z.A.C. des Halles à Nîmes (Gard), Nîmes, p. 29-79 ( $1^{\text {er }}$ suppl. au Bulletin de l'Ecole Antique de Nimes).

PY M.

1978, L'oppidum des Caslels à Nages (Gard), fouilles 1969-1978, Paris, CNRS, 363 p. (35 $5^{\mathrm{e}}$ suppl. à Gallia).

1981a, Recherches sur Nîmes pré-romaine. Habitals el sépultures, Paris, CNRS, 242 p. (41 ${ }^{\mathrm{c}}$ suppl. à Gallia).

1981b, Sondage au pied de la Tour Magne : note sur un lot de céramiques des environs de $16-15$ av.

J.-C., Bulletin de l'École Antique de Nîmes, 16, p. 91-100.

1983, Nouvelle tombe du I Ir s. av. J.-C. à Nages (Gard), Documents d'Archéologie Méridionale, 6, p. 148-151.

1990a, Culture, économie et société protohistoriques dans la région nîmoise, Rome, 2 vol., 957 p. (Coll. EFR, 131).

1990b, I a céramique de l'îlot 4-nord, in : M. Py (dir.), Fouilles dans la ville antique de Lattes, les îlots 1, 3 et 4-nord du quartier Saint-Sauveur, I attes, p. 247-268 (I attara, 3).

PY M. dir.

1993, Dictionnaire des céramiques antiques en Méditerranée nord-occidentale, Lattes, 624 p. (Lattara, 6).

PY M., IEBEAUPIN D.

1986, Stratigraphie du Marduel, III, les niveaux des $\mathrm{II}^{\mathrm{c}}$ et $\mathrm{I}^{\mathrm{cr}}$ s. av. n. è. sur le Chantier Central, Documents d'Archéologie Méridionale, 9, p. 9-80.

RANCOULF. G.

1980, La Lagaste, agglomération gauloise du bassin de l'Aude, Carcassonne, 170 p. (Atacina, 10).

1989, Usages funéraires dans l'Aude au premier Age du fer et au début du second, Documents d'Archéologie Méridionale, 12, p. 41-49. 
RAPIN A.

1988, Boucliers, lances, in : J.-I.

Brunaux ct A. Rapin, Gournay II, boucliers et lances, dépôts et trophées, Paris, $245 \mathrm{p}$.

\section{RAPIN A., SCHWALLER M.}

1987, Contribution à l'ćtude de l'armement celtique : la tombe 163

d'Ensćrune (Hérault), RAN, XX, p. 155-183.

\section{$R I G I$}

LEJEUNE M., 1985, Recueil des inscriptions gauloises, I, Texles gallo-grecs, Paris, CNRS, 459 p. ( $45^{\mathrm{e}}$ suppl. à Gallia).

SAUVAGE L.

1993, Une installation artisanale de potiers du troisième quart du $\mathrm{I}^{\mathrm{er}} \mathbf{s}$. av. J.-C., in: M. Monteil (dir.), Les fouilles de la Z.A.C. des Halles à Nîmes (Gard), Nîmes, p. 81-91 ( $1^{\mathrm{cr}}$ suppl. au Bulletin de l'École Antique de Nîmes).

SCHEID J.

1984, Contraria facere : renversements et déplacements dans les rites funéraires, Annali dell Instituto

Universitario Orienlale di Napoli, 6 , p. 117-139.

\section{SERRE A}

1989, Les mues de Nîmes, Du Moyen Age à nos jours, Nîmes.

TENDili.e C.

1982, Mobiliers métalliques protohistoriques de la région nîmoise : instruments et outils divers (V), Documents

d'Archéologie Méridionale, 5, p. 33-52.

\section{ULBERT G.}

1984, Cáceres el Viejo. Ein spätrepublikanisches Legionslager in SpanischExtremadura, Madrider Beitrüge, 11.

\section{VARÈNE P.}

1992, L'enceinte gallo-romaine de Nîmes. Les murs et les tours, Paris, CNRS, 178 p., 138 fig., 12 tabl. (53 ${ }^{\mathrm{c}}$ suppl. à Gallia).
VAULINA M., WASOWICZ A.

1974, Bois grecs et romains de l'Ermitage, Ossolineum.

VIDAL I., CÉLIÉ M.

1989, La Z.A.C. des Carmes à Nîmes (Gard), Rapport de sauvetage urgent, Archives du Service régional de l'archéologie du Languedoc-Roussillon, 32 p., 16 fig.

\section{VIDAL I.}

1990, Contribution à l'inventaire archéologique de Nîmes (Gard) : Les séprullures isolées et les nécropoles antiques, mémoire de maîtrise d'Histoire de l'Art et d'Archéologie, C. Llinas (dir.), université Paul-Valéry, Montpellier, 2 vol., 201 p., 130 fig. (inédit).

VIGNE A.

1899, Un coin du sol nîmois, Bulletin du Comité de l'Art Chrétien du Diocèse de Nîmes, p. 42-66. 